HELENA LIBERATORI GIMAIEL

ESTUDO DAS CAMADAS TRANSPORTADORAS DE ELÉTRONS EM DISPOSITIVOS POLIMÉRICOS EMISSORES DE LUZ 
HELENA LIBERATORI GIMAIEL

\section{ESTUDO DAS CAMADAS TRANSPORTADORAS DE ELÉTRONS EM DISPOSITIVOS POLIMÉRICOS EMISSORES DE LUZ}

Dissertação apresentada à Escola Politécnica da Universidade de São Paulo para obtenção do título de Mestre em Engenharia.

Área de concentração: Engenharia Elétrica: Microeletrônica

Orientador Prof. Dr. Fernando Josepetti Fonseca

Co-orientador Prof. Dr. Ely Antonio Tadeu Dirani 


\section{FICHA CATALOGRÁFICA}

Gimaiel, Helena Liberatori

Estudo das camadas transportadoras de elétrons em dispositivos poliméricos emissores de luz / Gimaiel, A. S. - São Paulo, 2008.

$115 \mathrm{p}$.

Dissertação (Mestrado) - Escola Politécnica da Universidade de São Paulo. Departamento de Sistemas Eletrônicos.

1. Nanotecnologia, Microeletrônica, PLED, ETL, Displays, Eletrônica Molecular.

I. Universidade de São Paulo. Escola Politécnica. Departamento de Sistemas Eletrônicos. Grupo de Eletrônica Molecular. 


\section{DEDICATÓRIA}

Dedico este trabalho aos meus avós que durante todos os meus estágios sorriem, sem dúvida, ao meu lado. 


\section{AGRADECIMENTOS}

Agradeço em primeiro lugar aos meus pais Elias Gimaiel e Carmen S. Liberatori Gimaiel, irmãs Eliane e Heloysa Liberatori Gimaiel e sobrinha Laura G. Gimaiel pelo amor, apoio e compreensão incondicionais e cotidianos.

Agradeço aos colaboradores do Grupo de Eletrônica Molecular da EPUSP pelo trabalho contínuo.

Ao meu orientador Fernando J. Fonseca e ao meu co-orientador Ely A. T. Dirani pelo empenho, direcionamento e atenção constantes.

A FAPESP, CNPq e IMMP pelo apoio financeiro científico deste e de tantos outros trabalhos.

Aos funcionáios da Sala Limpa do LME pelos serviços prestados.

Aos colegas de grupo Alex Frazatti, Alex Chen, Gerson dos Santos e John Paul H. Lima pelo valioso auxílio no desenvolvimento deste trabalho.

Aos companheiros de trabalho da CNEC Engenharia, com especial atenção a Fernando Rhein, Henrique Gaudio, Emiliano Paulista e colegas da UTE Cubatão pela compreensão, credibilidade e paciência.

As antigas queridas e querido Jaqueline Bibiano, Adriana Saita, Jacqueline Soga, Priscila Calíope, Camille Martins, Flainer Rosa, Lidiane Spinola e Carlos Jefferson pelo apoio e por contribuírem para o sentido de amizade que tenho guardado comigo.

Aos novos queridos Kamille Raupp, Priscila Freitas, Maria Lúcia, Valmir Cabral e Rogerio Queiroz pela presença diária durante todo este processo de conquista.

A Dona Lucia Fernandes por abrir, carinhosamente, as portas de sua casa após certas noites de trabalho noturno.

Ao companheiro e confidente Caio M. B. Fernandes pela grande dedicação a mim prestada e por tantas noites perdidas, ao meu lado, em busca deste sonho. 


\section{RESUMO}

Este trabalho tem como objetivo o estudo de camadas transportadoras de carga, em especial de elétrons, em dispositivos poliméricos emissores de luz (PLEDs). Estes dispositivos são obtidos basicamente através da deposição de uma camada emissiva polimérica entre dois eletrodos. Dispositivos poliméricos luminescentes apresentam vantagens quando comparados aos LEDs convencionais, entre elas a possibilidade de fabricação de mostradores ultrafinos, com baixo custo de fabricação e flexíveis. A eficiência dos PLEDs está intimamente ligada a viabilidade de comercialização destes displays. Neste trabalho, a primeira estrutura confeccionada é formada pela deposição de um filme do polímero emissivo $\mathrm{OC}_{1} \mathrm{C}_{10}$ - PPV - poly[2-metoxi-5-(3,7-dimetiloctiloxi)-1,4-fenilenovinileno - entre o anodo ITO (Oxido de Índio-Estanho) e o catodo alumínio. Sobre o eletrodo transparente ITO o polímero $\mathrm{OC}_{1} \mathrm{C}_{10}-\mathrm{PPV}$ e o $\mathrm{Al}$ são depositados sob forma de filme através das técnicas Spin Coating e Evaporação Térmica, respectivamente. Em uma segunda etapa, foram fabricadas amostras com uma estrutura diferenciada, de modo que foram introduzidas camadas de filmes relacionadas aos fenômenos de transporte de cargas capazes de aumentar a eficiência do dispositivo. Estas camadas são responsáveis por uma redução da barreira de potencial existente entre o polímero emissivo e os eletrodos e podem também confinar um número maior lacunas no interior da camada emissiva. Este feito implica num aumento da população de elétrons e lacunas no interior da camada ativa, gerando uma maior recombinação de cargas. Neste sentido, filmes de Alq3 (tris-(8-hydroxyquinolate)-aluminum) com diferentes espessuras foram introduzidos entre a camada ativa e o catodo, gerando uma emissão luminosa superior. Por fim, diferentes concentrações de Alq3 foram adicionadas à solução de $\mathrm{OC}_{1} \mathrm{C}_{10}$-PPV, resultando em compostos $\mathrm{OC}_{1} \mathrm{C}_{10}$-PPV:Alq3 utilizados como camada ativa, o que proporcionou um aumento da eficiência luminosa em mais de 10 vezes quando comparado aos dispositivos fabricados na primeira etapa do trabalho. A utilização do polímero PEDOT:PSS - Poli (3,4-etilenodioxitiofeno) :

Poliestireno Sulfonado- como camada transportadora de lacunas (HTLs) depositada entre o alumínio e o polímero eletroluminescente se mostrou indispensável para o funcionamento dos dispositivos fabricados, evitando o curto circuito entre eletrodos.

Palavras chave: PLEDs, ETLs, $\mathrm{OC}_{1} \mathrm{C}_{10}$-PPV, Alq3. 


\begin{abstract}
This work has the objective to study charge carried layers, especially of electrons, in polymer light emitting devices (PLEDs). These devices are obtained basically by polymer emissive layer deposition between two electrodes. Polymer luminescent devices show advantages when compared to conventional LEDs, such as the thin displays manufacture possibility, with low cost of manufacture and flexible. The PLEDs efficiency is closely linked the commercialization feasibility these displays. In this work, the first structure fabricated is composed by the deposition of OC1C10 - PPV [poly(2-(3,7-dimethyloctyloxy)-5-(2'-methoxy-1,4-phenylene vinylene)]- emissive polymer film between the anode ITO (Indium Tin Oxide) and the aluminum cathode. On the transparent electrode ITO the polymer OC1C10-PPV and Al are deposited as a film through spin coating and thermic evaporation techniques, respectively. In other step, samples were fabricated with a differentiated structure, which films layers related to charges transport were introduced and increase efficiency device. These layers are responsible for reduction of potential barrier between polymer emissive and the electrodes and they can confine a higher number of holes in the emissive layer. This imply in an increase of electrons and hole population in active layer, producing a higher luminous emission. Finally, different Alq3 concentrations were added to solution of the OC1C10-PPV, resulting in compost OC1C10-PPV:Alq3 used as active layer, that increase the luminous efficiency more 10 times than the devices fabricated in first stage of this work. The use polymer PEDOT:PSS - Poly(3,4-ethylenedioxythiophene): Poly(StyreneSulfonate) - as hole transport layer (HTLs) deposited between the aluminum and the polymer electroluminescent showed essential to operation of devices produced, avoiding the short circuit between electrodes.
\end{abstract}

Keywords: PLEDs, ETLs, $\mathrm{OC}_{1} \mathrm{C}_{10}$-PPV, Alq3. 


\section{ÍNDICE DE FIGURAS}

Figura 2.1.1.1 - Mostrador flexível produzido com LED orgânicos aplicado sobre o tecido de uma roupa ${ }^{[8]}$

Figura 2.1.1.2 Estrutura simplificada de um diodo polimérico emissor de luz (ITO/PPV/Al).

Figura 2.1.1.1 Estrutura do trans-poliacetileno

Figura 2.1.1.2 Ilustração de um defeito na estrutura do polímero trans - poliacetileno. 22 Figura 2.1.1.1 - Representação da estrutura de bandas de um diodo emissor de luz convencional

Figura 2.1.1.2 - Mecanismo de Emissão: (1) Injeção, (2) Condução da Carga, (3)

Éxciton e (4) Emissão ${ }^{[x v i i i]}$ 24

Figura 2.1.1.3 Estrutura de bandas dos PLEDs fabricados 26

Figura 2.1.1.1 Representação esquemática da estrutura de bandas de uma junção metal/polímero para o modelo de injeção termiônica. 29

Figura 3.1.1.1 Estrutura química do PEDOT e do PSS, respectivamente...................... 35

Figura 3.1.2.1 - Estrutura química do polímero OC1C10 - PPV ................................... 36

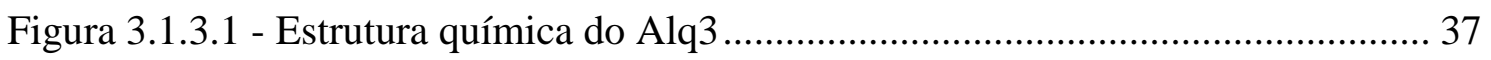

Figura 3.2.2.1 - Geometria do filme de ITO sobre substrato de vidro. ......................... 39

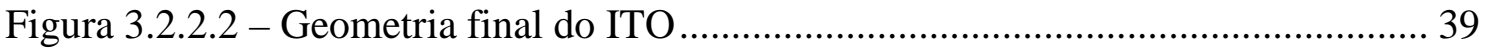

Figura 3.2.6.1 - Representação da máscara de cobre utilizada no processo de evaporação térmica.

Figura 3.2.6.2 - Representação final da máscara de cobre utilizada no processo de evaporação térmica

Figura 3.2.6.3 - Evaporadora em esquema montado para fabricação de um tipo de dispositivo por processo.

Figura 3.2.6.4 - Evaporadora em esquema montado para fabricação de dois tipos de

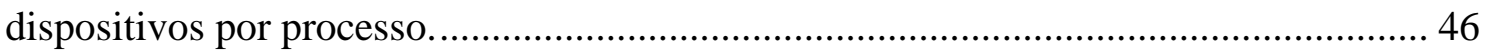

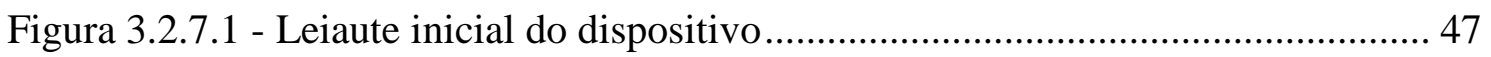

Figura 3.2.7.2 Leiaute com a arquitetura final do dispositivo.................................... 48

Figura 3.3.1.1 - Aparato utilizado para caracterização................................................. 49

Figura 4.2.1.1 Curva IxV de dispositivo sem Alq3 ….................................................5 57

Figura 4.2.1.2 - Curva IxV de dispositivo com Alq3 …................................................ 58

Figura 4.2.2.1 - Curva IxV de dispositivo sem ETL ................................................... 59 
Figura 4.2.2.2 - Relação Luminância x Densidade de corrente de dispositivo sem ETL60 Figura 4.2.2.3 - Intensidade luminosa x comprimento de onda de dispositivo sem ETL

Figura 4.2.2.4 Curva IxV de dispositivos com ETL

Figura 4.2.2.5 - Relação entre Luminância x Densidade de corrente de dispositivos com ETL 62

Figura 4.2.2.6 - Intensidade luminosa x Comprimento de onda de dispositivo com ETL

Figura 4.2.2.7 - Registro fotográfico de dispositivo sem Alq3 …................................. 64

Figura 4.2.2.8 Registro fotográfico de dispositivo com ETL. ......................................... 65

Figura 4.2.3.1 - Curva IxV de dispositivo com 14 nm de Alq3 ................................... 66

Figura 4.2.3.2 - Relação entre Luminância e Densidade de corrente de dispositivo com

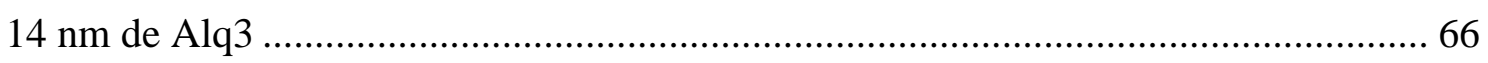

Figura 4.2.3.3 - Relação entre Intensidade luminosa e Comprimento de onda de dispositivo com 14nm de Alq3.

Figura 4.2.3.4 - Registro fotográfico frontal de dispositivo com 14nm de Alq3 68

Figura 4.2.3.5 Registro fotográfico com vista lateral de dispositivo com 14nm de Alq3

Figura 4.2.4.1 Curva IxV de dispositivo com 9nm de Alq3. 69

Figura 4.2.4.2 - Relação entre luminância e densidade de corrente de dispositivos com 9nm de Alq3 70

Figura 4.2.4.3 - Relação Intensidade luminosa x comprimento de onda de dispositivo

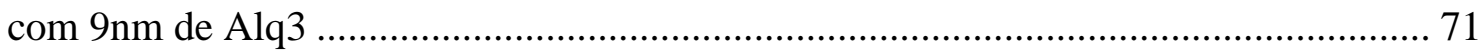

Figura 4.2.4.4 - Registro fotográfico de dispositivo com 9nm de ETL......................... 72

Figura 4.2.5.1 - Curva IxV de dispositivo com 7nm de ETL ........................................ 73

Figura 4.2.5.2 - Relação entre luminância e densidade de corrente de dispositivo com

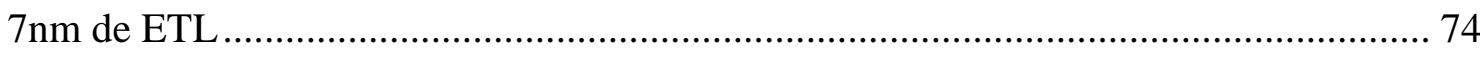

Figura 4.2.5.3 - Relação de Intensidade luminosa x comprimento de onda de dispositivo

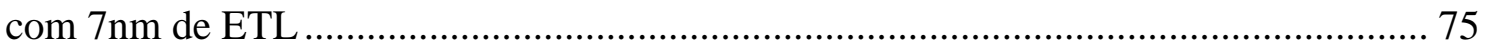

Figura 4.2.5.4 - Registro fotográfico de dispositivo com $7 \mathrm{~nm}$ de ETL........................ 76

Figura 4.2.6.1 Relação de curvas IxV de dispositivos com e sem ETL ......................... 77

Figura 4.2.6.2 Intensidade x comprimento de onda de dispositivos com e sem ETL de $17 \mathrm{~nm}$ 78 
Figura 4.2.6.3 - Intensidade luminosa x comprimento de onda de dispositivos com

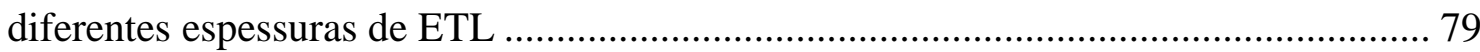

Figura 4.3.1.1 - Curva IxV de dispositivos com 4\% de Alq3 na camada ativa. 81 Figura 4.3.1.2 - Luminância x densidade de corrente de dispositivos com 4\% de Alq3 na camada ativa 82

Figura 4.3.1.3 - Intensidade luminosa x comprimento de onda de dispositivos com $4 \%$ de Alq3 na camada ativa. 83

Figura 4.3.1.4 - Diagrama de cromaticidade de dispositivo com 4\% de Alq3 na camada ativa. 84

Figura 4.3.1.5 - Registro fotográfico de dispositivo com 4\% de Alq3 na camada ativa. 84 Figura 4.3.2.1 - Curva IxV de dispositivo com 8\% de Alq3 na camada ativa. 85 Figura 4.3.2.2 - Luminância x Densidade de corrente de dispositivo com 8\% de Alq3 na camada ativa. 86

Figura 4.3.2.3 - Intensidade luminosa x Comprimento de onda de dispositivo com 8\% de Alq3 na camada ativa.

Figura 4.3.2.4 - Diagrama de cromaticidade de dispositivo com 8\% de Alq3 na camada ativa.

Figura 4.3.2.5 - Registro fotográfico de dispositivo com 8\% de Alq3 na camada ativa. 89 Figura 4.3.3.1 - Curva IxV de dispositivo com 10\% de Alq3 na camada ativa. 89

Figura 4.3.3.2 - Luminância x Densidade de corrente de dispositivo com 10\% de Alq3 na camada ativa. 90

Figura 4.3.3.3 - Diagrama de cromaticidade de dispositivo com 10\% de Alq3 na camada ativa.

Figura 4.3.3.4 - Registro fotográfico de dispositivo com 10\% de Alq3 na camada ativa.

Figura 4.3.4.1 - Curva IxV de dispositivo com 13\% de Alq3 na camada ativa. 92

Figura 4.3.4.2 - Luminância x Densidade de corrente de dispositivo com 13\% de Alq3 na camada ativa. 93

Figura 4.3.4.3 - Diagrama de cromaticidade de dispositivo com 13\% de Alq3 na camada ativa. 94

Figura 4.3.5.1 - Curva IxV de dispositivo com 16\% de Alq3 na camada ativa. 95

Figura 4.3.5.2 - Luminância x Densidade de corrente de dispositivo com 16\% de Alq3 na camada ativa. 96 
Figura 4.3.5.3 - Diagrama de cromaticidade de dispositivo com 16\% de Alq3 na camada ativa. 97

Figura 4.3.5.4 - Registro fotográfico de dispositivo com 16\% de Alq3 na camada ativa.

Figura 4.3.6.1 -Curva IxV de dispositivo com 19\% de Alq3 na camada ativa. 98

Figura 4.3.6.2 - Luminância x Densidade de corrente de dispositivo com 19\% de Alq3 na camada ativa. 99

Figura 4.3.6.3 - Diagrama de cromaticidade de dispositivo com 19\% de Alq3 na camada ativa. 100

Figura 4.3.6.4 - Registro fotográfico de dispositivo com 19\% de Alq3 na camada ativa.

Figura 4.3.7.1 - Curva IxV de dispositivo com 23\% de Alq3 na camada ativa. 101

Figura 4.3.7.2 - Luminância x Densidade de correntede dispositivo com 23\% de Alq3 na camada ativa. 102 Figura 4.3.7.3 - Diagrama de cromaticidade de dispositivo com 23\% de Alq3 na camada ativa. 103

Figura 4.3.7.4 - Registro fotográfico de dispositivo com 23\% de Alq3 na camada ativa.

Figura 4.3.8.1 - Curva IxV de dispositivo com 10\% de Alq3 na camada ativa e sem ETL 104

Figura 4.3.8.2 - Cruva IxV de dispositivo com 10\% de Alq3 na camada ativa e sem ETL

Figura 4.3.8.3 - Diagrama de cromaticidade de (a) dispositivos sem qualquer presença de Alq3, (b) com 10\% de Alq3 na camada ativa e sem ETL e (c) com 10\% de Alq3 e com $7 \mathrm{~nm}$ de ETL.

Figura 4.3.8.4 - Curvas IxV de dispositivos feitos com compósitos $\mathrm{OC}_{1} \mathrm{C}_{10}$-PPV:Alq3 e de dispositivo com $\mathrm{OC}_{1} \mathrm{C}_{10}$-PPV apenas 107 


\section{ÍNDICE DE TABELA}

Tabela 3.3.1 - Relação de lote de amostras e estruturas fabricadas............................... 51

Tabela 4.2.1 - Relação das medidas de espessura realizadas pelo cristal da evaporadora e pelo profilômetro 56

Tabela 4.2.2 Relação de eficiência luminosa, luminância máxima e tensão de operação de dispositivos com e sem ETL

Tabela 4.2.1 - Relação entre estruturas, espessura de Alq3, eficiência luminosa e luminância máxima dos dispositivos 80

Tabela 4.3.1 Relação dos lotes produzidos a partir de compósitos e seus respectivos valores de eficiência luminosa. 


\section{ÍNDICE DE EQUAÇÕES}

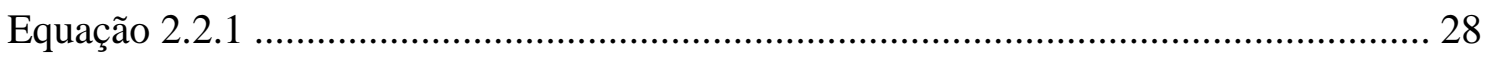

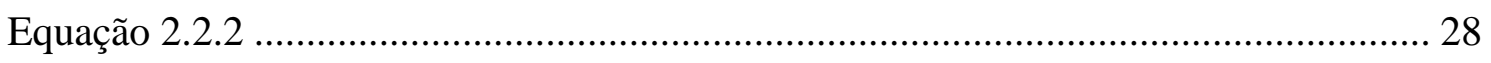

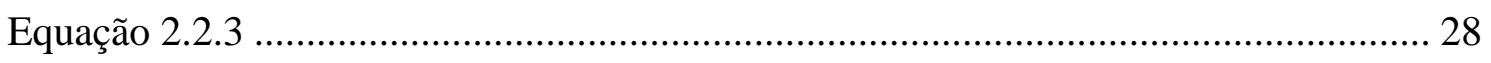

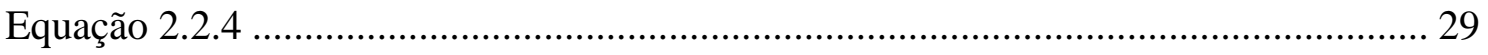

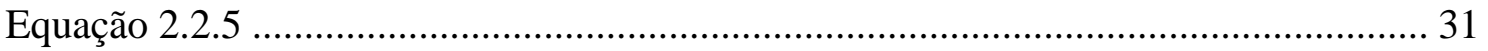

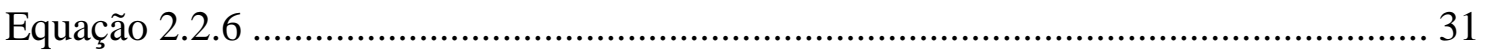

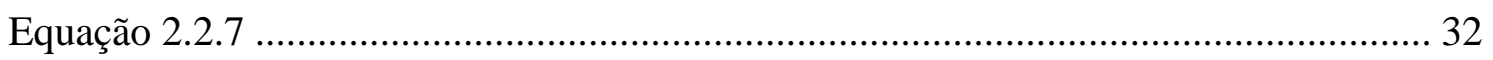

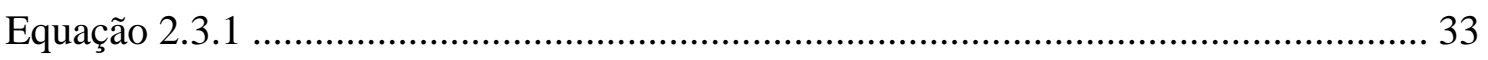

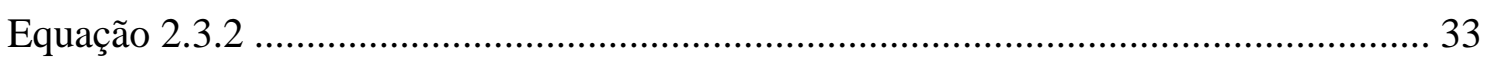




\section{LISTA DE ABREVIAÇÕES}

PLEDs - Diodos poliméricos emissores de luz.

LEDs - Diodos emissores de luz.

$\mathrm{OC}_{1} \mathrm{C}_{10}$ - PPV - poly[2-metoxi-5-(3,7-dimetil-octiloxi)-1,4-fenilenovinileno

ITO - Oxido de Índio-Estanho

$\mathrm{Al}$ - Alumínio

Alq3 (tris-(8-hydroxyquinolate)-aluminum)

PEDOT:PSS - Poli (3,4-etilenodioxitiofeno) : Poliestireno Sulfonado

PPV - poli( $p$-fenileno vinilideno)

CDT - Cambridge Display Tecnology

ETRI - Electronics and Telecommunications Research Institute

RGB - Red green blue

OLEDs - Diodos orgânicos emissores de luz.

HTL - Hole transport layer

ETL - Electron transport layer

HBL - Hole Blocking Layer

EBL - Electron Blocking Layer

EIL - Electron Injection Layer

HIL - Hole Injection Layer

LiF - fluoreto de lítio

LCD - Liquid Cristal Display

LUMO - Lowest Unoccupied Molecular Orbital

HOMO - Highest Occupied Molecular Orbital 


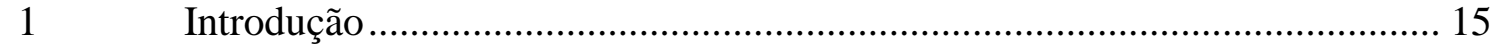

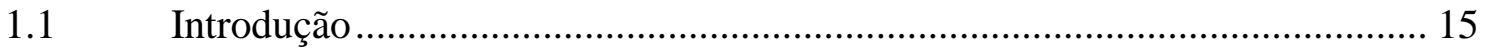

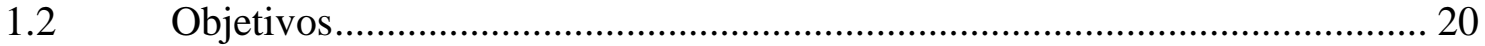

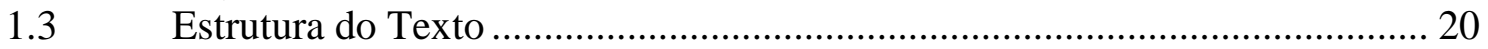

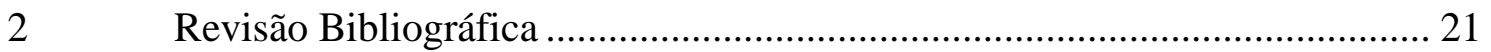

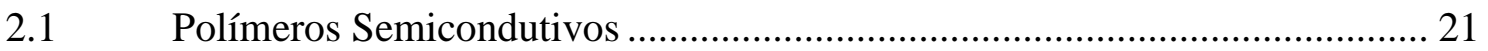

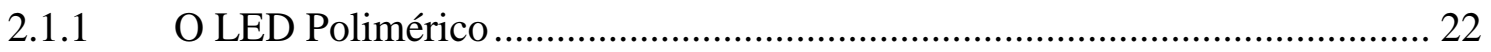

2.2 Injeção e Transporte de Portadores ........................................................... 27

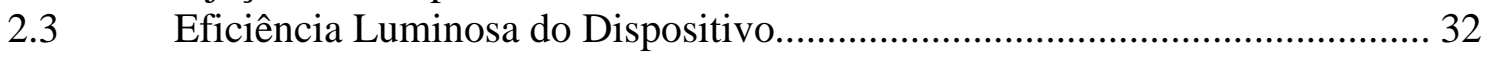

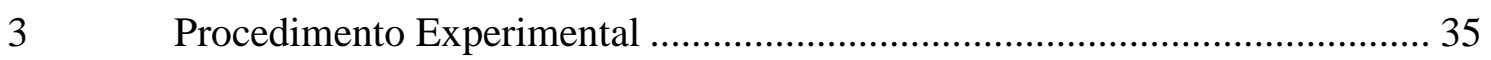

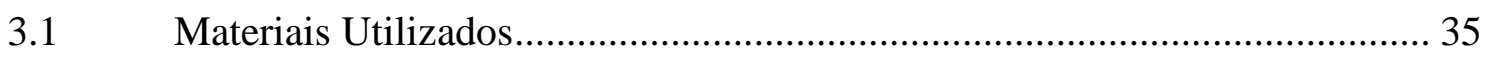

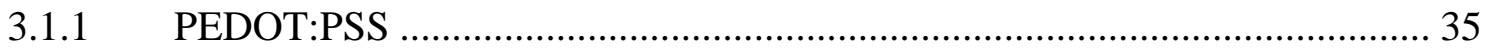

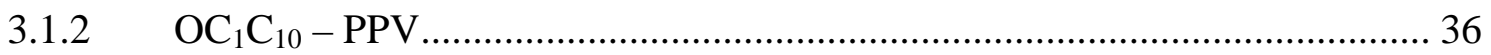

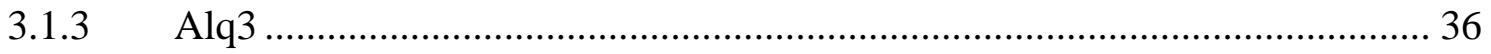

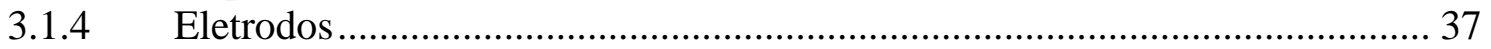

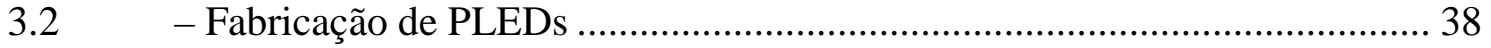

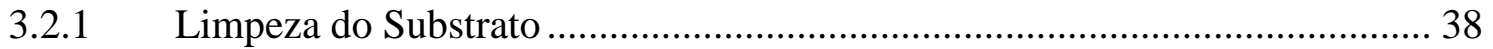

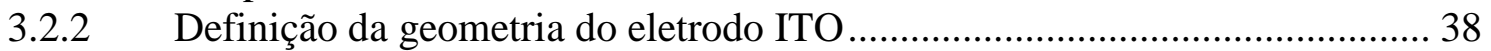

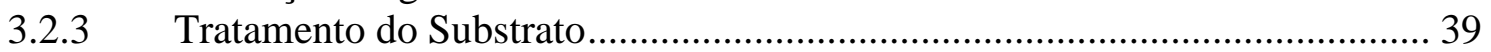

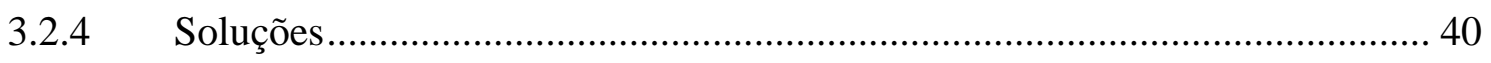

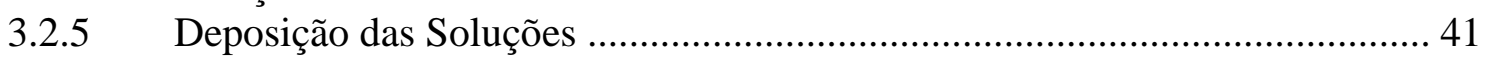

3.2.6 Definição da Geometria da ETL e Eletrodo............................................... 43

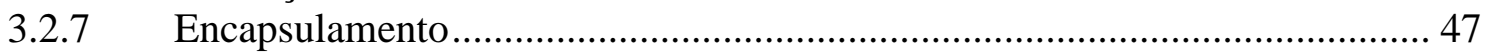

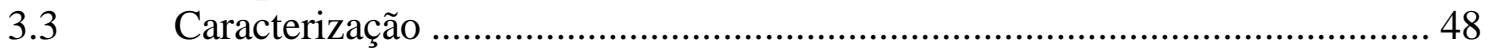

3.3.1 Medidas de Intensidade Luminosa e Luminância .......................................... 48

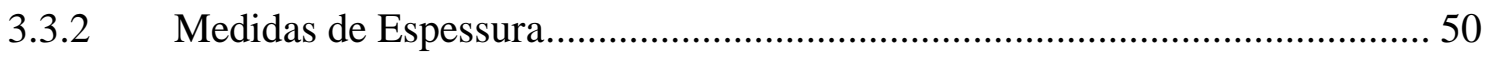

3.3.3 Registro Fotográfico de Dispositivos ...................................................... 51

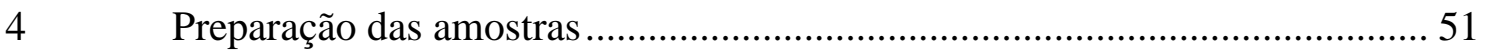

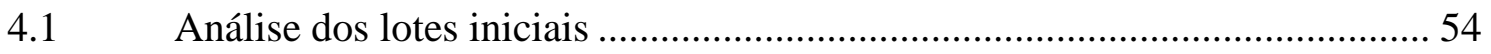

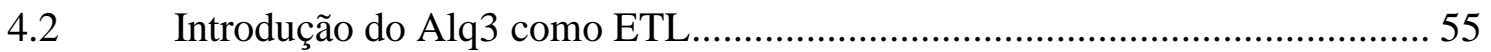

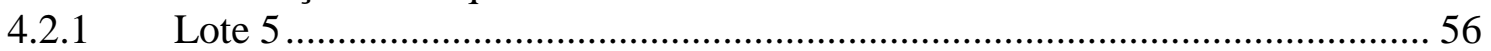

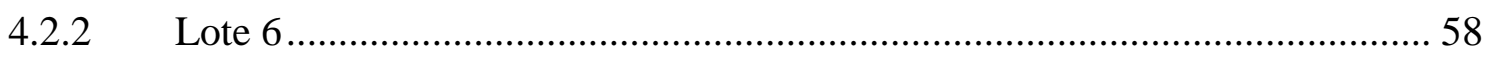

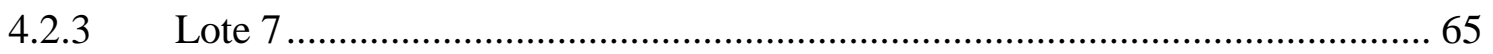

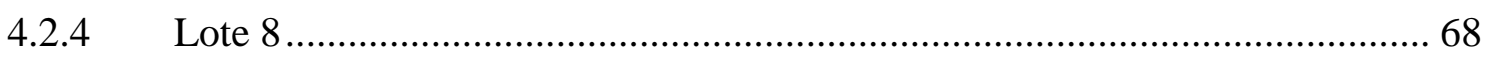

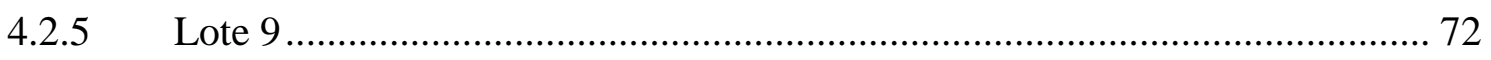

4.2.6 Análise de resultados: filmes Alq3 …...................................................... 76

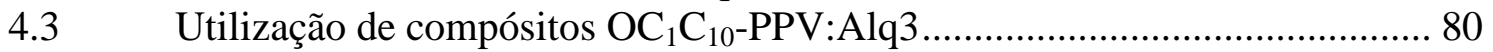

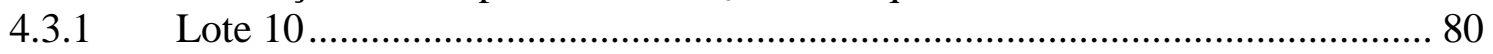

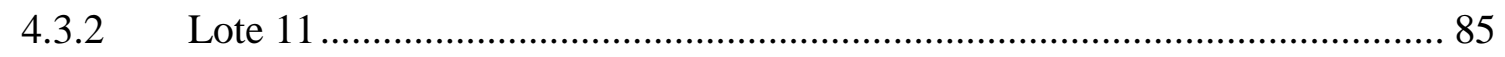

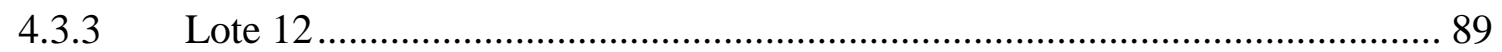

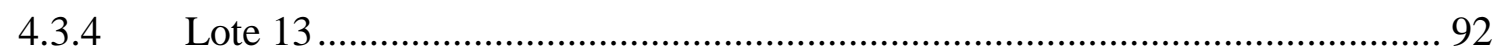

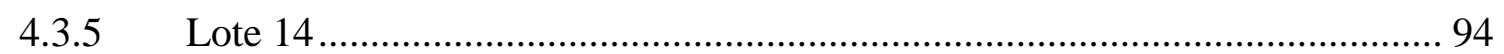

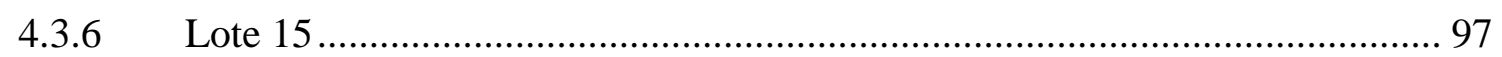

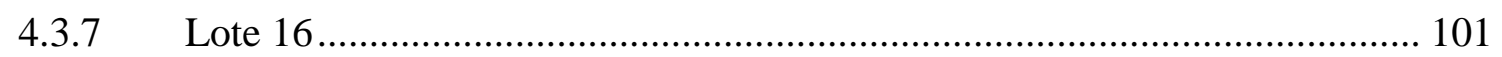

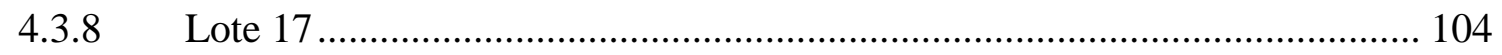




\section{Introdução}

\subsection{Introdução}

Mais comumente conhecidos como isolantes elétricos e acústicos, os materiais poliméricos têm sido amplamente estudados por apresentarem características até há pouco tempo ignoradas. No início dos anos $60^{[1]}$ foi feito o primeiro relato da eletroluminescência (EL) em materiais orgânicos, no caso cristais de antraceno, que emitiram luz em função da aplicação de campos elétricos elevados numa estrutura formada por uma fina camada do material entre eletrodos metálicos. A baixa eficiência deste processo fez com que se desconsiderasse por muito tempo a possibilidade de se fabricar dispositivos emissores de luz à base de materiais orgânicos. Porém, em meados da década de 80, surgem os primeiros relatos de dispositivos orgânicos baseados em heteroestruturas ${ }^{[2]}$. Estes dispositivos emitiram luz para valores bastante inferiores de tensão elétrica $(<100 \mathrm{~V})$, quando comparados àqueles primeiros, apresentando intensidade luminosa relativamente alta. Estes resultados levaram a área a um novo impulso.

Enquanto novas descobertas relacionadas às propriedades físicas de sólidos moleculares eram realizadas, ocorreu um grande impulso no estudo de materiais poliméricos. A descoberta acidental da possibilidade de dopagem do polímero poliacetileno, pela simples exposição deste a vapores de iodo, com o conseqüente aumento da condutividade elétrica em várias ordens de grandeza (de $10^{-5} \mathrm{~S} / \mathrm{cm}$ até $10^{2}$ S/cm) mais a explicação dos mecanismos de condução elétrica em polímeros, resultou no prêmio Nobel de Química aos pesquisadores H. Shirakawa, A. J. Heeger e A. MacDiarmid em 2000 que publicaram este estudo em 1977 $7^{[3]}$. Em 1979, abriu-se um novo campo para estudos de novos sistemas condutores poliaromáticos com $\mathrm{o}$ descobrimento do poli( $p$ - fenileno) incluindo o polipirrol, o politiofeno e a polianilina $^{[4]}$. Em 1990, o grupo do Prof. Friend divulgou na revista Nature, o primeiro diodo emissor de luz (light emitting diode - LED) polimérico, utilizando como camada ativa o polímero poli( $p$-fenileno vinilideno) - $\mathrm{PPV}^{[5]}$. Este fato marcou definitivamente o rumo da pesquisa em dispositivos eletrônicos poliméricos. Em 1991, surge o primeiro 
trabalho de um mostrador polimérico ( 3 x 5 pixels) e no ano seguinte nasce, a partir do grupo da Universidade de Cambridge, a empresa CDT (Cambridge Display Tecnology). Já no ano de 1997, a CDT recebe investimentos superiores a 10 milhões de dólares, através do governo britânico e de parcerias com empresas privadas como a Intel. No ano de 2003 a CDT anuncia ter atingido uma vida útil estimada dos dispositivos poliméricos de aproximadamente 20.000 horas e, no ano seguinte, este número chega em 80.000 horas com uma emissão luminosa de $100 \mathrm{~cd} / \mathrm{m}^{2[6]}$. Estes dados animadores vislumbram as inúmeras aplicações possíveis desta tecnologia no mercado de mostradores.

Quando comparados aos mostradores de cristal líquido, os mostradores baseados em LEDs poliméricos apresentam importantes vantagens, dentre as quais se destacam o ângulo de visão próximo de $180^{\circ}$, a redução de elementos construtivos adicionais como iluminação posterior - backlight (redução do consumo de energia) e filtros ${ }^{[6]}$, facilidade de processamento e um atrativo comercial muito grande: a possibilidade de confecção de mostradores flexíveis, leves e de baixo custo. Estes mostradores podem operar com baixas tensões e alta eficiência ${ }^{[7]}$. A Figura 2.1.1.1 ilustra um protótipo de mostrador flexível para roupas produzido pelo instituto de pesquisa coreano ETRI (Electronics and Telecommunications Research Institute $)^{[8]}$.

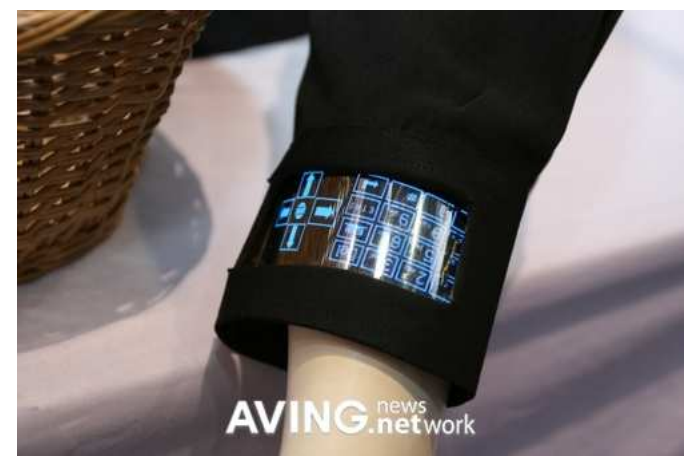

Figura 2.1.1.1 - Mostrador flexível produzido com LED orgânicos aplicado sobre o tecido de uma roupa $^{[8]}$.

Os mostradores poliméricos são formados por dispositivos de emissão luminosa poliméricos, os chamados PLEDs (Polymer Light Emitting Diodes), que vêm sendo investigados e desenvolvidos por diversos centros de pesquisa como Sony, Seiko-Epson e Philips Research ${ }^{[9]}$, entre outros. A estrutura básica destes dispositivos é formada pela deposição de um material polimérico eletroluminescente entre dois eletrodos, sendo um deles transparente (óxido transparente condutivo) para permitir visualizar a luz emitida. Quando ocorre a polarização do dispositivo, são injetados elétrons pelo cátodo e lacunas 
pelo ânodo, na camada ativa polimérica. A partir da recombinação dos pares elétronlacuna, com a conseqüente geração de um estado excitado, ocorre o decaimento radiativo e a emissão de luz na faixa do espectro visível ${ }^{[5]}$. A Figura 2.1.1.2 apresenta um diagrama esquemático de uma estrutura de um PLED, com as diferentes camadas: anôdo formado por um filme de óxido de índio e estanho (indium thin oxide - ITO), uma camada polimérica - PPV e o cátodo de alumínio.

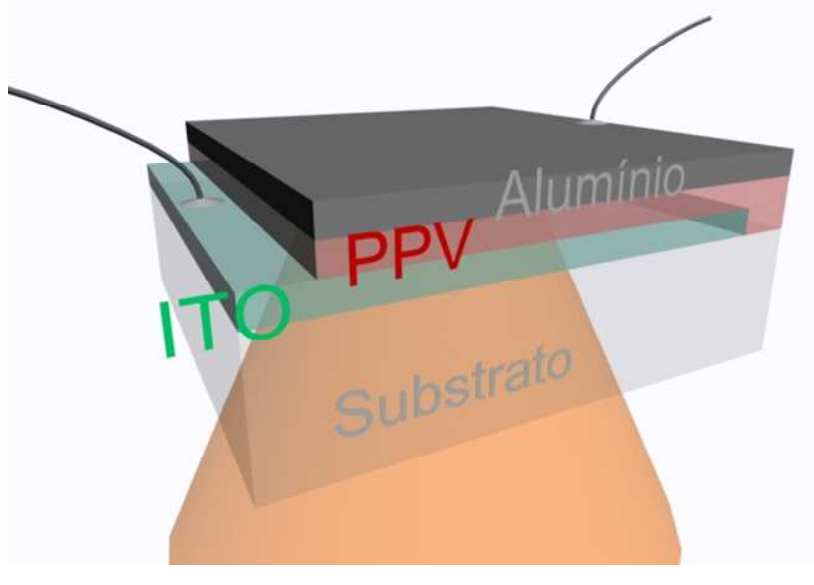

Figura 2.1.1.2 Estrutura simplificada de um diodo polimérico emissor de luz (ITO/PPV/AI).

Entre as principais vantagens desta tecnologia que despertou o interesse de tantos grupos de pesquisa e empresas fabricantes de mostradores, está justamente a relativa simplicidade no processo de preparação dos dispositivos. Para a fabricação de PLEDs, há diferentes técnicas de deposição dos filmes poliméricos, entre elas: Spin Coating, Casting ou Automontagem. No entanto, para produzir mostradores coloridos, ou mesmo monocromáticos com grande definição da área dos pixels, a técnica mais empregada tem sido a deposição dos filmes finos por impressão a jato de tinta. Nesta técnica, a solução polimérica é impressa diretamente sobre o substrato na geometria desejada ${ }^{10}$. Este quesito é particularmente importante quando se deseja a produção de um mostrador colorido onde se torna necessário depositar polímeros que venham a constituir PLEDs que emitam nas três cores básicas - vermelho, verde e azul (RGB, em inglês). Estes dispositivos podem ser utilizados na produção de grandes painéis, flexíveis ou não, sem a necessidade do emprego de equipamentos com vácuo, definição de geometrias por processos de fotolitografia ou uso de máscaras mecânicas, e ainda processos em elevadas temperaturas ${ }^{[11]}$. Na técnica de impressão dos polímeros por jato de tinta, a 
limitação da área do mostrador está relacionada ao tamanho da impressora utilizada. Quanto maior a impressora, maior a área e a quantidade de PLEDs que podem ser depositados.

Outro termo que também é muito utilizado na literatura para se referir a dispositivos orgânicos de emissão luminosa são os OLEDs. Neste caso, as moléculas do material orgânico são de dimensões inferiores às que caracterizam um material polimérico. No caso de mostradores OLEDs, os filmes emissivos são depositados majoritariamente por evaporação térmica. Sendo assim, o principal obstáculo para construir mostradores de grandes dimensões com dispositivos OLEDs é justamente o processo de deposição do material.

De qualquer forma, quando se pensa em dispositivos PLEDs de maior eficiência, há a necessidade de introdução de camadas intermediárias entre os eletrodos e o filme emissivo para aumentar a eficiência e o desempenho dos dispositivos. Pesquisas e novas descobertas mostram que camadas intermediárias entre o polímero eletroluminescente e os eletrodos aumentam consideravelmente o número de portadores no interior da camada ativa polimérica ${ }^{[12]}$. A introdução das camadas transportadoras de carga pode aumentar a eficiência do dispositivo, uma vez que a elevação do número de cargas na camada ativa implica em uma maior recombinação e em uma emissão luminosa superior. Estas camadas intermediárias são conhecidas como HTLs (Hole Transport Layers) quando transportam lacunas e ETLs (Eletron Transport Layers) quando são transportadoras de elétrons. Estas mesmas camadas podem funcionar como bloqueadoras de portadores, evitando que um portador saia de um eletrodo e chegue ao outro, sem que haja recombinação. Quando possuem a função de bloqueadoras, estas camadas recebem o nome de HBL (Hole Blocking Layer) e EBL (Electron Blocking Layer $^{13}{ }^{14}$ ). Materiais utilizados como camadas transportadoras e/ou bloqueadoras de carga podem ainda ser adicionados à camada emissiva com a mesma finalidade de aumentar o desempenho do dispositivo ${ }^{[15]}$.

Faz-se necessário, neste momento, mencionar a confusão de nomenclaturas encontradas na bibliografia quando tratamos de camadas intermediárias transportadoras de carga. Alguns autores ${ }^{[16],[17]}$ utilizam os termos EIL (electron injection layer) e HIL (hole injection layer) quando se referem a estas camadas. Entretanto, entende-se como camada injetora aquelas que provocam uma redução da barreira de potencial de modo a aumentar a população de portadores no interior do polímero. As camadas intermediárias 
transportadoras de cargas facilitam a trajetória do portador até o polímero emissivo após sua passagem pela camada injetora, seja ela um eletrodo ou uma camada injetora intermediária. A camada transportadora de cargas não reduz necessariamente a barreira de potencial entre o eletrodo e a camada ativa. Uma camada pode, ainda, possuir a função de injetora e de transportadora, reduzindo a barreira de potencial e, ao mesmo tempo, facilitando o transporte por conta de sua alta condutividade.

Neste trabalho, são utilizadas camadas HTL, formadas por filmes de polieletrolítico polimérico poli(3,4-etilenodioxitiofeno):poli(estireno ácido sulfonico) (PEDOT:PSS) e ETL, formadas por filmes de [tris-(8-hidroxiquinolato)-aluminio] ou Alq3. O polímero eletroluminescente é o poli[2-metóxi-5-(3,7-dimetil-octiloxi)-1,4fenilenovinileno], ou $\mathrm{OC}_{1} \mathrm{C}_{10}-\mathrm{PPV}$.

Diferentes estruturas foram estudadas neste trabalho, visando um aumento no desempenho dos dispositivos. O foco principal residiu no estudo da camada transportadora de elétrons e da camada emissiva. O conjunto de amostras deste trabalho compreendeu dispositivos fabricados com as estruturas: ITO/OC $\mathrm{C}_{10}-\mathrm{PPV} / \mathrm{Al}$; ITO/PEDOT:PSS/OC ${ }_{1} \mathrm{C}_{10}$-PPV/Al; ITO/PEDOT:PSS/OC $\mathrm{C}_{10}-\mathrm{PPV} / \mathrm{LiF} / \mathrm{Al}$ (apenas um lote para teste), utilizando o fluoreto de lítio (LiF) como ETL.

A segunda etapa deste trabalho teve como principal objetivo a realização da analise comparativa da eficiência entre dispositivos que continham o material ETL e dispositivos que não continham ETL, mantendo a primeira estrutura fabricada. Para verificar a influência do filme fino de Alq3, diferentes espessuras deste filme foram utilizadas na preparação das ETLs. Outro estudo importante do trabalho residiu na camada emissiva dos dispositivos. Para tanto, foram utilizadas diferentes concentrações de Alq3 misturadas ao polímero emissivo, formando compósitos $\mathrm{OC}_{1} \mathrm{C}_{10}$-PPV:Alq3. Os últimos cinco lotes de dispositivos foram fabricados utilizando diferentes concentrações em massa de $\mathrm{Alq} 3$ adicionadas às soluções de $\mathrm{OC}_{1} \mathrm{C}_{10}$-PPV. Para que houvesse uma avaliação mais precisa do papel do Alq3 no filme emissivo e, ainda neste caso como camada transportadora de elétrons, foram fabricados dispositivos com e sem Alq3 como ETL, nestas últimas estruturas.

A influência da presença de Alq3 no desempenho do dispositivo e a relação de sua espessura quando camada transportadora de carga foi avaliada através de medidas de intensidade luminosa x comprimento de onda, luminância, curvas $\mathrm{IxV}$ e cálculos de eficiência luminosa. 


\subsection{Objetivos}

Este trabalho tem como objetivo estudar a influência da utilização do Alq3 em estruturas de PLEDs, ora como camada transportadora de elétrons, ora como elemento constituinte da camada ativa, formando um compósito com o polímero eletroluminescente. Este estudo visa correlacionar a aplicação deste material com o desempenho e eficiência do dispositivo, tendo por base o polímero emissivo $\mathrm{OC}_{1} \mathrm{C}_{10^{-}}$ PPV.

\subsection{Estrutura do Texto}

Este texto está dividido em 5 capítulos que descrevem a evolução e os resultados deste trabalho de mestrado. Como já foi visto, o capítulo 1 contém uma breve introdução sobre o tema e a evolução científico-tecnológica sobre o tema para que o leitor possa se situar e atentar para as grandes promessas dos novos materiais em questão.

No capítulo 2 está contida a revisão bibliográfica. Neste capítulo inicia-se a descrição dos fundamentos teóricos da semicondutividade em materiais poliméricos e do emprego destes materiais em dispositivos eletrônicos. Este capítulo apresenta os mecanismos de condução de carga, o modelo de estrutura de bandas dos polímeros e do dispositivo emissor de luz polimérico. Trata da descrição dos diferentes modelos de transporte de carga em um semicondutor.

O capítulo 3 descreve os processos envolvidos na confecção de um PLED. É necessário frisar que os métodos relatados não são únicos, mas foram eleitos através de resultados obtidos por outros pesquisadores do grupo e pela ampla indicação da bibliografia.

Os métodos de caracterização óptica e elétrica dos dispositivos são descritos no capítulo 4.

As conclusões deste trabalho são apresentadas no capítulo 5.

No capítulo 6 estão relacionadas as propostas futuras para a continuidade do tema tratado neste projeto. 


\section{Revisão Bibliográfica}

\subsection{Polímeros Semicondutivos}

Como já mencionado, até meados da década de 1970, os polímeros eram reconhecidos como materiais de excelente isolação elétrica. Nesta época, uma nova classe de polímeros foi desenvolvida, com características elétricas diferenciadas, podendo apresentar altos valores de condutividade elétrica ou propriedades luminescentes. Esta classe de polímeros, chamados polímeros conjugados, possui a característica da semicondutividade, antes presente apenas em compostos inorgânicos como o Silício e o Germânio.

A conjugação dos polímeros se dá pela alternância de ligações simples (C-C), ligação $\sigma$ (sigma), e ligações duplas $(\mathrm{C}=\mathrm{C})$, ligações $\sigma$ e $\pi$, entre os átomos de carbono da cadeia principal. Como os comprimentos das ligações duplas e simples são de tamanhos diferentes, ocorre a perda da simetria da cadeia. A estrutura eletrônica equivalente a de bandas de energia é resultante das interações de energia de orbitais moleculares, abrindo uma região proibida (gap) entre o HOMO (Highest occupied molecular orbital) e o LUMO (lowest unoccupied molecular orbital) do polímero, algo equivalente à banda de valência e de condução dos materiais inorgânicos. Os valores de gap para os polímeros conjugados, ou seja a diferença de energia entre estes dois orbitais, situa-se entre 1,5 e 4 eV. A cor da emissão está diretamente relacionada à energia de recombinação e ao valor de gap entre os níveis HOMO e LUMO do polímero.

A Figura 2.1.1.1ilustra uma estrutura conjugada do polímero trans-poliacetileno (tPA).

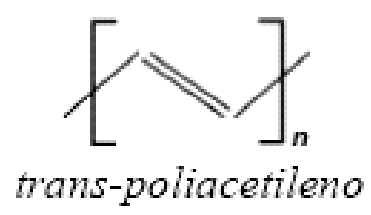

Figura 2.1.1.1 Estrutura do trans-poliacetileno

Pelo fato de apresentar a estrutura química mais simples entre os polímeros conjugados, o trans-poliacetileno (t-PA) é quase sempre empregado para exemplificar o 
comportamento elétrico dos polímeros conjugados. No estado fundamental, o t-PA pode apresentar defeitos estruturais na cadeia polimérica. Estes defeitos, denominados sólitons, não alteram a energia da cadeia, possuem carga neutra e estão relacionados a introdução de um nível de energia no meio do gap do polímero. A Figura 2.1.1.2 ilustra a presença de um sóliton no polímero t-PA ${ }^{[18],[19]}$.

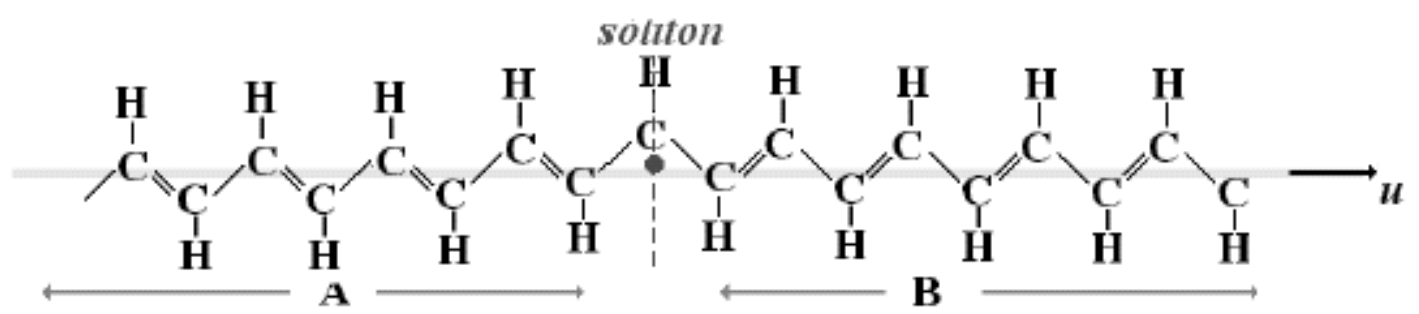

Figura 2.1.1.2 Ilustração de um defeito na estrutura do polímero trans - poliacetileno.

A degenerescência de estados ${ }^{[20]}$, característica exclusiva do t-PA, leva a uma situação na qual, para que se consiga restabelecer a condição de equilíbrio de energia na cadeia e o sistema mantenha a condição de mínima energia, o surgimento de defeitos, sólitons e anti-sólitons, ocorre sempre de forma simultânea, ou seja, os sólitons coexistem com os anti-sólitons (anti-defeitos). Um par de sólitons em um polímero conjugado pode ser carregado positiva ou negativamente; neste caso, os defeitos passam a ser chamados de pólarons positivos (quando carregados positivamente) e pólarons negativos (quando carregados negativamente). Estes pares possuem spin eletrônico 1/2, sendo que um pólaron positivo pode encontrar um pólaron negativo, recombinar e formar o que a literatura chama de éxciton singleto ${ }^{[21]}$. Quando um éxciton singleto relaxa, ocorre a emissão um fóton e, por este motivo, diz-se que estes defeitos são os grandes responsáveis pela emissão de luz em polímeros conjugados ${ }^{[20]}$.

\subsubsection{O LED Polimérico}

Dispositivos eletrônicos emissores de luz convencionais, mais conhecidos por LEDs (Light Emitting Diodes), são confeccionados utilizando materiais inorgânicos como camada ativa. A Figura 2.1.1.1 ilustra a estrutura de bandas de um diodo emissor de luz convencional. 


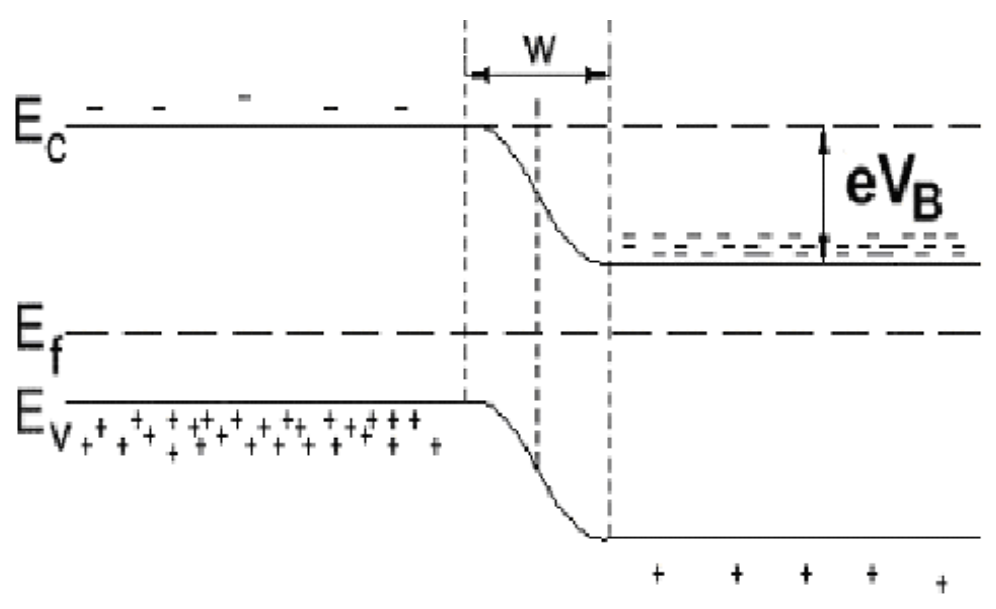

Figura 2.1.1.1 - Representação da estrutura de bandas de um diodo emissor de luz convencional

Sendo:

$$
\begin{aligned}
& E_{C}=\text { Energia de Condução } \\
& E_{f}=\text { Energia de Fermi } \\
& E_{V}=\text { Energia de Valência } \\
& W=\text { Largura da Região de Depleção } \\
& e V_{B}=\text { Barreira Energética vista pelo elétron. }
\end{aligned}
$$

Na Figura 2.1.1.1, a energia necessária vista pelo elétron para saltar a barreira energética existente é representada por $\mathrm{eV}_{\mathrm{B}}$. A existência de uma barreira de potencial é o que aproxima os PLEDs dos diodos convencionais. Desta forma, um diodo emissor de luz polimérico é assim chamado por apresentar barreiras que devem ser ultrapassadas pelos portadores para que ocorra a emissão de luz. Entretanto, um PLED difere de um dispositivo convencional em relação aos processos de fabricação, à estrutura física apresentada e aos fenômenos observados durante sua polarização. Sendo assim, é necessário dizer que a utilização do nome "Diodo Poliméricos Emissor de Luz" está relacionada apenas ao fato de PLEDs possuírem barreiras de potencial análogas as de um diodo Schottcky. 
A eletroluminescência é resultado do processo de recombinação de portadores e há várias etapas para que este fenômeno ocorra. A primeira delas é a injeção de elétrons e lacunas pelos eletrodos que formam uma estrutura do tipo sanduíche com o polímero eletroluminescente. Portadores negativos são injetados pelo catodo no orbital HOMO e portadores positivos são injetados pelo anodo no orbital LUMO do polímero, formando pólarons positivos e negativos, que podem se mover através do campo elétrico e se encontrar em um mesmo segmento de molécula, formando um éxciton singleto ${ }^{[20]}$. O passo seguinte é a relaxação do éxciton e o decaimento radiativo, provocando a emissão de luz em um comprimento de onda específico. Portanto, para que o fenômeno da eletroluminescência ocorra nos dispositivos são necessários quatro processos físicos:

1 - Injeção de portadores de carga pelos eletrodos por meio de polarização direta.

2 - Transporte de cargas ou polarons carregados através do volume do material polimérico.

3 - Encontro e a recombinação de cargas dentro da mesma cadeia polimérica.

4 - Geração de um estado excitado e seu posterior decaimento radiativo que promove a emissão de luz.

A Figura 2.1.1.2 ilustra o processo de injeção e recombinação de cargas com a geração de luz.

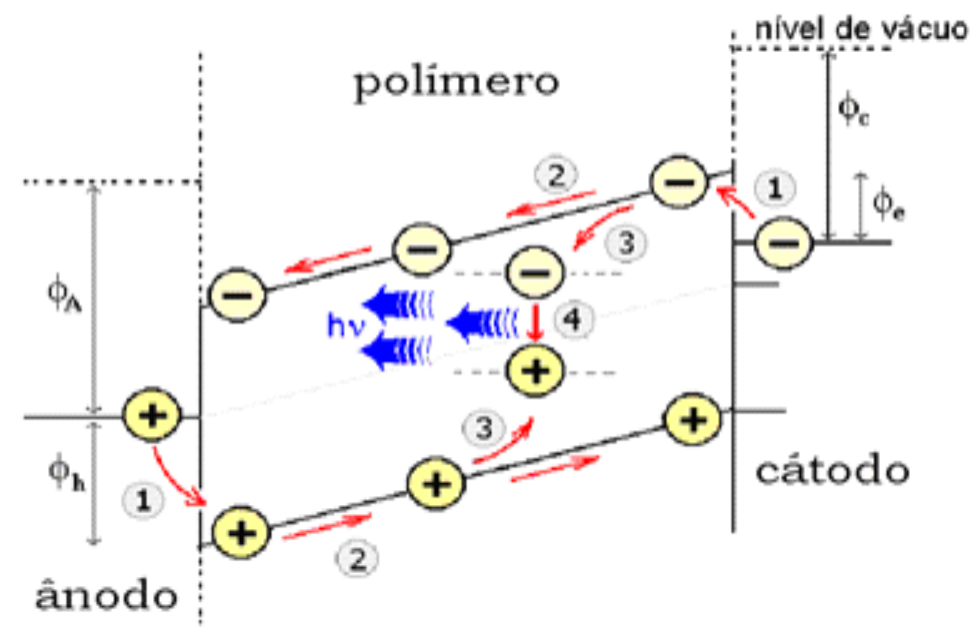

Figura 2.1.1.2 - Mecanismo de Emissão: (1) Injeção, (2) Condução da Carga, (3) Éxciton e (4) Emissão ${ }^{[20]}$. 
Observa-se que as cargas são injetadas no interior do polímero e, após a interação entre polarons de cargas opostas, ocorre a emissão de luz em um determinado comprimento de onda hv. É necessário, entretanto notar que algumas partículas passam pelo polímero sem sofrer o processo de recombinação. Os éxcitons podem decair não radiativamente ou ainda ser capturados por armadilhas, o que limita a emissão deste processo.

A eficiência e o desempenho do dispositivo depende de um balanceamento das cargas injetadas no polímero emissivo. Caso haja grande predominância de um tipo de portador, haverá apenas uma contribuição para a corrente elétrica e não para a emissão, uma vez que muitos portadores atravessarão a camada polimérica sem se recombinar ${ }^{[22]}$. A mobilidade de lacunas em polímeros conjugados é maior que a mobilidade de elétrons ${ }^{[23],[24]}$ (cerca de 100 vezes maior ${ }^{[25]}$ ). Considerando que a quantidade de lacunas injetadas também é maior, há um comprometimento da eficiência luminosa do dispositivo. A bibliografia aponta duas justificativas para a ocorrência deste fato: a primeira está relacionada à dopagem tipo p, que é grande o suficiente para compensar as armadilhas de lacunas; a segunda razão é que o processo de oxidação contribui para o aparecimento de armadilhas de elétrons, mas não de lacunas ${ }^{[26],[27]}$. Somada a redução da mobilidade de portadores negativos, as armadilhas de elétrons são capazes de confinar o processo de eletroluminescência para a região próxima do cátodo. Contatos metálicos, entretanto, absorvem todos os fótons emitidos provocando uma região de extinção da eletroluminescência, o que compromete fortemente a eficiência do dispositivo.

Para tentar solucionar este problema, utiliza-se uma camada intermediária entre o polímero eletroluminescente e o eletrodo metálico com a finalidade de aumentar o número de cargas negativas no interior da camada ativa e, ao mesmo tempo, funcionar como bloqueadora de lacunas. Isto acarretaria um deslocamento da região de eletroluminescência ${ }^{[28]}$ para próximo do contato transparente (anodo).

Estas questões relacionadas à mobilidade dos portadores e à quantidade relativa de cada tipo que é injetado (balanceamento de cargas) motiva o estudo dos mecanismos e materiais que contribuem para promover um equilíbrio ou balanceamento de cargas, aumentando a eletroluminescência ${ }^{[29]}$.

Visando aumentar a quantidade de cargas negativas e, conseqüentemente, contribuir para o equilíbrio de cargas injetadas na camada ativa, neste trabalho foram 
fabricados dispositivos para verificar o efeito das camadas transportadoras de elétrons, no caso filmes finos de $\mathrm{Alq3}$. $\mathrm{O}$ polímero $\mathrm{OC}_{1} \mathrm{C}_{10}$-PPV foi empregado como camada emissiva, eletrodos de ITO e de $\mathrm{Al}$ como anodo e catodo respectivamente e Alq3 como camada transportadora de elétrons. A Figura 2.1.1.3 representa a estrutura de bandas dos PLEDs fabricados.
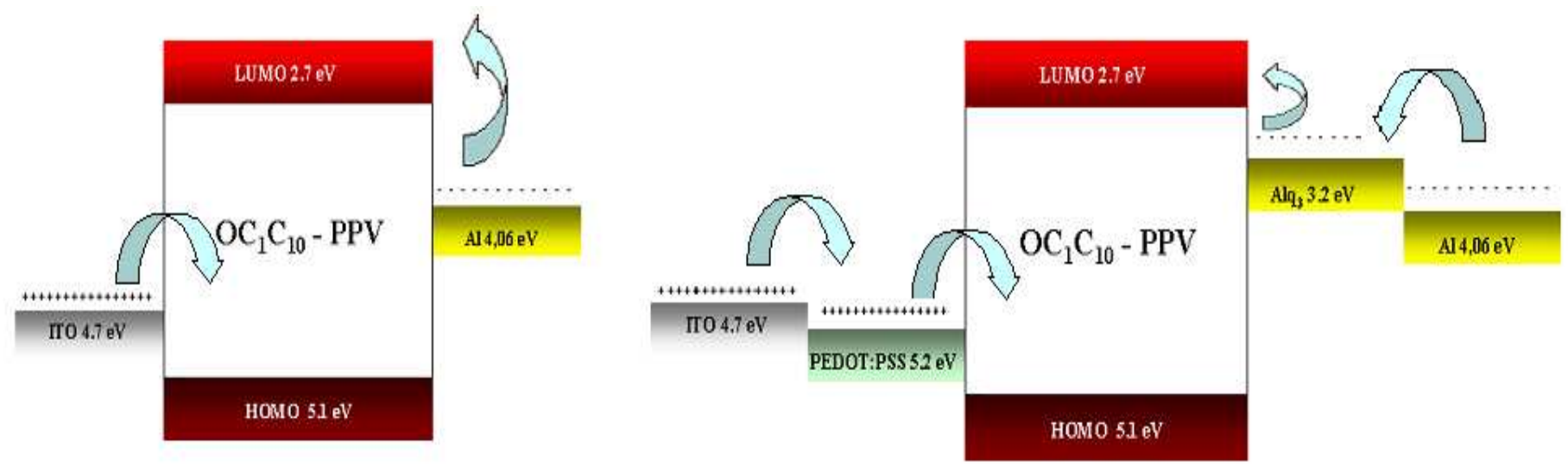

Figura 2.1.1.3 Estrutura de bandas dos PLEDs fabricados

A Figura 2.1.1.3 ilustra a função das camadas transportadoras de carga em um dispositivo poliméricos emissor de luz. Na primeira estrutura, o elétron deverá saltar uma barreira de $1,36 \mathrm{eV}$ para poder chegar no polímero $\mathrm{OC}_{1} \mathrm{C}_{10}-\mathrm{PPV}$; com a introdução da camada transportadora de elétrons Alq3, o portador deverá realizar um salto de 0,87 $\mathrm{eV}$, seguido de outro de $0,5 \mathrm{eV}$. Este feito, facilitará a trajetória do elétron até o polímero emissor de luz. A presença do PEDOT:PSS é indispensável neste trabalho por motivos que serão discutidos posteriormente e que não estão necessariamente ligados a natureza transportadora de lacunas em PLEDs deste complexo.

Já foi demonstrado que a introdução de grupos transportadores de carga em materiais emissivos pode aumentar a desempenho de dispositivos ${ }^{[30]}$.O aumento da injeção de elétrons, em especial, pode se dar pela adição de um material na camada emissiva que possui afinidade com este tipo de portador $^{[31]}$. Desta maneira, foi, ainda neste trabalho, desenvolvida uma segunda alternativa capaz de aumentar a eficiência luminosa dos dispositivos. Esta alternativa se concentra na introdução de diferentes porcentagens em massa do material transportador de elétrons na solução emissiva, com a finalidade de se produzir compósitos $\mathrm{OC}_{1} \mathrm{C}_{10}$-PPV:Alq3. Uma explicação razoável para o aumento da eficiência dos dispositivos fabricados a partir dos 
compósitos está relacionada a um surgimento de um novo canal de transporte de cargas formado pela agregação do material "convidado"[15].

O compósito pode ainda induzir a formação de um segundo tipo de heterojunção provocada pela redução dos níveis HOMO e LUMO do Alq3, que pode retardar a formação do éxciton. Isto se dá porque, como já foi dito, a mobilidade de lacunas em polímeros conjugados é maior que a mobilidade de elétrons e este fato pode ser responsável pela passagem de cargas positivas pelo polímero emissivo sem que haja qualquer interação com as cargas negativas. Como se sabe, o material Alq3 é um transportador de elétrons, mas também pode ser usado como bloqueador de lacunas. Sendo assim, o compósito pode facilitar a chegada de elétrons e ainda ajudar a bloquear lacunas, contribuindo para o balanço de cargas, para o aumento do número de recombinações e, conseqüentemente, para o aumento da emissão luminosa.

O tempo de vida do dispositivo deve ser estendido tanto quanto possível. Durante o processo de fabricação dos dispositivos, fatores como fotoxidação e umidade podem comprometer o desempenho final do PLED. Sendo assim, algumas variáveis inerentes ao processo de fabricação foram avaliadas e um encapsulamento foi adicionado a todos os dispositivos confeccionados. A quebra da conjugação (perda da ligação dupla entre os átomos de carbono da cadeia principal) leva à perda das características elétricas do polímero e pode ser causada pela incidência de radiação no espectro visível e pela presença de oxigênio ${ }^{[32,33]}$.

\subsection{Injeção e Transporte de Portadores}

A injeção e o transporte de portadores no interior de uma cadeia polimérica são assuntos constantemente discutidos e recorrentes na literatura, mas ainda não foi possível elaborar um modelo absolutamente confiável para explicar o comportamento dos portadores de carga nestes materiais. Isso se dá por conta da estrutura desordenada, característica dos polímeros, que limita drasticamente a mobilidade dos portadores por conta da existência de defeitos estruturais e conformacionais ${ }^{[20]}$. Na maior parte dos casos o que se tem é uma aproximação dos modelos de injeção e transporte de portadores em materiais inorgânicos para tentar explicar o que ocorre em um material polimérico. 
O primeiro ponto que deve ser considerado neste estudo é o efeito das interfaces entre os diferentes filmes que formam um dispositivo ${ }^{[34],[35]}$. As barreiras de potencial existentes nas interfaces ânodo/polímero/cátodo são responsáveis pela densidade de portadores no polímero ativo. Apesar de haver na literatura referência à existência de um contato ôhmico entre o eletrodo transparente e o polímero emissivo MEH-PPV ${ }^{[36]}$, tanto os buracos injetados pelo ânodo como os elétrons injetados pelo cátodo devem ultrapassar uma barreira de potencial para poderem atingir o polímero emissivo. Desta forma, a compreensão dos fenômenos envolvidos na injeção e transporte destes portadores através destas barreiras de potencial e mesmo no interior da camada polimérica emissiva, respectivamente, torna-se fundamental para permitir a proposição de uma estrutura que vise uma melhoria no desempenho dos dispositivos.

Entre os modelos propostos para tentar explicar o mecanismo de injeção e transporte, os três mais citados e que melhor explicam o comportamento elétrico dos portadores são: SCLC - corrente limitada por carga espacial, injeção termiônica de RS (Richardson-Schottky) e tunelamento de FN (Fowler-Nordhein) ${ }^{[37],[38],[39]}$.

No modelo de injeção termiônica (RS), os parâmetros considerados são a temperatura, o campo elétrico aplicado e a carga imagem originada pelo portador ao deixar o eletrodo. O campo elétrico é responsável pelo entortamento da barreira de potencial $^{40}$. Quanto maior o campo, maior o entortamento e maior a probabilidade de ocorrência de tunelamento do portador através da barreira de potencial da junção. A carga imagem pode ser entendida como aquela originada quando o elétron migra do eletrodo para o polímero, após ultrapassar a interface, deixando neste eletrodo uma carga de sinal oposto a ele. Esta carga exerce uma força de atração coulombiana que dificulta o deslocamento do portador para o interior da camada polimérica.

Equação 2.2.1

$$
J=J_{0} \exp (q V / n k T)\{1-\exp (-q V / k T)\}
$$

Equação 2.2.2

$$
J_{0}=A^{*} T^{2} \exp \left[-q \phi_{\mathrm{e}} / k T\right]
$$

Equação 2.2.3

$$
A^{*}=m^{*} q k^{2} / 8 \pi^{2} \hbar^{3}
$$


Equação 2.2.4

$$
n=\left[1-\left(\partial \phi_{e} / \partial V\right)\right]^{-1}(4)
$$

Sendo que:

$\Phi e=$ Altura efetiva da barreira.

A Equação 2.2.1, a Equação 2.2.2, a Equação 2.2.3 e a Equação 2.2.4 representam a corrente de um determinado portador, segundo a injeção termiônica. Pode-se notar a forte dependência da injeção de portadores com a temperatura.

Na Figura 2.1.1.1 é ilustrado o modelo de injeção termiônica, onde a curva vermelha representa uma resultante da somatória dos efeitos do campo elétrico e da carga imagem ao longo da espessura do polímero. A curva ilustra o caminho e o tamanho do salto que o portador necessita para ser injetado no interior do polímero.

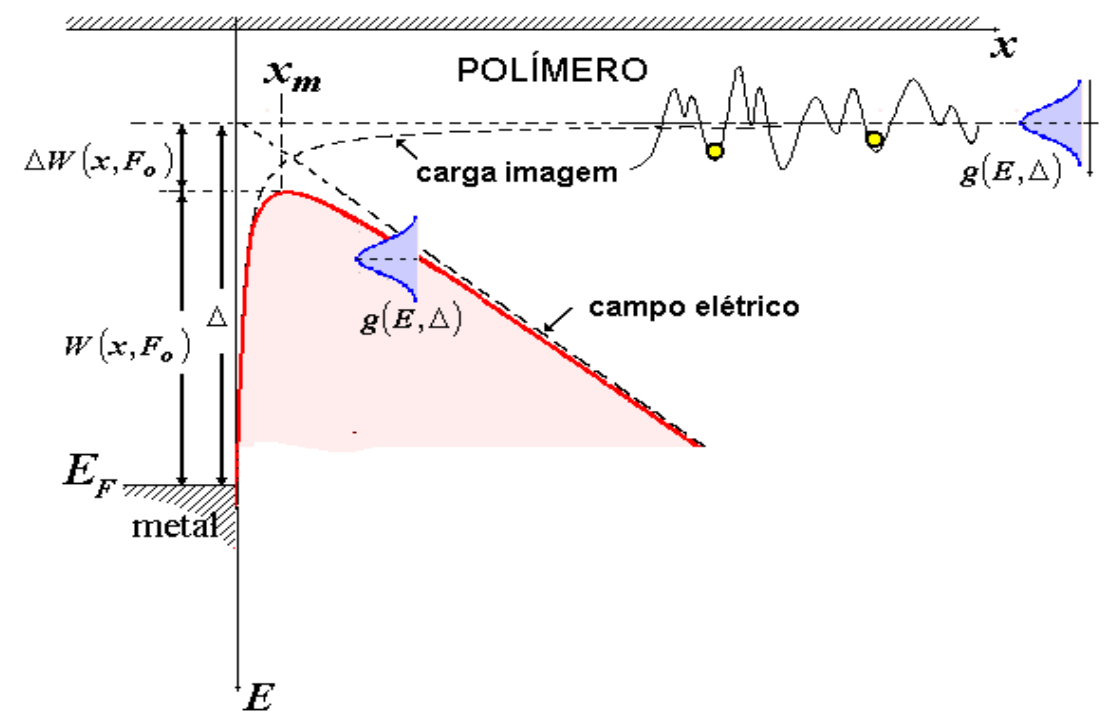

Figura 2.1.1.1 Representação esquemática da estrutura de bandas de uma junção metal/polímero para o modelo de injeção termiônica.

Sendo que:

$\mathrm{E}=$ Energia

$\Delta=$ Energia que o portador necessita para poder ser injetado dentro do polímero, desconsiderando o campo e a carga imagem. 
$\mathrm{x}=$ distância que representa o tamanho do salto do portador.

$\Delta \mathrm{W}=$ Diferença de energia levando em consideração os parâmetros envolvidos na condução termiônica.

$\mathrm{g}(\mathrm{E}, \Delta)=$ Distribuição das diferentes funções trabalho encontradas no polímero.

A injeção termiônica se mostra mais coerente na justificativa de certos fenômenos como a variação da injeção de cargas nos filmes poliméricos em função da temperatura ${ }^{[41]}$. Outros modelos, como o tunelamento, não levam em conta ou negligenciam a presença da variação de fenômenos como este ${ }^{[39], \text { [42] }}$.

É válido dizer que o polímero, diferente de um sólido cristalino, tem uma estrutura desordenada que implica na presença de diferentes valores de gap para um mesmo material. Sendo assim, o valor da energia de gap do polímero é uma aproximação ao redor de um valor médio. A distribuição dos valores de gap está esquematizada na Figura 2.1.1.1 pela distribuição $\mathrm{g}(\mathrm{E}, \Delta)$.

Segundo o modelo termiônico, o valor Xm corresponde à distância mínima que deve ser vencida pelo portador no interior do polímero, a partir da interface eletrodo/polímero. Se a energia fornecida ao portador não for suficiente para que ele possa ultrapassar Xm, o mesmo retorna para o eletrodo através da atração exercida pela carga imagem.

Através da análise do comportamento de injeção de carga, segundo o modelo termiônico, fica claro que uma barreira de potencial $\Delta$ sofrerá, muito provavelmente, uma redução se se considerar fatores como a temperatura, campo elétrico e efeito da carga imagem.

Embora haja diferentes relatos na literatura que levem em conta a estrutura desordenada dos polímeros e sua implicação no tipo de injeção e condução de portadores [43],[44], muitos estudos precisam ser realizados para que se possa equacionar com maior precisão o fenômeno da condução polimérica.

O modelo denominado Tunelamento (FN) propõe que a carga tenha energia suficiente para tunelar a barreira de potencial e não saltar sobre ela. Este modelo prevê que a corrente é independente da temperatura e dependente do campo elétrico aplicado. A aplicação de campos elevados contribui para o tunelamento de cargas 
pois o portador "enxerga" no salto da barreira um caminho muito maior que aquele "visto" pelo tunelamento, ou seja, o portador prefere "atravessar" a barreira a saltar sobre ela.

A equação 5 representa a corrente de portadores no modelo de tunelamento FN, através de barreira triangular.

$$
\begin{gathered}
\text { Equação 2.2.5 } \\
J=\sigma_{0} F^{2} \exp \left[-\frac{4 \sqrt{2 m^{*}}\left(q \phi_{e}\right)^{3 / 2}}{3 q \hbar F}\right]
\end{gathered}
$$

$$
\begin{gathered}
\text { Equação 2.2.6 } \\
\sigma_{0}=q^{3} / 16 \pi^{2} \hbar\left(q \phi_{\mathrm{e}}\right)
\end{gathered}
$$

Sendo que:

$\mathrm{F}=$ Campo Elétrico

$\mathrm{m}^{*}=$ Massa Efetiva do Elétron

$\phi_{\mathrm{e}}=$ Altura da Barreira Energética

$\sigma_{0}=$ Mobilidade

$\mathrm{h}=$ Constante de Planck

Através da Equação 2.2.5 e da Equação 2.2.6, pode-se notar que o tunelamento FN ignora a presença de temperatura na injeção de cargas.

O tunelamento se aplica, por exemplo, a semicondutores inorgânicos muito dopados. A alta dopagem faz com que o semicondutor seja degenerado, tornando a largura da região de depleção muito pequena; este processo facilitaria o tunelamento do portador através da barreira de potencial. Poderíamos aplicar este conceito aos semicondutores orgânicos; contudo, é necessário levar em conta a diferença estrutural entre os dois tipos de semicondutores citados e a inviabilidade da alta dopagem para polímeros semicondutores utilizados na confecção de dispositivos PLEDs.

Pode-se, ainda através da Figura 2.1.1.1, observar que o tunelamento pode acontecer quando campos elétricos muito elevados são aplicados. Em casos como este, a reta referente ao campo elétrico se desloca para a esquerda, se aproximando do eixo E. Uma 
vez que o portador sempre tenta encontrar o caminho mais fácil de chegar ao interior do polímero, tunelar significa facilitar a trajetória do portador.

Quando se trata de transporte de cargas no interior do material polimérico, deve-se citar o modelo SCLC (Space Charge Limit Current) o qual estabelece que o transporte de cargas dentro do polímero é capaz de limitar a corrente ${ }^{[45]}$. Supondo que um semicondutor de espessura w esteja em contato com um eletrodo que, por virtude da sua pequena barreira de potencial, seja capaz de fornecer um número ilimitado de cargas de um tipo. A corrente, neste caso, é limitada pela carga espacial do próprio polímero que, em um caso extremo, reduz o campo elétrico do contato injetor a zero. A densidade de cargas espaciais no polímero semicondutor decresce com o aumento da distancia do contato injetor $^{[46]}$. Através da equação de Poison e da continuidade, obtém-se a Equação 2.2.7 para o modelo SCLC, livre de armadilhas.

$$
\begin{array}{r}
\text { Equação 2.2.7 } \\
J=\frac{9 \varepsilon \mu V^{2}}{8 w^{3}}
\end{array}
$$

Onde

$\varepsilon=$ Permissividade do polímero

$\mu=$ Mobilidade do portador de carga

$\mathrm{V}=$ Potencial aplicado.

$\mathrm{w}=$ Espessura do filme.

A interferência da SCLC deve ser relativamente fraca, tendo em vista que a velocidade dos portadores injetados $\left(5,4 * 10^{6} \mathrm{~cm} / \mathrm{s}\right)$ é muito superior a velocidade das cargas no interior do polímero $(100 \mathrm{~cm} / \mathrm{s})$. Desta maneira, dificilmente o modelo SCLC será, de fato, algum mecanismo de limitação de grande relevância ${ }^{[47]}$.

\subsection{Eficiência Luminosa do Dispositivo}

São encontradas na literatura, quando se trata de dispositivos orgânicos emissores de luz, muitas diferenças e até contradições com relação às medidas de eficiência. É 
consenso, entretanto, que as quantidades fotométricas são usadas para descrever as propriedades de dispositivos, dando-se uma principal atenção para a Luminância e para Eficiência Luminosa ${ }^{[48],[49],[50] \text { e [51]. }}$

Para que os parâmetros relacionados à eficiência do dispositivo sejam calculados e analisados, uma emissão Lambertiana ${ }^{[48]}$ ideal é considerada. Nesta situação, a emissão é isotrópica, emitindo igualmente a radiação em qualquer ângulo sólido no interior do hemisfério visível. É necessário lembrar, entretanto, que um PLED convencional é composto por camadas orgânicas e inorgânicas e que cada uma delas possui um índice de refração diferente. Esta estrutura "empilhada" introduz interferências que modificam e diferenciam a emissão quando comparada a emissão lambertiana.

Desta maneira, é preciso ressaltar que os métodos de cálculos de eficiência utilizados neste trabalho implicam numa aproximação entre os valores calculados e os reais.

Neste trabalho, valores de eficiência luminosa e potência luminosa são calculados a partir de medidas de luminância. Um radiômetro foi utilizado para medir valores de luminância do dispositivo. Desta maneira, são obtidos dados que são analisados graficamente através de curvas L x J. É necessário que se escolha um valor de luminância de uma região com comportamento linear para que os cálculos sejam realizados. O cálculo da eficiência luminosa é feito a partir da Equação 2.3.1.

\section{Equação 2.3.1}

$$
\eta_{\mathbf{L}}=\mathbf{L} / \mathbf{J}
$$

Sendo que:

$\eta_{L}$ - Eficiência Luminosa

L - Luminância

J - Densidade de Corrente

A partir da eficiência luminosa pode-se chegar ao valor da eficiência de potência luminosa através da expressão:

Equação 2.3.2

$\eta_{\mathbf{P}}=\eta_{\mathrm{L}} / \mathrm{U}$ 
Sendo que:

$\eta_{\mathrm{P}}$ - Eficiência de Potência Luminosa

U - Tensão Aplicada

Valores de eficiência luminosa são utilizados em cálculos de eficiência quântica externa $\left(\eta_{\mathrm{EXT}}\right)$. Este parâmetro pode ser definido como a relação entre o número de fótons emitidos pelo dispositivo em direção a visualização e o número de elétrons injetados. A Equação 2.2.2 pode ser utilizada para calcular a $\eta_{\text {EXT. }}$ 


\section{Procedimento Experimental}

Neste capítulo são descritos todos os procedimentos e amostras preparadas neste trabalho, incluindo as etapas de confecção de um PLED e as técnicas de caracterização dos diferentes dispositivos fabricados.

\subsection{Materiais Utilizados}

Neste item são descritos os materiais empregados na confecção dos PLEDs desenvolvidos no trabalho.

\subsubsection{PEDOT:PSS}

O complexo polieletrolítico polimérico poli(3,4-etilenodioxitiofeno): poli(estireno ácido sulfonico) (PEDOT:PSS) foi adquirido comercialmente pela Baytron, já na forma líquida. O solvente utilizado pelo fabricante é água e a proporção da suspensão indicada é de 1:6 (massa : massa). O valor da resistividade fornecida é de $500-5000 \Omega \mathrm{m}$ e o tamanho da partícula da suspensão varia entre 80 e $100 \mathrm{~nm}$.

Este complexo é utilizado na fabricação de PLEDs por possuir uma função trabalho, segundo a literatura, de 5,2 $\mathrm{eV}^{[12]}$, podendo funcionar como uma camada transportadora de lacunas. A introdução desta HTL aumenta a eficiência e estabilidade do dispositivo, vez que aumenta o número de portadores na camada ativa. ${ }^{[12]}$ A Figura 3.1.1.1 representa a estrutura química do complexo PEDOT:PSS
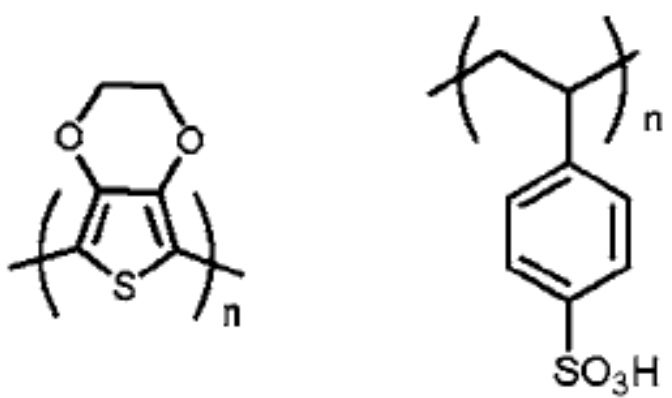

Figura 3.1.1.1 Estrutura química do PEDOT e do PSS, respectivamente 


\subsection{2 $\mathrm{OC}_{1} \mathrm{C}_{10}-\mathrm{PPV}$}

O segundo polímero a ser utilizado neste estudo, desta vez como camada ativa polimérica, é o Poli[2-metóxi-5-(3,7-dimetil-octiloxi)-1,4-fenilenovinileno], ou $\mathrm{OC}_{1} \mathrm{C}_{10}$

- PPV. Este material exibe propriedades excelentes em relação à eficiência luminosa ${ }^{[52]}$ é solúvel em tolueno, clorofórmio e clorobenzeno e também tem emissão próxima da cor alaranjada. A estrutura química deste polímero está representada na Figura 3.1.2.1. A literatura relata energias de HOMO e LUMO do polímero $\mathrm{OC}_{1} \mathrm{C}_{10}-\mathrm{PPV}$ de $5.1 \mathrm{eV}$ enquanto e $2.7 \mathrm{eV}$, respectivamente ${ }^{[53]}$.

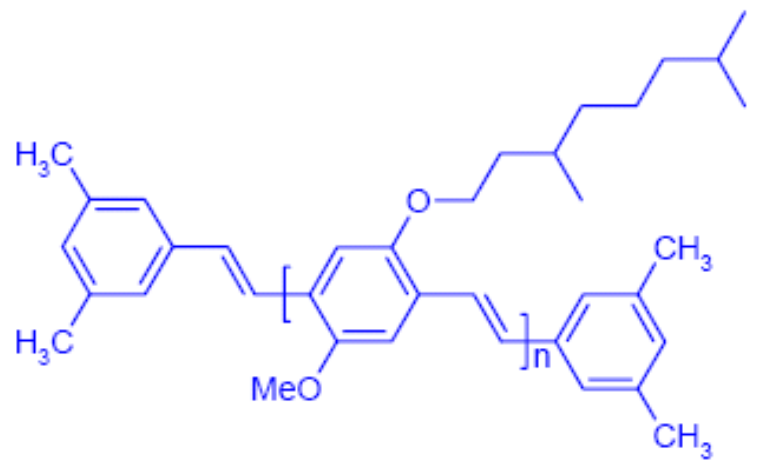

Figura 3.1.2.1 - Estrutura química do polímero OC1C10 - PPV

\subsubsection{Alq3}

O composto tris-(8-hydroxyquinolate)-aluminum, Alq3, é neste trabalho utilizado como transportador de elétrons e como "convidado" na camada ativa. Filmes de Alq3 podem também ser utilizados como único material na camada ativa de um dispositivo OLED (Organic Light Emitting Diode), uma vez que é também um material eletroluminescente. Através da aplicação de um potencial, pode-se obter a emissão de luz visível, com tom amarelado, em $520 \mathrm{~nm}^{[54]}$.

Este material é também solúvel em clorofórmio e poderia ser preparado da mesma maneira que os polímeros emissivos para que pudesse ser depositado sobre a camada ativa como ETL. Entretanto, a presença de um solvente comum aos polímeros eletroluminescentes acarretaria na destruição do filme emissivo previamente depositado. Deste modo, o injetor de elétrons Alq3 deve ser depositado de maneira que não 
necessite sua diluição em clorofórmio (por evaporação térmica, por exemplo) ou através da adição de outro solvente que não tenha afinidade com os polímeros emissivos. Sua energia de HOMO e LUMO, respectivamente segundo a literatura, é de 5,95 eV e 3,25 $\mathrm{eV}^{[55],[56]}$ e sua estrutura química é representada pela figura 3.1.3.1 abaixo.

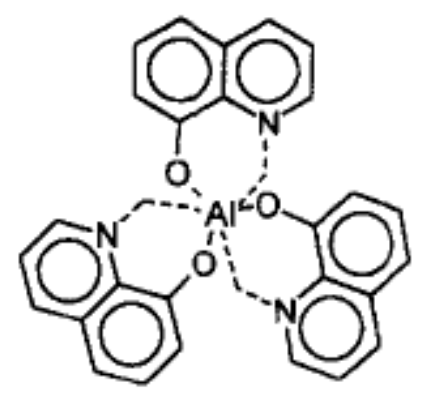

Figura 3.1.3.1 - Estrutura química do Alq3

\subsubsection{Eletrodos}

Como já foi dito anteriormente, a escolha dos eletrodos está diretamente relacionada ao desempenho do dispositivo, já que são eles os responsáveis pela injeção de cargas no interior da camada ativa polimérica. Sendo assim, a função trabalho dos eletrodos tem que estar muito bem adequada à do polímero utilizado.

Dispositivos fabricados com o polímero eletroluminescente MEH-PPV e com diferentes catodos são citados na bibliografia através de uma análise comparativa. A escolha do Alumínio como catodo é tida como um tanto problemática por conta da diferença de sua função trabalho comparada a do MEH-PPV (4,06eV do Al para 2,8 eV do MEH-PPV). Utilizando o Cálcio, cuja função trabalho é de 2,7 eV pode-se obter uma eficiência quântica do dispositivo de $1 \%$ ( 0,01 fóton por elétron injetado) enquanto que para o Alumínio este número seria algo como $0,01 \%(0,0001$ fóton por elétron injetado $)^{[57]}$. Entretanto, apesar das grandes vantagens relatadas nos estudos sobre o uso do Cálcio como catodo, optou-se pelo Alumínio neste trabalho, uma vez que o Cálcio é altamente instável (oxidável) e contaminante. Nesta linha, a utilização das camadas intermediárias injetoras de elétrons é de uso mais conveniente, na medida em que deve reduzir a barreira de potencial e facilitar a injeção de cargas negativas, sem apresentar as desvantagens provocadas pelo Cálcio. 


\section{2 - Fabricação de PLEDs}

Embora já tenha sido mencionado que a simplicidade de produção de um dispositivo polimérico se tornou um dos principais atrativos para seu estudo e desenvolvimento tecnológico, é necessário salientar que muitos processos de microeletrônica são envolvidos na confecção do PLED. Neste tópico serão listados todos os processos utilizados desde o primeiro lote até o último.

\subsubsection{Limpeza do Substrato}

A existência de quaisquer partículas e/ou presença de gordura no substrato de vidro, adquirido já com uma película fina de ITO depositada, interfere diretamente nos resultados e no desempenho do dispositivo. Por isto, estes substratos devem passar por um rigoroso processo de limpeza, haja vista que também a aderência dos filmes ao substrato é afetada diretamente pela condição desta superfície.

A limpeza convencional consiste basicamente na imersão em cada uma das três soluções citadas abaixo, mantendo a temperatura do banho em $80^{\circ} \mathrm{C}$ por 20 minutos:

- Tricloroetileno (TCE);

- Acetona;

- Álcool isopropílico.

Depois de realizados os 3 banhos, as amostras são secas e encaminhadas para o processo de decapagem do ITO.

\subsubsection{Definição da geometria do eletrodo ITO}

Para construir o dispositivo eletroluminescente polimérico - PLED - é necessário demarcar regiões da lâmina que terão parte do eletrodo transparente (ITO) removido para delimitar a região ativa do dispositivo. A definição da geometria é obtida pelo processo de fotolitografia.

Para realizar a decapagem do ITO, utiliza-se uma haste com algodão umedecida em uma solução de $\mathrm{HCl}$ mais pó de zinco para, em seguida, espalhar a mistura sobre a 
região a ser decapada. Uma reação entre o ácido clorídrico e o pó de zinco ocorre, resultando em cloreto de zinco. O cloreto de zinco é corrosivo para o ITO, formando sais de estanho que são solúveis em água ${ }^{[58]}$. Após a decapagem do ITO ser realizada, as amostras são imersas em um recipiente com água para remover o excesso de cloreto de zinco e dos sais de estanho e uma nova limpeza é realizada. A Figura 3.2.2.1 ilustra a geometria do ITO obtida através deste processo.

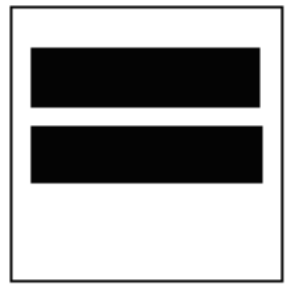

Figura 3.2.2.1 - Geometria do filme de ITO sobre substrato de vidro.

Após uma série de experimentos, foi desenvolvida outra geometria para o catodo, conforme ilustrado na Figura 3.2.2.2. Esta geometria foi utilizada na maioria dos lotes para evitar acionamento cruzado dos dispositivos durante a polarização, fato verificado nos lotes iniciais.

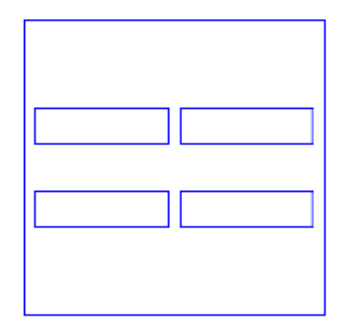

Figura 3.2.2.2 - Geometria final do ITO

O processo de decapagem do ITO para obter o novo desenho foi realizado com a utilização de fita adesiva na definição da geometria. Este procedimento foi adotado em função da premência na obtenção de novas estruturas e da dificuldade em preparação de novas fotomáscaras.

\subsubsection{Tratamento do Substrato}


Após a definição do eletrodo e a realização da limpeza, é realizado o tratamento da superfície do ITO objetivando melhorar o desempenho dos dispositivos ${ }^{59}$. Estes tratamentos podem ser úmidos ou secos, como Água-Régia [ref] e Plasma de Oxigênio [ref].

Neste trabalho optou-se pelo tratamento de plasma de oxigênio com duração de 10 minutos. Foi utilizado um reator do tipo RIE (Reactive Ion Etch), de fabricação $\mathrm{x}$ modelo Y, disponível no LME. Os parâmetros para esse tratamento são:

- Pressão de 100 mtorr;

- Tempo de Processo dependente de cada lote de amostras;

- Vazão do gás de 50 sccm;

- Potência de RF de 100 Watts;

- Temperatura da câmara de $20^{\circ} \mathrm{C}$.

\subsubsection{Soluções}

Para preparar a solução polimérica foi utilizado o polímero $\mathrm{OC}_{1} \mathrm{C}_{10}-\mathrm{PPV}$, adquirido da Merck. O material Alq3 foi adquirido pela Baytron.

\subsubsection{Solução de $\mathrm{OC}_{1} \mathrm{C}_{10}-\mathrm{PPV}$}

O polímero utilizado como camada emissiva foi adquirido na forma de pó e segue um esquema único na preparação da solução:

- O primeiro passo consiste basicamente na limpeza realizada nos materiais envolvidos no processo.

- O polímero utilizado na preparação da solução é separado do frasco inicial, em ambiente inerte, para que o restante do pó que não será utilizado conserve suas características originais.

- Em seguida, pesa-se o polímero em questão para que seja possível realizar uma relação entre o valor medido e a quantidade de solvente. A cápsula 
agitadora já deve estar localizada no interior do frasco no qual se localiza o polímero.

- Diluição do polímero no solvente clorofórmio na concentração desejada.

- O frasco é levado então ao agitador e lá permanece por aproximadamente 4 horas sem que a temperatura da solução seja alterada.

É válido lembrar que durante todo o processo de preparo da solução, o recipiente deve ser constantemente protegido e coberto com um papel alumínio a fim de evitar qualquer contato com a luz. Após o termino deste processo, a solução, caso não seja usada, deve ser armazenada em um refrigerador.

\subsubsection{Solução de $\mathrm{OC}_{1} \mathrm{C}_{10}-\mathrm{PPV}$ :Alq3}

As soluções do compósito $\mathrm{OC}_{1} \mathrm{C}_{10}-\mathrm{PPV}$ :Alq3 foram feitas através do mesmo procedimento utilizado na preparação da solução de $\mathrm{OC}_{1} \mathrm{C}_{10}-\mathrm{PPV}$, mantendo a concentração de 7mg/ml. A concentração de Alq3 em relação a $\mathrm{OC}_{1} \mathrm{C}_{10}-\mathrm{PPV}$ é calculada em peso. Sendo assim, os valores necessários em massa do polímero $\mathrm{OC}_{1} \mathrm{C}_{10}$ - PPV e do Alq3 são calculados para que o compósito seja fabricado em proporções desejadas. Foram preparadas soluções com 4\%, $8 \%, 10 \%, 13 \%, 18 \%$ e $23 \%$ de Alq3.

\subsubsection{Deposição das Soluções}

A deposição do polímero eletroluminescente $\mathrm{OC}_{1} \mathrm{C}_{10^{-}} \mathrm{PPV}$, do compósito $\mathrm{OC}_{1} \mathrm{C}_{10^{-}}$ PPV:Alq3 e do polímero condutor PEDOT:PSS consiste na técnica spin coating enquanto que a deposição da ETL se deu pela evaporação térmica.

\subsubsection{Filtragem da Solução}

A solução do polímero eletroluminescente deve ser filtrada antes que venha a ser depositada. Este cuidado tem como finalidade diminuir a rugosidade do filme polimérico, já que elimina partículas que não foram diluídas durante a agitação da solução. Foram utilizados filtros de $1 \mu \mathrm{m}$, encaixados na ponta da seringa utilizada. A 
solução é posta pela traseira da seringa e toda a solução filtrada a ser depositada é dirigida para um novo frasco limpo.

\subsubsection{Spin Coating}

$\mathrm{O}$ método utilizado para deposição de filmes finos de $\mathrm{OC}_{1} \mathrm{C}_{10} \mathrm{PPV}, \mathrm{OC}_{1} \mathrm{C}_{10}-$ PPV:Alq3 e de PEDOT:PSS é chamado de Spin Coating, o qual realiza o espalhamento da solução polimérica sobre um substrato. $\mathrm{O}$ equipamento utilizado para realizar esta deposição consiste em um motor de passo que faz com que um aparato de metal acoplado a ponta do eixo rotacione e fixe o substrato através de uma bomba de vácuo, possibilitando a deposição por espalhamento rotacional.

Primeiramente liga-se o Spinner e ajustam-se os valores desejados referentes a velocidade de rotação e o tempo em que a amostra permanecerá em movimento. Em seguida o substrato é colocado sobre o aparato e a bomba a vácuo é ligada para que este se encontre preso. Com o auxílio de uma pipeta, a solução polimérica é gotejada sobre o substrato, o Spinner é ligado e o excesso de solução é expelido formando filmes finos da ordem de nanômetros. A variação dos parâmetros do equipamento (velocidade e tempo de rotação) tem influência direta na espessura e na uniformidade do filme produzido. É possível também ajustar a aceleração e a desaceleração do Spinner, apesar de serem fatores que pouco ou nada influenciam nas características finais do filme ${ }^{[60]}$.

Para confecção dos dispositivos, quando se utiliza a presença de HTL, a solução de PEDOT:PSS é depositada sobre vidro com uma rotação de $3000 \mathrm{rpm}$ durante 30 segundos e, em seguida, os substratos são direcionados a uma estufa, lá permanecendo por 30 minutos a $100^{\circ} \mathrm{C}$. Em seguida, ocorre a deposição de $\mathrm{OC}_{1} \mathrm{C}_{10}$-PPV ou de $\mathrm{OC}_{1} \mathrm{C}_{10}$ - PPV:Alq3 sobre o filme de PEDOT:PSS e as amostras são novamente acondicionadas em uma estufa durante $60 \mathrm{~min}$ a uma temperatura de aproximadamente $50^{\circ} \mathrm{C}$. O objetivo é o de promover a completa eliminação de qualquer resíduo de solventes químicos. $\mathrm{O}$ vácuo produzido pela estufa e o aumento da temperatura são capazes de eliminar grande parte do oxigênio adquirido pelo filme durante sua deposição, caso esta não seja realizada em ambiente inerte.

Os filmes foram depositados após o preparo da solução e o spinner foi ajustado de maneira que operasse com velocidade de rotação de $3000 \mathrm{rpm}$ durante 60 segundos. 
Estes parâmetros foram previamente estabelecidos por outros pesquisadores do grupo para que se pudesse obter filmes de aproximadamente $100 \mathrm{~nm}$ de espessura, valor este sugerido pela literatura ${ }^{[61]}$.

\subsubsection{Deposição da ETL}

Como já foi mencionado, o Alq3 em forma de solução utiliza o mesmo solvente dos polímeros emissivos utilizados neste trabalho. Isto dificulta o processo de fabricação de filmes por spin coating por conta da influência do clorofórmio no filme eletroluminescente previamente depositado. Desta forma, adotou-se o método de evaporação térmica para, mencionado pela literatura ${ }^{[62]}[63]$.

\subsubsection{Definição da Geometria da ETL e Eletrodo.}

Para que seja realizada a deposição da ETL e eletrodo metálico, é necessária a utilização de uma máscara mecânica a fim de delimitar a área a ser recoberta com o material transportador de elétrons e, em seguida, com alumínio. Dessa forma, foram utilizadas máscaras de cobre vazadas, conforme a figura 11, para deposição dos filmes de Alq3 e Al sobre as amostras que já possuíam a camada emissiva.

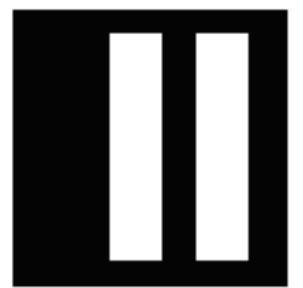

Figura 3.2.6.1 - Representação da máscara de cobre utilizada no processo de evaporação térmica.

Houve uma substituição da máscara mecânica na segunda etapa deste trabalho com a finalidade de aperfeiçoar a arquitetura do dispositivo. A Figura 3.2.6.2 abaixo ilustra a máscara utilizada e, consequentemente, mostra a região formada após a deposição seja da ETL, seja do alumínio. 


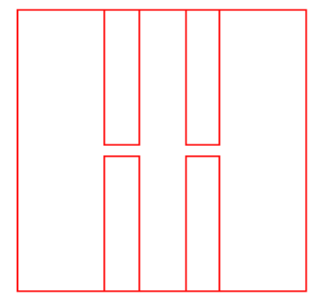

Figura 3.2.6.2 - Representação final da máscara de cobre utilizada no processo de evaporação térmica

No início dos testes realizados com o Alq3, ocorreu a troca do fornecedor do substrato com ITO. Neste momento, tornou-se necessário refazer um dispositivo mantendo a estrutura básica para que uma comparação coerente com os demais dispositivos fosse realizada. Desta maneira, iniciou-se tentativas de se produzir, durante um mesmo processo, dispositivos com e sem ETL para comprovar a veracidade dos resultados.

Em uma primeira tentativa em garantir resultados confiáveis, foram postas duas amostras com ITO/PEDOT:PSS/OC ${ }_{1} \mathrm{C}_{10}$-PPV na evaporadora e um filme fino de Alq3 foi evaporado utilizando a máscara ilustrada na Figura 3.2.6.3. Em seguida, o vácuo foi quebrado e a porta traseira da evaporadora foi aberta para receber outras duas amostras com a estrutura ITO/PEDOT:PSS/OC $\mathrm{C}_{10}$-PPV para que fosse realizada a deposição do filme de alumínio. Abrindo a porta traseira o ambiente permaneceria inerte e as novas amostras inseridas na evaporadora não conteriam filme de Alq3.

Após a evaporação dos filmes finos de Alq3 e Al, as amostras encapsuladas e retiradas da câmara. Observou-se que houve um deslocamento da máscara mecânica por conta da quebra de vácuo. Desta maneira, o filme de Alq3 foi depositado em uma região da amostra e o filme de Al, que deveria possuir exatamente a mesma área e estar posicionado apenas sobre a ETL, sofreu um deslocamento. A região em que houve um deslocamento do filmes de $\mathrm{Al}$ e permaneceu a estrutura ITO/PEDOT:PSS/OC $\mathrm{C}_{10^{-}}$ PPV/Al não apresentou eletroluminescência. Em contrapartida, a pequena região na qual se encontrava a estrutura ITO/PEDOT:PSS/OC $\mathrm{C}_{10}$-PPV/Alq3/Al apresentou eletroluminescência. Este foi o primeiro indício de que o filme de Alq3, de alguma forma, facilita a promoção de emissão luminosa.

Embora a quebra do vácuo para inserção de novas amostras na evaporadora tenha sido descartada, a idéia de fabricação de dois tipos de dispositivos durante um mesmo 
processo não pôde ser abandonada por ser esta a garantia de que todos os parâmetros se manteriam constantes na produção dos dois tipos de dispositivos. Sendo assim, fez-se necessária a utilização de uma segunda máscara mecânica a fim de proteger alguns dos dispositivos contidos na câmara de evaporação no momento em que o filme de Alq3 fosse evaporado. Esta máscara, representada na Figura 3.2.6.3 abaixo, se manteve presa ao "shutter" da evaporadora. Este feito viabilizou a locomoção da máscara pelo lado de fora da evaporadora, evitando a necessidade de quebra do vácuo para retirada da máscara. Após a deposição do filme de ETL, o "carrossel” no qual as amostras estavam localizadas era movimentado através de um comando no painel da evaporadora e a máscara deixava de proteger os dispositivos selecionados, deixando-os livres para receber o filme de Al depositado na seqüência. Desta maneira, foram obtidos em um único processo, dispositivos com e sem a presença de ETL.

A Figura 3.2.6.3 e a Figura 3.2.6.4 abaixo ilustram a evaporadora vista do lado de fora. Na primeira imagem tem-se uma situação em que são feitas amostras com um mesmo tipo de estrutura. A segunda imagem mostra uma situação em que são feitas amostras com diferentes estruturas, através da introdução da máscara mecânica capaz de impedir a deposição de Alq3 em parte dos dispositivos. 


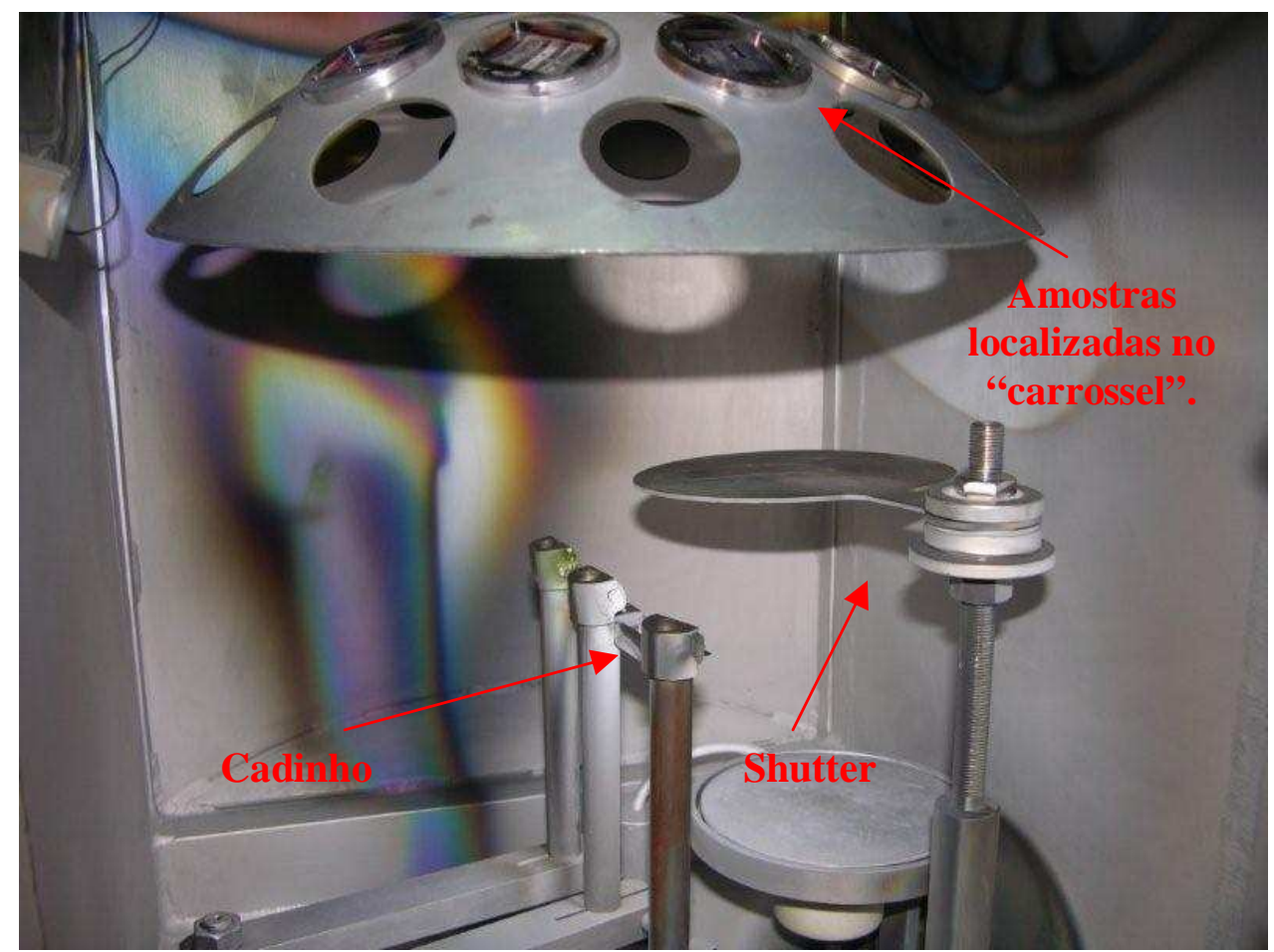

Figura 3.2.6.3 - Evaporadora em esquema montado para fabricação de um tipo de dispositivo por processo.

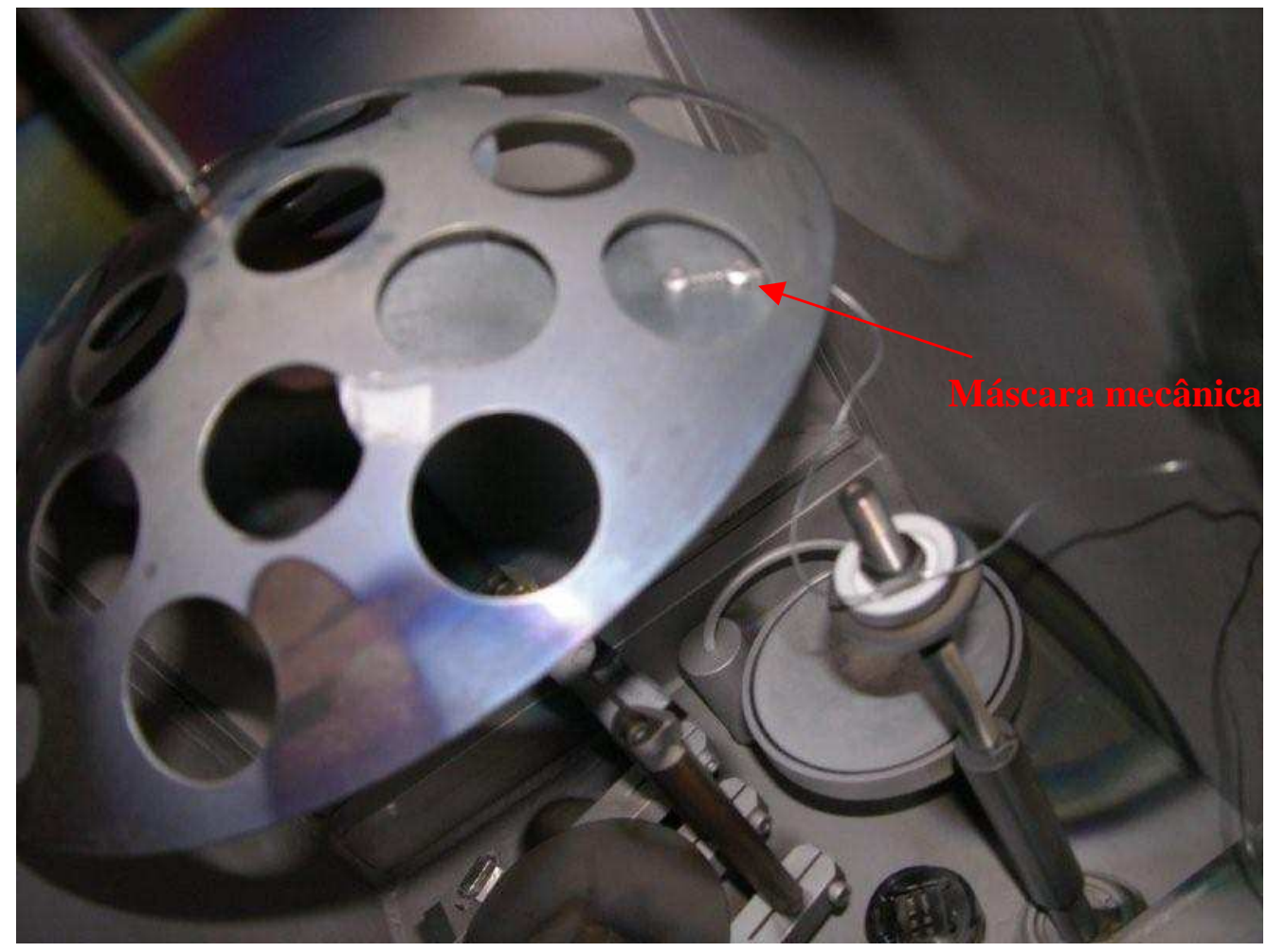

Figura 3.2.6.4 - Evaporadora em esquema montado para fabricação de dois tipos de dispositivos por processo. 
Para realizar a evaporação do Alq3 foi utilizado um cadinho específico de cerâmica. A indicação do uso de cadinho cerâmico para este tipo de aplicação partiu do Prof. Dr. Luiz Pereira, da Universidade de Aveiro. A taxa de evaporação foi mantida entre 0,2 e $0,6 \AA$ A $/$ s. Na deposição do filme de Al, utilizando um cadinho de tungstênio, a taxa de evaporação ficou entre 2 e $10 \AA$ /s a uma pressão de aproximadamente $4 * 10^{-5}$ mbar.

\subsubsection{Encapsulamento}

Para que não houvesse degradação polimérica por conta da presença de luz e oxigênio durante os testes de caracterização, os dispositivos foram submetidos a um processo de encapsulamento dentro da glove boxe após a metalização do Al.

Após a realização do vácuo, as amostras eram retiradas de dentro da evaporadora e passavam diretamente para o interior da eclusa central da câmara, sem passar pelo ambiente. $\mathrm{O}$ encapsulamento se deu pela adição de duas placas de vidro em torno do dispositivo, coladas com adesivo a base de epoxi, de forma que se formasse uma espécie de barreira contra o ar. Desta maneira, o dispositivo não se livra da incidência de luz, mas deixa de sofrer degradação do filme polimérico por conta da presença de oxigênio. O leiaute final dos dispositivos iniciais, já com os pixels definidos e com o encapsulamento é apresentado na figura na Figura 3.2.7.1.

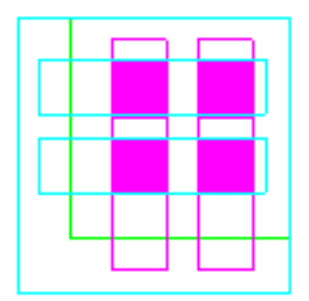

Figura 3.2.7.1 - Leiaute inicial do dispositivo

$\mathrm{Na}$ figura acima, os quadrados pintados de rosa representam os pontos que irão apresentar luminescência (pixels) e o quadrado verde representa a área protegida pelo encapsulamento. Os pixels apresentam, nesta arquitetura, área de $25 \mathrm{~mm}^{2}$.

O segundo leiaute dos dispositivos é representado pela Figura 3.2.7.2. 


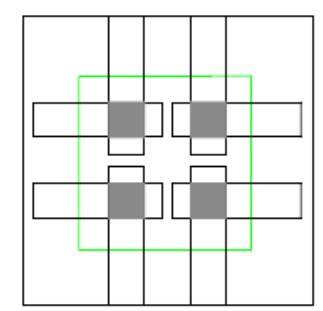

Figura 3.2.7.2 Leiaute com a arquitetura final do dispositivo

$\mathrm{Na}$ arquitetura representada pela Figura 3.2.7.2, os pixels possuem uma área de 9 mm2 e são representados pelas regiões pintadas de cinza e o encapsulamento foi realizado da mesma maneira, sendo apresentado na figura pelo quadrado verde na região central.

\subsection{Caracterização}

A caracterização dos filmes e dos dispositivos fabricados é responsável pela explicação dos fenômenos observados durante e depois dos processos de fabricação. São através destas caracterizações que são fundamentadas as conclusões referentes a cada resultado obtido. Neste capítulo serão enumeradas e detalhadas as técnicas de caracterização e o porquê de suas utilizações.

\subsubsection{Medidas de Intensidade Luminosa e Luminância}

As medidas de intensidade luminosa e de luminância estão diretamente relacionadas ao desempenho do dispositivo e são, portanto, fundamentais para o estudo da influência do Alq3. Um arranjo de equipamentos utilizado neste tipo de caracterização comporta um microcomputador para iniciar as medidas e para visualizar as curvas e medidas obtidas. Ao computador, são conectadas uma fonte de tensão utilizada na polarização do dispositivo e uma fibra óptica capaz de medir a intensidade luminosa e o comprimento de onda emitido. O radiômetro Minolta é ainda posicionado sobre o pixel a ser caracterizado para que a varredura da luminância seja obtida juntamente com os demais dados. Abaixo 'é ilustrada a disposição dos equipamentos mencionados, a exceção do microcomputador localizado a esquerda da Figura 3.3.1.1. 


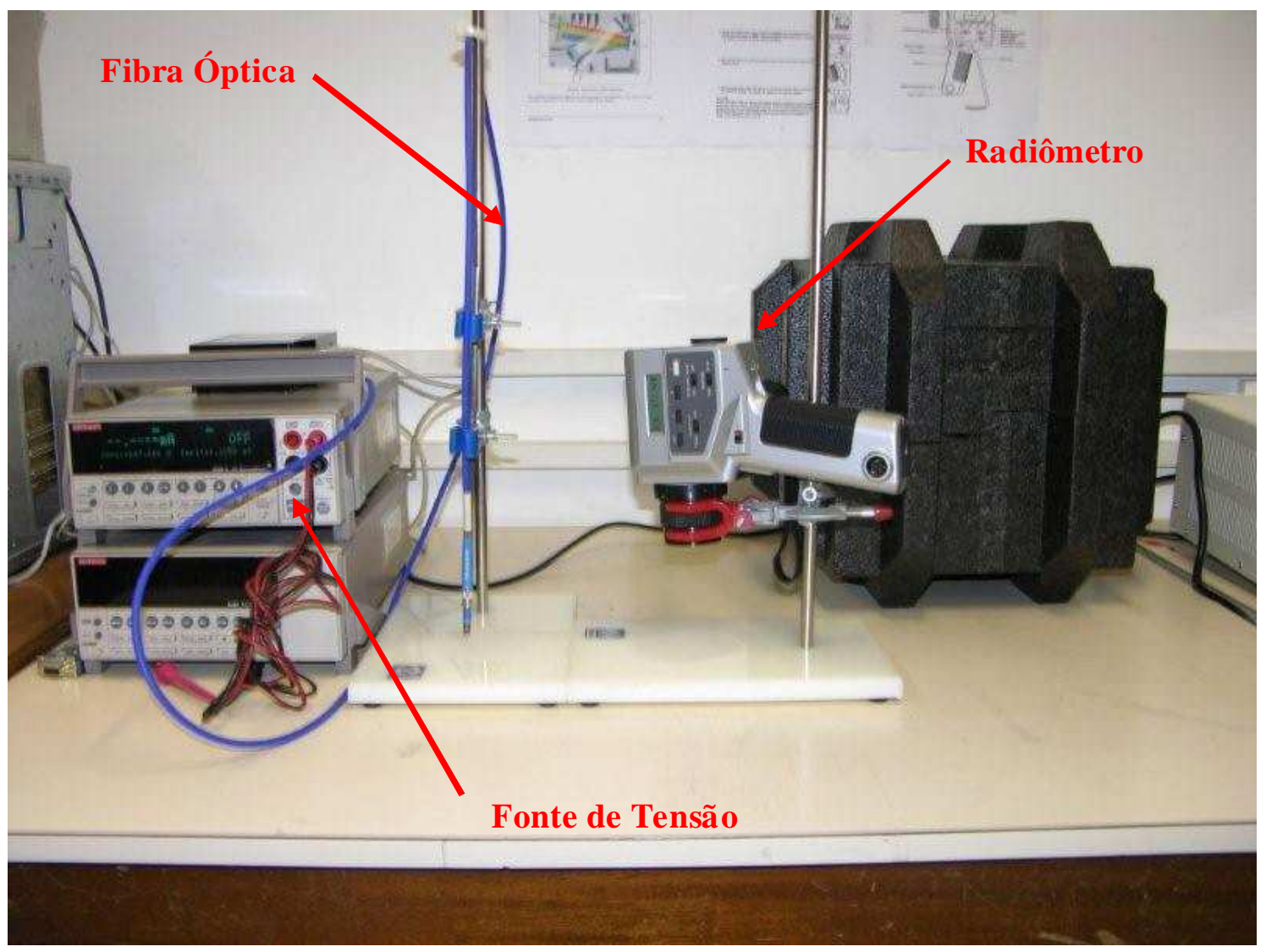

Figura 3.3.1.1 - Aparato utilizado para caracterização

A distância do radiômetro e do dispositivo é precisamente mantida para todos os casos e compatível com a lente utilizada. O equipamento é capaz de medir uma luminância de referência já existente e subtrair a mesma daquela emitida pelo dispositivo. A medida se inicia através do estabelecimento de determinados parâmetros ainda no programa instalado no microcomputador capaz de integrar as medidas IxV e luminância. Este programa, nomeado Eval, foi desenvolvido por integrantes do GEM e minimiza eventuais incompatibilidades nas medidas, já que possibilita a captura da curva IxV e a luminância do dispositivo em apenas uma varredura. Nas caracterizações realizadas antes do surgimento do Eval as diferentes medidas eram realizadas de maneira isolada. A degradação do dispositivo provocada pela polarização e pelo tempo existente entre as medidas comprometia a veracidade da relação entre as mesmas.

Como já foi mencionada, a caracterização destes dispositivos se inicia com a definição de determinados parâmetros como limitação de tensão e corrente de polarização, quantidade de pontos medidos durante a varredura, porta de comunicação 
escolhida e a pasta em que todos os dados serão armazenados no microcomputador e o nome que o arquivo receberá. Deve-se ter o cuidado de alterar o nome do arquivo para cada diferente medida, uma vez que o programa transfere todas as medidas para o arquivo escolhido, independente de já existirem outros dados armazenados com o mesmo nome. Após se iniciar as medidas da curva $\mathrm{IxV}$ e da luminância, nenhum parâmetro pode ser alterado e há um cuidado especial em se manter a luminância do ambiente constante de modo que não ocorram interferências externas nas medidas. Ao final da varredura, têm-se os dados necessários para que curvas IxV sejam traçadas e para que o cálculo da eficiência luminosa seja realizado.

O gráfico da intensidade luminosa versus comprimento de onda é obtido através da medição do espectro luminoso do dispositivo medido pelo Espectrofotômetro Ocean Optics, também acoplado ao microcomputador. A fibra óptica visualizada na Figura 3.3.1.1 é posicionada sobre o pixel polarizado e os dados do espectro da luz emitida pelo dispositivo podem ser armazenados em alguma pasta do microcomputador para que, em seguida, a curva seja traçada. A intensidade luminosa é dada em uma escala de corrente que será em seguida convertida através de uma tabela em unidades de intensidade luminosa u.a. O comprimento de onda é medido em $\mathrm{nm}$.

\subsubsection{Medidas de Espessura}

As medições de espessura estão diretamente relacionadas ao desempenho de um dispositivo. No caso de um filme emissivo muito espesso, há a necessidade de uma aplicação de campo elétrico muito maior que aquele aplicado em uma espessura reduzida. Tendo em vista que outros trabalhos já foram realizados no sentido de encontrar a melhor espessura, é necessário que haja um monitoramento dos valores para que se mantenha o padrão já adquirido. Em relação à camada de ETL, serão necessárias muitas medidas de espessura para realizar o estudo da melhor espessura, vez que ainda não obtivemos resultados neste sentido em nossas pesquisas.

O equipamento utilizado na medição da espessura é um Profilômetro da Alfa Step 500 da Tencor Instruments. Através da decapagem de parte do material (filme) que será medido surge um degrau existente entre a região depositada e a região decapada. Esta região é medida através de uma agulha que faz a varredura do material. Este desnível 
aparece na tela do equipamento e, através de uma aproximação dos valores, tem-se a espessura do filme.

Medidas de espessuras foram realizadas neste trabalho, através da técnica profilometria. Nestes testes, foram utilizadas amostras testes que não seriam utilizadas na fabricação de PLEDs. As medidas realizadas com estas amostras representam uma aproximação do valor real dos dispositivos, uma vez que os filmes foram depositados com os mesmos parâmetros de deposição e com a mesma solução.

\subsubsection{Registro Fotográfico de Dispositivos}

Os dispositivos são testados através de uma fonte KEITHLEY, modelo 2420-C3A. O terminal positivo é conectado ao ITO e o terminal negativo é conectado ao Al para que haja uma polarização direta. As fotos contidas neste texto de dissertação foram produzidas durante a polarização realizada através deste aparelho, de modo que fosse registrada a máxima luminância obtida e após todas as caracterizações realizadas.

\section{Preparação das amostras}

A Erro! Fonte de referência não encontrada. relaciona todas as estruturas de dispositivos analisados neste trabalho. No total, foram preparados 14 lotes de amostras que permitiram estudar a influência das camadas transportadoras de elétrons e lacunas no desempenho elétrico e de eficiência luminosa dos dispositivos. Também foi realizado um estudo preliminar para determinar as características das camadas envolvidas no presente estudo.

Tabela 3.3.1 - Relação de lote de amostras e estruturas fabricadas

\begin{tabular}{|c|c|}
\hline LOTE & ESTRUTURA \\
\hline LOTE 1 & ITO/OC1C10-PPV/Al \\
\hline
\end{tabular}




\begin{tabular}{|c|c|}
\hline & ITO/PEDOT:PSS/OC1C10-PPV/Al \\
\hline \multirow{3}{*}{ LOTE 2} & ITO/OC1C10-PPV/Al \\
\hline & ITO/PEDOT:PSS/OC1C10-PPV/Al \\
\hline & ITO/PEDOT:PSS/OC1C10-PPV/LiF/Al \\
\hline LOTE 3 & ITO/PEDOT:PSS/OC1C10-PPV/Al \\
\hline LOTE 4 & ITO/PEDOT:PSS/OC1C10-PPV/Al \\
\hline \multirow{2}{*}{ LOTE 5} & ITO/PEDOT:PSS/OC1C10-PPV/Al \\
\hline & $\begin{array}{c}\text { ITO/PEDOT:PSS/OC1C10- } \\
\text { PPV/Alq3(23nm)/Al }\end{array}$ \\
\hline \multirow{2}{*}{ LOTE 6} & ITO/PEDOT:PSS/OC1C10-PPV/Al \\
\hline & $\begin{array}{c}\text { ITO/PEDOT:PSS/OC1C10- } \\
\text { PPV/Alq3(8nm)/Al }\end{array}$ \\
\hline LOTE 7 & $\begin{array}{l}\text { ITO/PEDOT:PSS/OC1C10- } \\
\text { PPV/Alq3(6nm)/Al }\end{array}$ \\
\hline LOTE 8 & $\begin{array}{c}\text { ITO/PEDOT:PSS/OC1C10- } \\
\text { PPV/Alq3(3nm)/Al }\end{array}$ \\
\hline LOTE 9 & $\begin{array}{c}\text { ITO/PEDOT:PSS/OC1C10- } \\
\text { PPV/Alq3(1nm)/Al }\end{array}$ \\
\hline LOTE 10 & $\begin{array}{c}\text { ITO/PEDOT:PSS/OC1C10- } \\
\text { PPV:Alq3(4\%)/Alq3(1nm)/Al }\end{array}$ \\
\hline LOTE 11 & $\begin{array}{c}\text { ITO/PEDOT:PSS/OC1C10- } \\
\text { PPV:Alq3(8\%)/Alq3(1nm)/Al }\end{array}$ \\
\hline LOTE 12 & $\begin{array}{c}\text { ITO/PEDOT:PSS/OC1C10- } \\
\text { PPV:Alq3(10\%)/Alq3(1nm)/Al }\end{array}$ \\
\hline LOTE 13 & $\begin{array}{c}\text { ITO/PEDOT:PSS/OC1C10- } \\
\text { PPV:Alq3(13\%)/Alq3(1nm)/Al }\end{array}$ \\
\hline LOTE 14 & $\begin{array}{c}\text { ITO/PEDOT:PSS/OC1C10- } \\
\text { PPV:Alq3(16\%)/Alq3(1nm)/Al }\end{array}$ \\
\hline
\end{tabular}


Os quatro lotes iniciais foram importantes para caracterizar todo o processo de preparação dos dispositivos com o polímero $\mathrm{OC}_{1} \mathrm{C}_{10}-\mathrm{PPV}$, determinando a concentração da solução e os parâmetros de deposição do spinner (rotação e tempo).

Assim, no lote 1 foram preparados dispositivos com estruturas $\mathrm{ITO} / \mathrm{OC}_{1} \mathrm{C}_{10^{-}}$ PPV/Al (estrutura 1) e ITO/PEDOT:PSS/OC $\mathrm{C}_{10}$-PPV/Al (estrutura 2). Todas as etapas de fabricação foram realizadas no interior da Glove Box, inclusive a deposição do polímero eletroluminescente.

No lote 2, foram preparados dispositivos reproduzindo as estruturas desenvolvidas no lote 1 . Também foi o primeiro teste de adição de uma camada transportadora de elétrons, formada por um filme fino de LiF evaporado, segundo a estrutura ITO/PEDOT:PSS/OC ${ }_{1} \mathrm{C}_{10}-\mathrm{PPV} / \mathrm{LiF} / \mathrm{AL}$ (estrutura 3 ). Dada a desuniformidade de espessura apresentada nos filmes preparados no lote 1, neste lote os filmes poliméricos foram depositados com um outro equipamento spinner alocado fora do ambiente controlado da Glove Box. Esta medida foi tomada para verificar se as irregularidades eram devidas ao equipamento utilizado e seus parâmetros de deposição (tempo de aceleração e desaceleração da rotação do prato do spinner) e não em relação à Glove Box.

No lote 3, após um ajuste da programação do equipamento de deposição dos filmes (spinner) para buscar melhorar a uniformidade destes, as amostras foram produzidas totalmente no interior da Glove Box, com a estrutura 2, sem a adição de uma camada ETL. Apesar de todos estes esforços, as amostras produzidas com o spinner do interior da Glove Box continuaram a apresentar desuniformidade na espessura.

Em razão destes resultados, após um criterioso estudo das etapas de deposição e construção dos dispositivos, todos os lotes seguintes (a partir do lote 4, inclusive) tiveram a camada emissiva depositada com o equipamento spinner instalado fora do ambiente controlado.

As amostras do lote 4 foram preparadas de acordo com a estrutura 2, sem a camada ETL, e foram empregadas para uma caracterização elétrica e óptica mais completa, envolvendo desde medidas IxV até a caracterização da intensidade luminosa em função do comprimento de onda e medidas de luminância.

A partir do lote 5 foi utilizado um substrato de ITO de outra procedência e, por conta deste fator, foram fabricados dispositivos novamente com a primeira arquitetura 
para servir como base de referência das possíveis alterações no desempenho dos dispositivos.

Também a partir do lote 5 foi iniciado um estudo mais detalhado sobre a utilização da camada transportadora de elétrons e o desempenho dos dispositivos. O foco principal envolveu o efeito da espessura da ETL nas características elétricas e ópticas dos dispositivos. Como a deposição da ETL se deu por evaporação térmica, a determinação da sua espessura foi realizada durante a deposição, através do medidor de espessura do equipamento de evaporação, e também depois do filme já depositado, através de medidas de profilometria e de microscopia de força atômica - AFM. Para tanto, substratos de vidro foram utilizados para a deposição de filmes de Alq3 para comparar os valores de espessuras obtidas pelos diferentes equipamentos e verificar se o medidor da evaporadora estava calibrado.

Nos lotes 5 e 6 foram produzidas amostras, com e sem ELT com um valor fixo de espessura, numa mesma lâmina para permitir comparar diretamente seu efeito no desempenho dos dispositivos.

Nos lotes 7, 8 e 9 foram preparadas amostras com diferentes espessuras de ETL.

A partir da obtenção da amostra com melhor desempenho, fixou-se o valor da espessura da ETL, e partiu-se para uma nova série de amostras (lotes 10 a 14) buscando explorar o efeito do material utilizado na ETL (Alq3) para a formação de um novo compósito com o polímero eletroluminescente - $\mathrm{OC}_{1} \mathrm{C}_{10}$-PPV:Alq3. Neste estudo foram adicionadas diferentes concentrações de $\mathrm{Alq} 3$ na solução de $\mathrm{OC}_{1} \mathrm{C}_{10}-\mathrm{PPV}$.

\subsection{Análise dos lotes iniciais}

Os quatro primeiros lotes de dispositivos apresentaram resultados importantes para determinar os passos a serem seguidos.

Foram produzidos dispositivos com e sem a presença da HTL no lote 1 e no lote 2. Em ambos os casos, apenas os dispositivos com HTL apresentaram comportamento de diodo. A ausência desta camada parece provocar curto-circuito entre os eletrodos. Foi , ainda no lote 2 , adicionada a um grupo de dispositivos uma camada de LiF com a finalidade de aumentar a eficiência dos dispositivos. Entretanto, a presença do filme fino de LiF contribuiu negativamente para a eficiência e vida dos dispositivos. Como já 
foi citado neste trabalho, há relatos na literatura sobre a necessidade de se depositar filmes de $\mathrm{LiF}$ com espessuras inferiores a $6 \mathrm{~nm}$. Filmes mais espessos prejudicam o desempenho do dispositivo. Devido a impossibilidade de se depositar filmes com espessuras inferiores a $4 \mathrm{~nm}$ por evaporação térmica, a idéia de se produzir dispositivos utilizando LiF como ETL foi descartada.

Os lotes 3 e 4 foram desenvolvidos para analisar a uniformidade dos filmes emissivos depositados em diferentes equipamentos. Chegou-se a conclusão que filmes depositados fora do ambiente inerte possuíam uma área emissiva mais uniforme e, deste modo, todos os demais filmes foram depositados da mesma maneira.

Há também a questão relacionada a eletroluminescência não desejada do pixel vizinho àquele polarizado. Este inconveniente foi corrigido a partir do desenvolvimento e uso de um novo leiaute de máscaras.

Os lotes de dispositivos descritos a seguir se tratam de estudos relacionados a introdução do material Alq3 como transportador de cargas e como parte de um compósito testado para aumentar a eficiência dos dispositivos.

\subsection{Introdução do Alq3 como ETL}

Foram realizados os primeiros testes relacionados à deposição do material transportador de elétrons. $\mathrm{Na}$ primeira tentativa, as amostras de vidro com ITO permaneceram em vácuo dentro da evaporadora por 48 horas. Em seguida, iniciou-se o processo de evaporação térmica em duas amostras testemunhas. A taxa de deposição observada no medidor variava constantemente apresentando valores que oscilavam de 4 a mais de $20 \AA$ As. O processo foi encerrado quando o medidor de espessura localizado na evaporadora acusava $60 \mathrm{~nm}$ de espessura.

Os filmes de $\mathrm{Alq}_{3}$ depositados sobre ITO foram submetidos a testes de medição de espessura por profilometria. Foram feitas três medidas para cada amostra e, ao contrário do que se imaginava, os resultados obtidos eram muito distintos daqueles apresentados pelo medidor da evapo. Os valores apresentados pelo profilômetro ultrapassaram 280 nm. Por conta da disparidade encontrada entre a medição visualizada no medidor da evaporadora e a medição apresentada pelo profilômetro, medidas de espessura externas a evaporadora foram realizadas para todos os filmes de Alq3 utilizados na confecção de 
dispositivos. Foi utilizada a técnica AFM, modo não contato, para realizar as medidas de espessura com valores apresentados pelo medidor da evaporadora inferiores a $24 \mathrm{~nm}$. Optou-se pela utilização da técnica AFM por conta da possibilidade de se caracterizar filmes com espessuras muito reduzidas.

A Tabela 4.2.1 abaixo relaciona as espessuras apresentadas pelo medidor da evaporadora para todos os filmes de Alq3 depositados e os valores das medidas realizadas por profilometria.

Tabela 4.2.1 - Relação das medidas de espessura realizadas pelo cristal da evaporadora e pelo profilômetro

\begin{tabular}{|c|c|c|}
\hline $\begin{array}{c}\text { CRISTAL DA EVAPORADORA } \\
(\mathrm{nm})\end{array}$ & $\begin{array}{c}\text { PROFILÔMETRO } \\
(\mathrm{nm})\end{array}$ & $\begin{array}{c}\text { MEDIDAS AFM } \\
(\mathrm{nm})\end{array}$ \\
\hline 60 & 285 & \\
\hline 35 & 238 & \\
\hline 24 & 43 & \\
\hline 8 & 17 & \\
\hline 6 & 14 & \\
\hline 3 & 7 & \\
\hline 1 & 9 & \\
\hline
\end{tabular}

Apesar da disparidade encontrada entre as medidas, constatou-se, através de mais de uma deposição, que a relação entre os valores apresentados pelo medidor de espessura da evaporadora e o valor das medidas de espessura externas à evaporadora, muito embora não sejam lineares, se mantiveram constantes e reprodutivas.

\subsubsection{Lote 5}

Iniciou-se, neste lote, um estudo sobre a introdução do Alq3 como ETL e a contribuição deste material na eficiência do dispositivo. Desta maneira, duas estruturas de dispositivos, uma com $45 \mathrm{~nm}$ de ETL e outra sem ETL foram fabricadas. A eletroluminescência apresentada por dispositivos deste lote desapareceu logo após sua polarização inicial, impedindo registros fotográficos e medidas de luminescência e do 
espectro luminoso. Sendo assim, apenas as curvas IxV puderam ser registradas, conforme é apresentado nas figuras

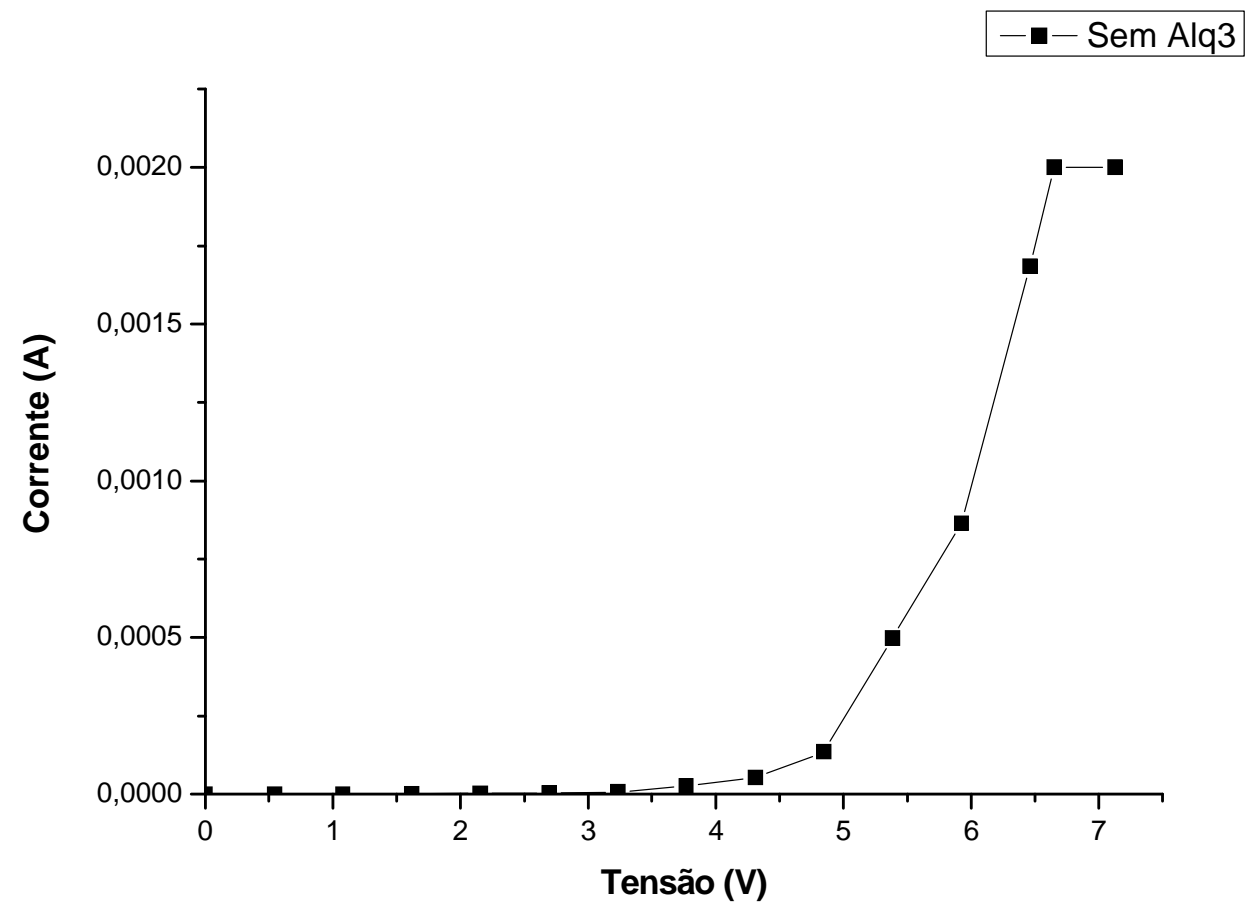

Figura 4.2.1.1 Curva IxV de dispositivo sem Alq3 


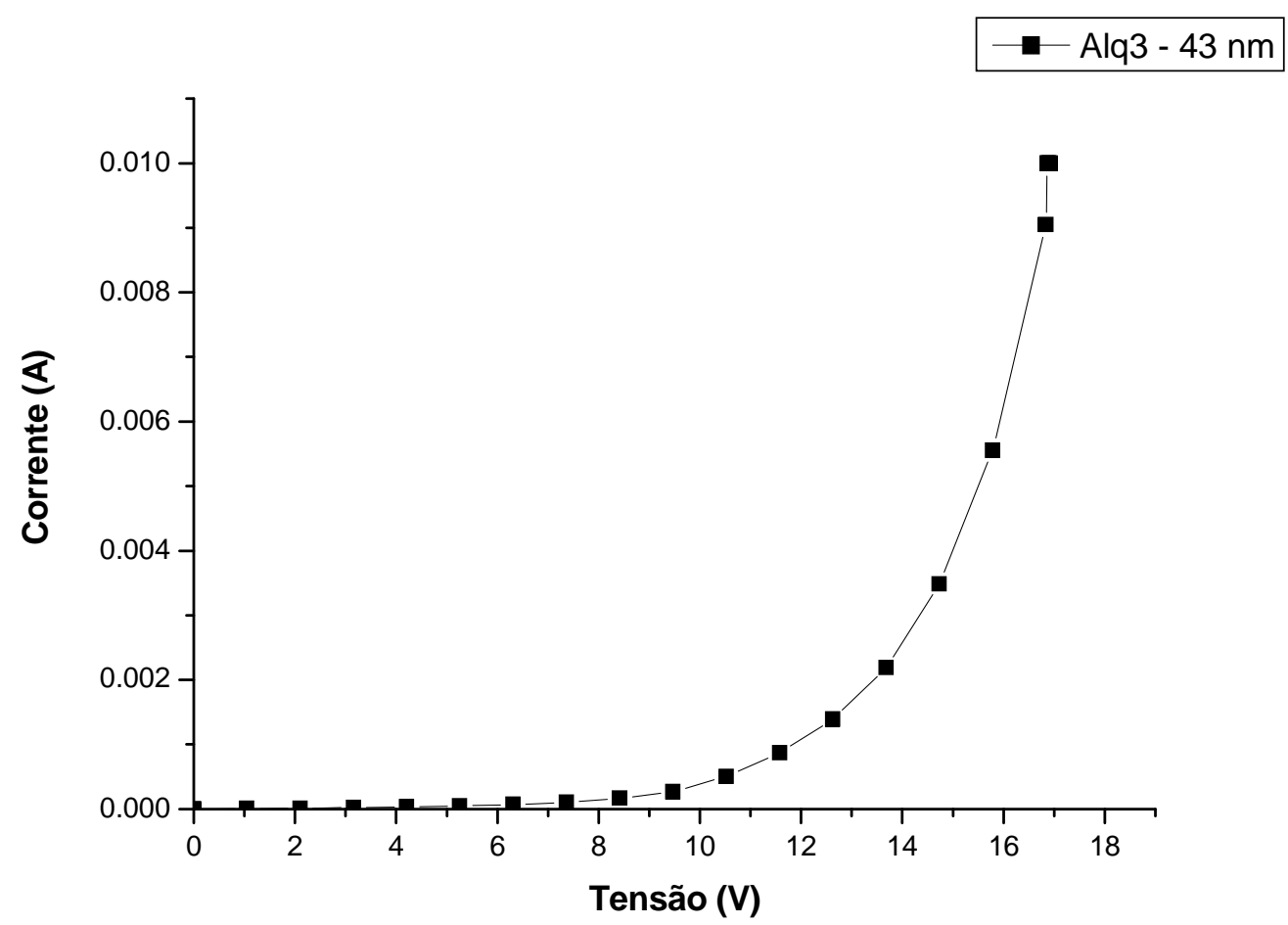

Figura 4.2.1.2 - Curva IxV de dispositivo com Alq3

Nota-se que a curva IxV dos dispositivos sem ETL do lote 5, ilustrada pela figura 4.2.1.1, apresentam comportamento de diodo com uma tensão de operação de aproximadamente $5 \mathrm{~V}$. A curva $\mathrm{IxV}$ dos dispositivos com ETL representada pela figura 4.2.1.2 apresenta, da mesma maneira, comportamento de diodo; entretanto, a tensão de operação sofreu um acréscimo considerável, com valores de aproximadamente $14 \mathrm{~V}$.

Por conta do grande acréscimo da tensão de operação e da morte do dispositivo, houve a suspeita de que a utilização de um filme de Alq3 tão espesso pudesse ter interferido de maneira negativa no desempenho do dispositivo. Pensando nisso, novos lotes de dispositivos com filmes de Alq3 de espessuras reduzidas foram fabricados.

\subsubsection{Lote 6}

Uma segunda tentativa foi realizada através do uso da máscara mecânica já mencionada. A utilização da máscara se mostrou eficiente e foram produzidas 4 amostras, com 4 PLEDs em cada uma delas.

Os dispositivos fabricados no segundo lote foram desenvolvidos usando a mesma estrutura dos primeiros. A diferença entre os dois se deu, entretanto, pela redução da 
espessura da ETL de $43 \mathrm{~nm}$ para $17 \mathrm{~nm}$ e pelo uso da máscara mecânica capaz de proteger dois dos quatro substratos durante a evaporação do filme de Alq3. Novamente foram fabricados dispositivos com e sem ETL.

A espessura de $8 \mathrm{~nm}$ observada no medidor foi novamente medida pelo profilômetro, apresentando uma medida de $17 \mathrm{~nm}$.

Foi possível realizar medidas de luminância e do espectro luminoso para todos os dispositivos fabricados neste lote. As figuras a seguir ilustram o comportamento elétrico e óptico dos dispositivos do lote 6.

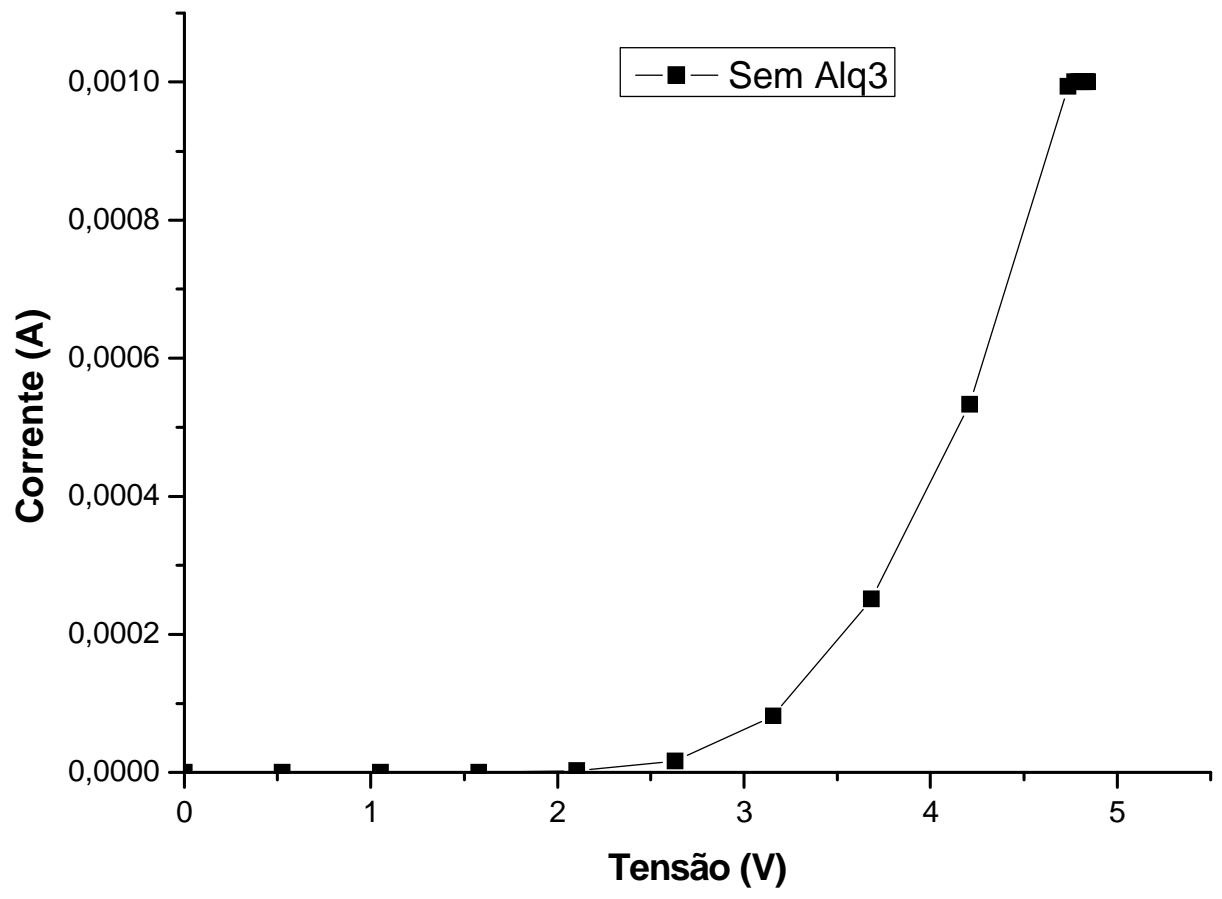

Figura 4.2.2.1 - Curva IxV de dispositivo sem ETL

A figura 4.2.2.1 representa o comportamento de diodo exibido por dispositivos sem ETL, com uma tensão de operação de aproximadamente 3,5V. Através dos valores de luminância medidos e do cálculo da densidade de corrente, chega-se ao gráfico LxJ, representado pela figura 4.2.2.2 abaixo. Um ponto de uma região linear do gráfico foi utilizado para calcular o valor da eficiência luminosa de $0,023 \mathrm{~cd} / \mathrm{A}$. 


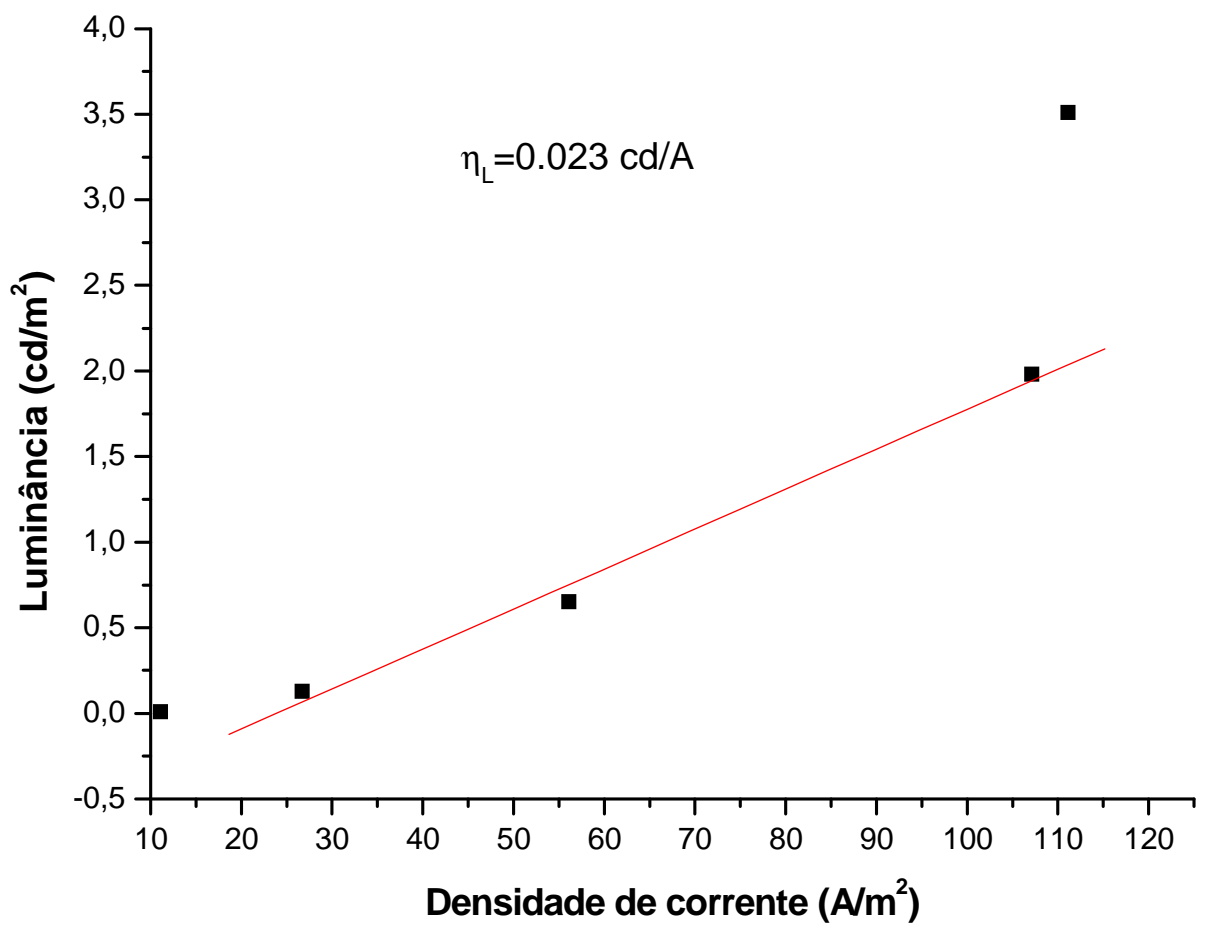

Figura 4.2.2.2 - Relação Luminância x Densidade de corrente de dispositivo sem ETL

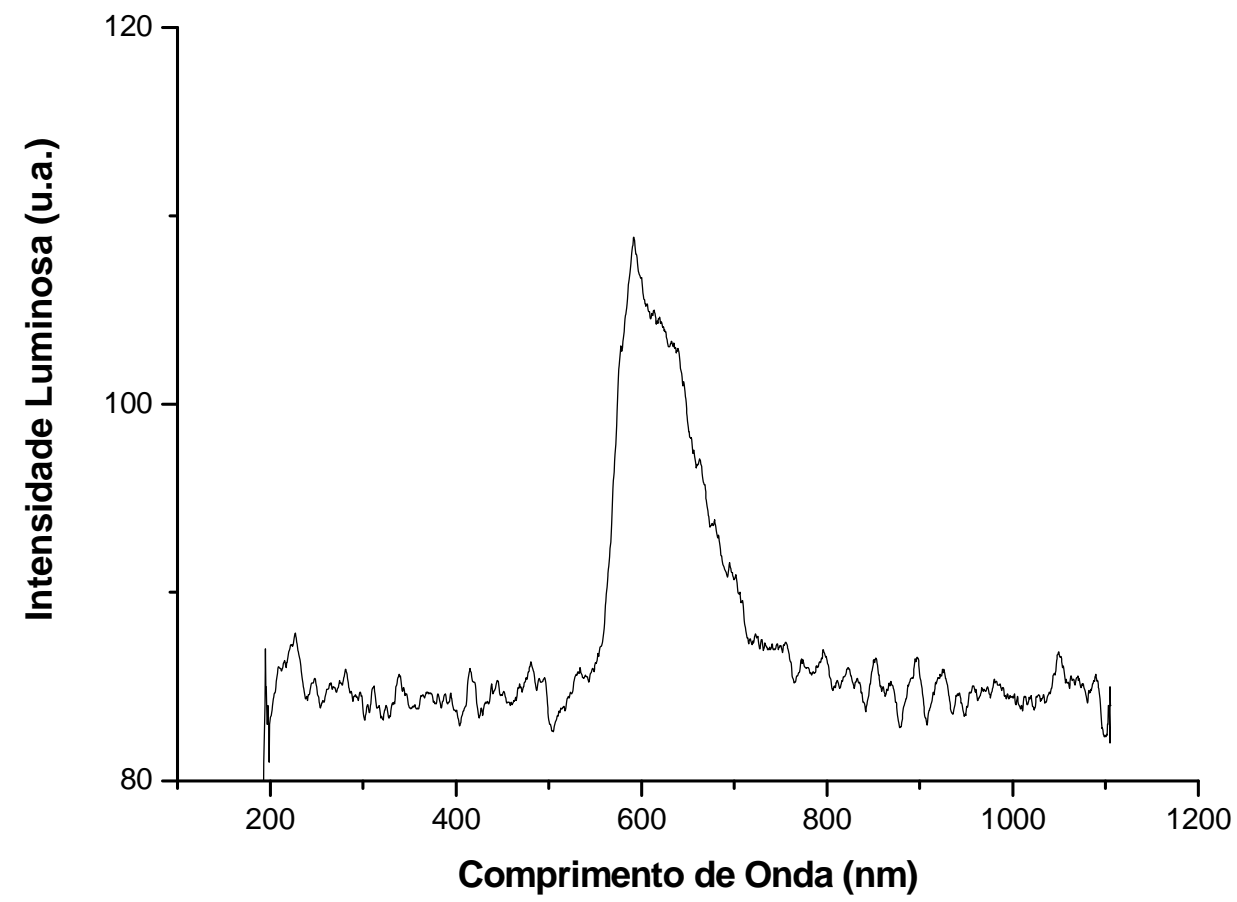

Figura 4.2.2.3 - Intensidade luminosa $x$ comprimento de onda de dispositivo sem ETL 
A figura 4.2.2.3 representa o gráfico de intensidade luminosa x comprimento de onda dos dispositivos sem ETL do lote 6. Nota-se, para este caso, um pico de emissão de cerca de $600 \mathrm{~nm}$.

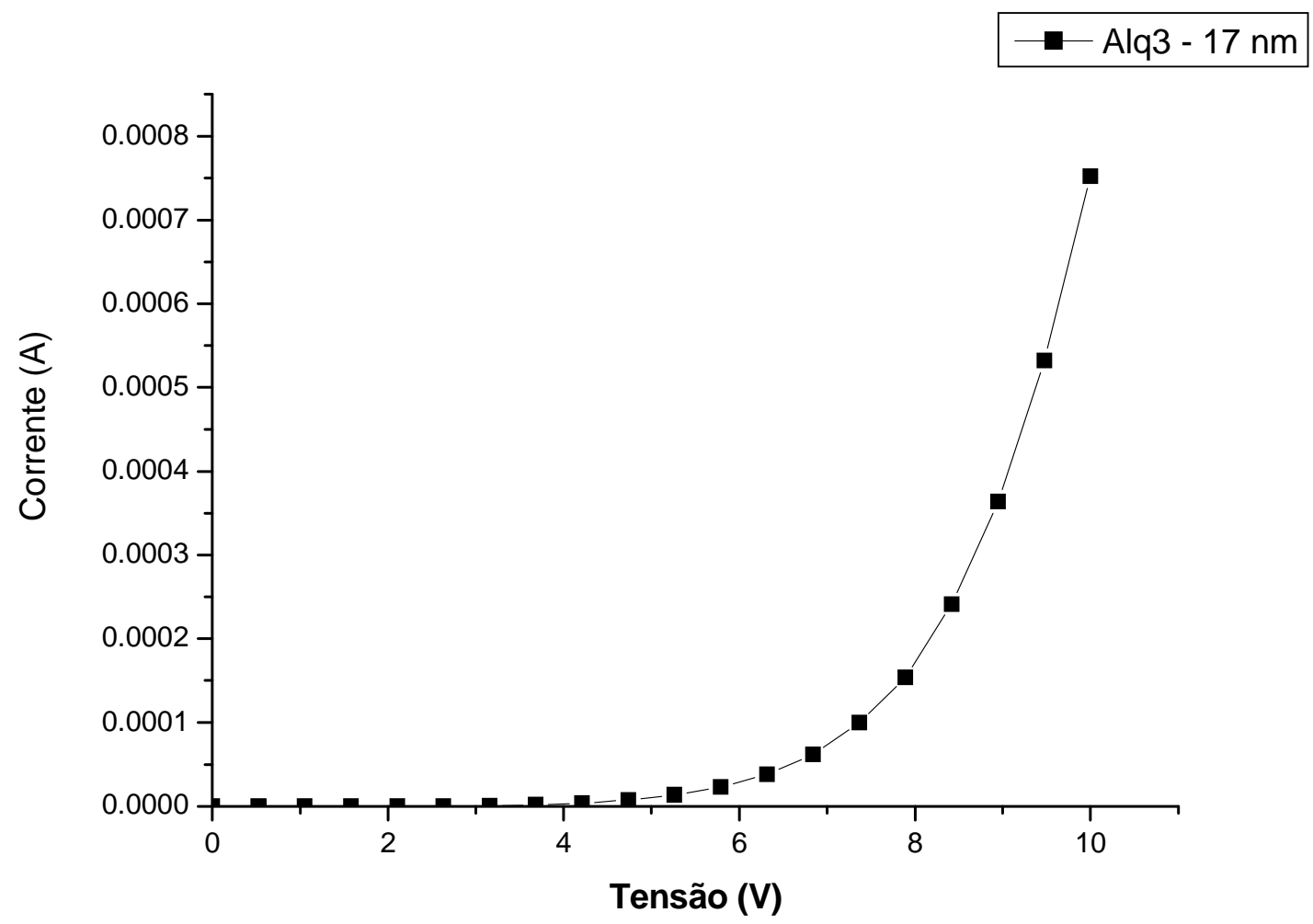

Figura 4.2.2.4 Curva IxV de dispositivos com ETL

$\mathrm{O}$ gráfico $\mathrm{IxV}$ dos dispositivos com ETL do lote 6 é representado pela figura 4.2.2.4. Nota-se novamente uma curva de diodo, apresentando uma tensão de operação de aproximadamente $7,5 \mathrm{~V}$. 


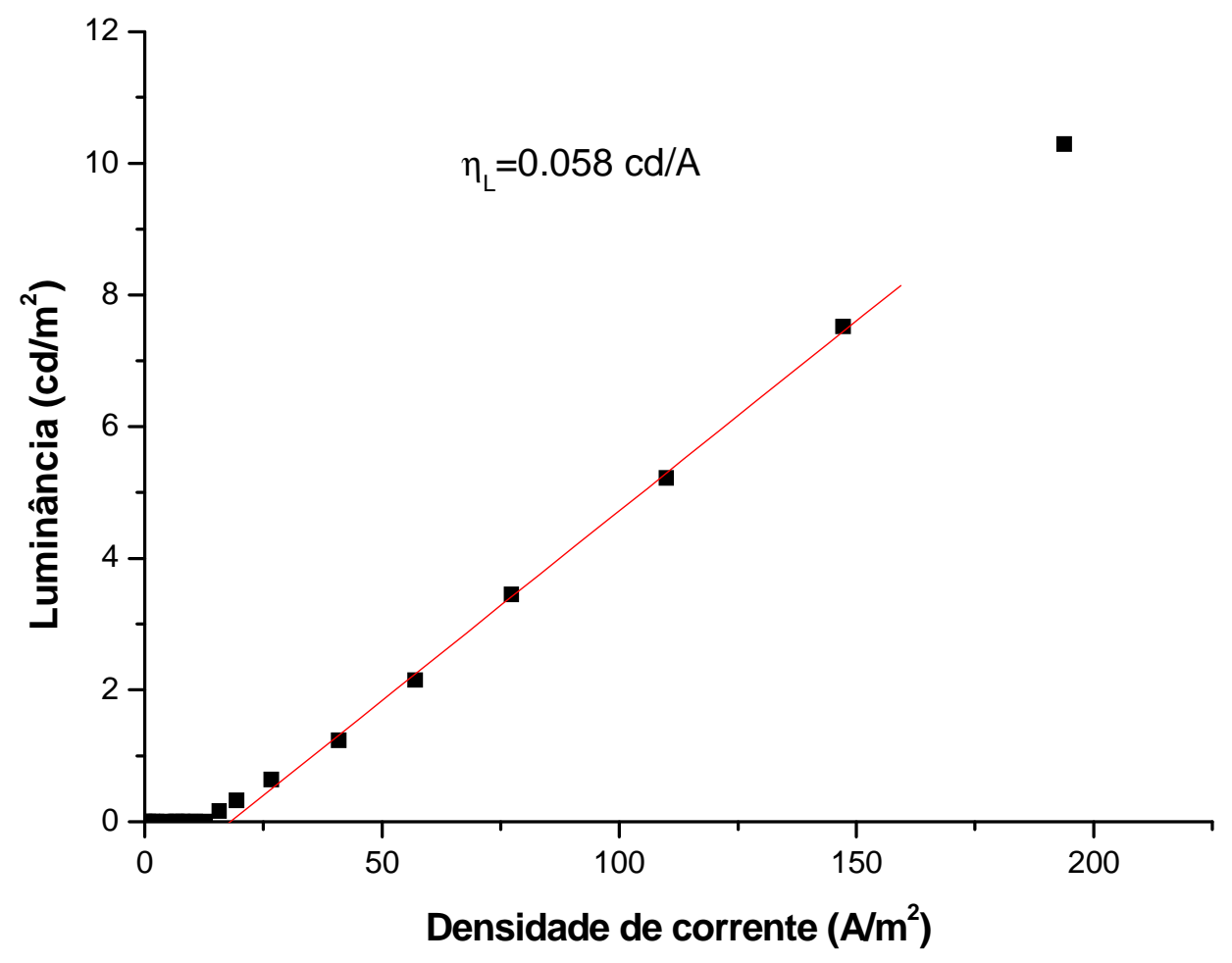

Figura 4.2.2.5 - Relação entre Luminância x Densidade de corrente de dispositivos com ETL

O gráfico JxL dos dispositivos com ETL do lote 6 é ilustrado pela figura 4.2.2.5 e apresenta o valor da eficiência luminosa de $0,058 \mathrm{~cd} / \mathrm{A}$, calculado a partir de um ponto da região linear do gráfico. 


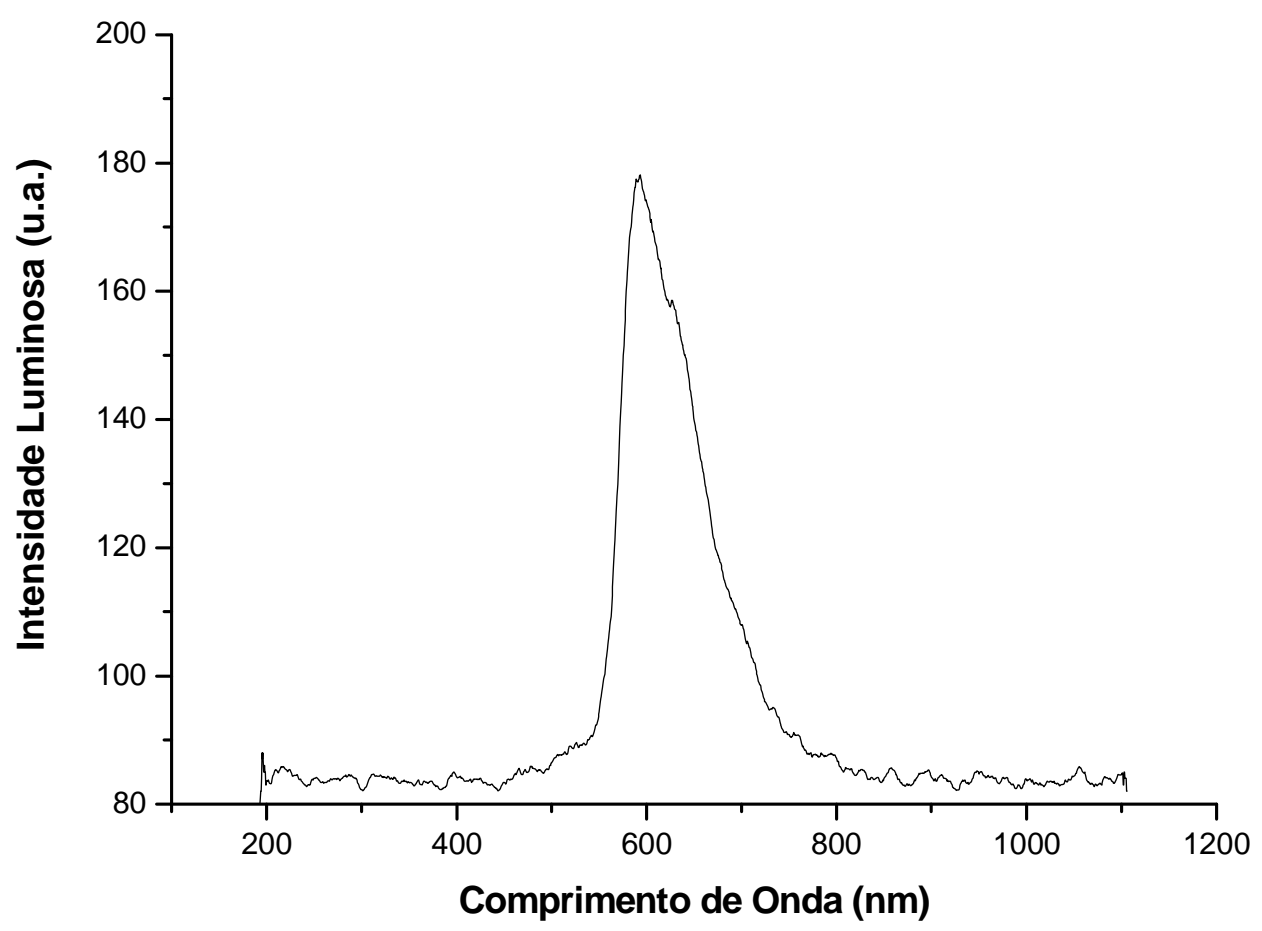

Figura 4.2.2.6 - Intensidade luminosa $x$ Comprimento de onda de dispositivo com ETL

Como pode-se notar, o espectro luminoso apresentado pela figura 4.2.2.6 indica que dispositivos com Alq3 mantiveram o mesmo pico de emissão dos dispositivos sem ETL, ou seja, aproximadamente $600 \mathrm{~nm}$. Este dado pode significar que, mesmo possuindo a característica da eletroluminescência, o filme de Alq3 esteja contribuindo apenas no transporte de cargas, sem alterar o comprimento de onda de emissão.

Tabela 4.2.2 Relação de eficiência luminosa, luminância máxima e tensão de operação de dispositivos com e sem ETL

\begin{tabular}{|c|c|c|c|}
\hline ESTRUTURA DOS DISPOSITIVOS & $\begin{array}{c}\text { TENSÃO } \\
\text { OPERAÇÃO (V) }\end{array}$ & $\begin{array}{c}\text { LUMINÂMCIA } \\
\text { MÁXIMA (cd/m2) }\end{array}$ & $\begin{array}{c}\text { EFICIÊNCIA } \\
\text { LUMINOSA } \\
\text { (cd/A) }\end{array}$ \\
\hline ITO/PEDOT:PSSOC1C10-PPV/Al & 3.5 & 57.5 & 0.023 \\
\hline ITO/PEDOT:PSSOC1C10-PPV/Alq3/Al & 7,5 & 166 & 0.058 \\
\hline
\end{tabular}


A tabela 4.2.2-1 representa um resumo das medidas de tensão de operação realizadas e dos cálculos da eficiência luminosa apresentada pelos dispositivos. Fica claro que, apesar da tensão de polarização ser relativamente maior para dispositivos com ETL a luminância máxima e a eficiência luminosa sofreram um grande acréscimo com a presença de Alq3.

Foi observado com relação aos resultados apresentados por dispositivos do lote 5 que a redução da espessura do filmes de Alq3 implicou numa tensão de operação também inferior. Desta maneira, os lotes seguintes de dispositivos foram produzidos no sentido de testar elétrica e opticamente dispositivos com filmes de espessura ainda mais reduzidas de Alq3.

As figuras 4.2.2.7 e 4.2.2.8 abaixo ilustram os registros fotográficos apresentados por dispositivos sem Alq3 e com Alq3, respectivamente.

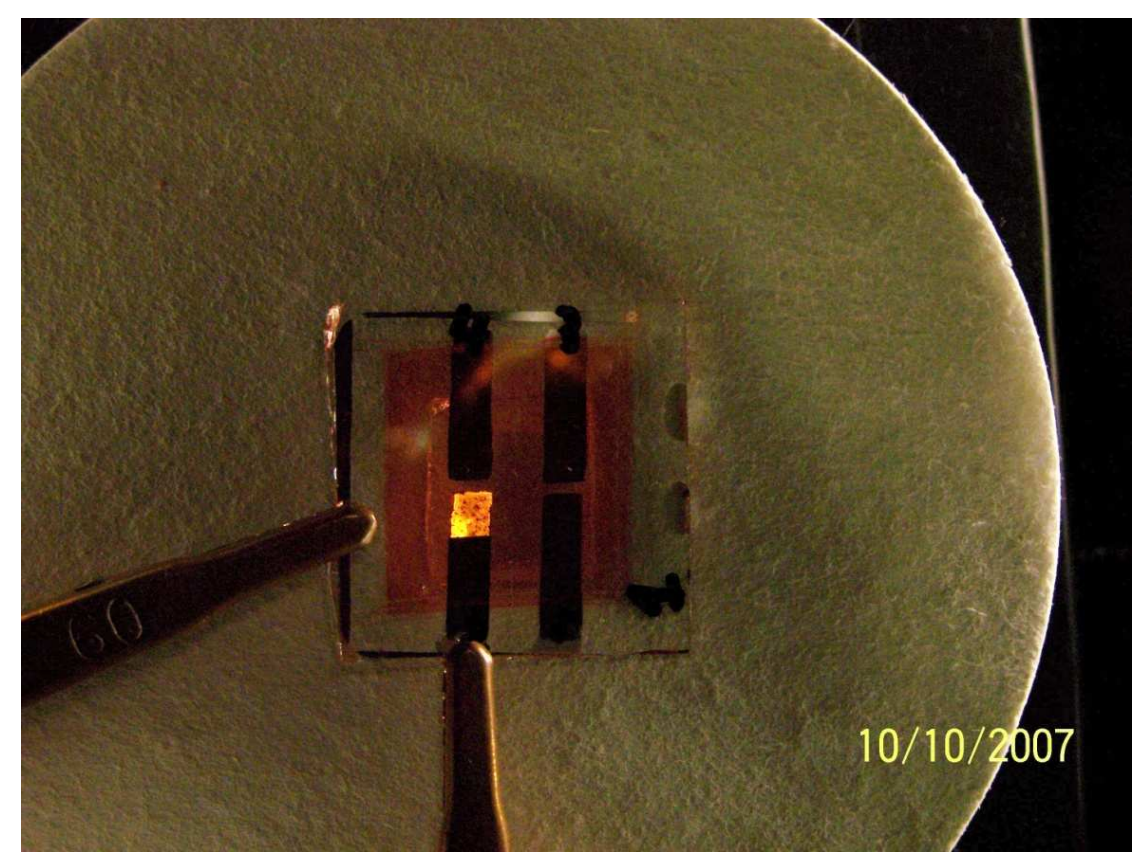

Figura 4.2.2.7 - Registro fotográfico de dispositivo sem Alq3 


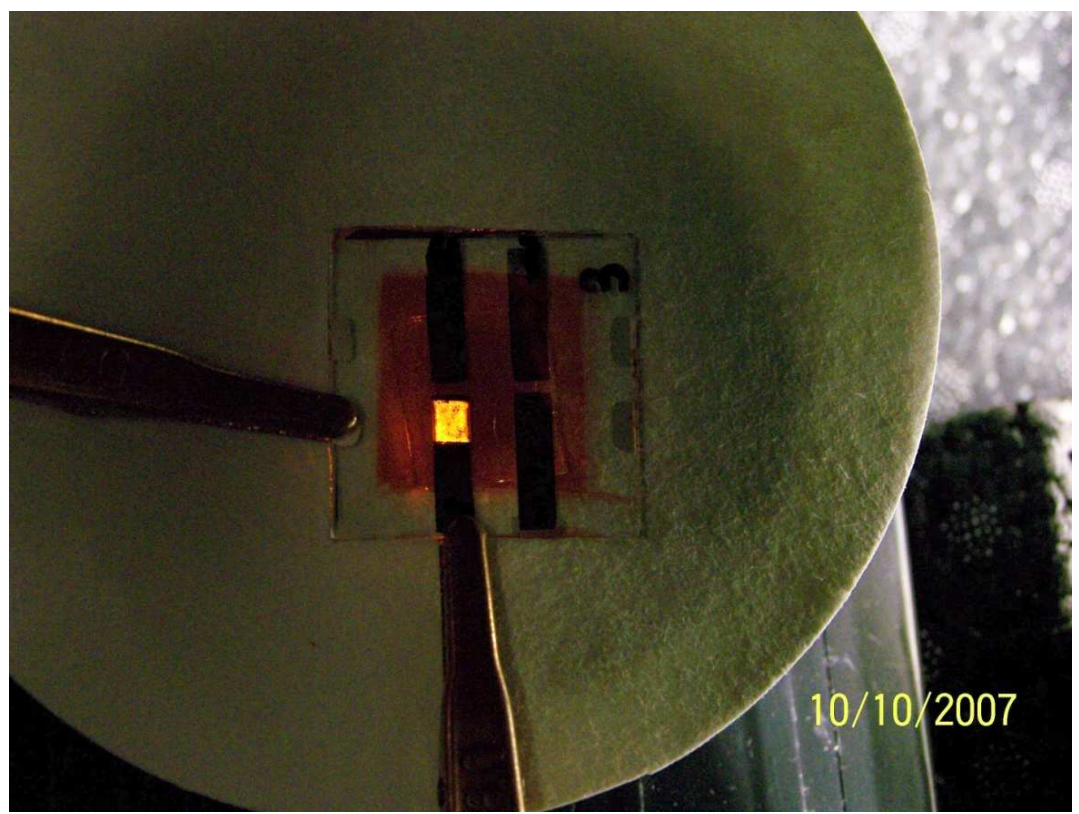

Figura 4.2.2.8 Registro fotográfico de dispositivo com ETL.

\subsubsection{Lote 7}

O lote de número 7 foi fabricado manteve os mesmos parâmetros de fabricação e deposição dos filmes de PEDOT:PSS e $\mathrm{OC}_{1} \mathrm{C}_{10} \mathrm{PPV}$, e foi adicionado aos dispositivos um filme de Alq3 com espessura de $14 \mathrm{~nm}$. Novas caracterizações foram realizadas e abaixo são apresentadas as representações gráficas obtidas e os registros fotográficos dos dispositivos. Neste lote, foram apenas fabricadas estruturas com ETL. 


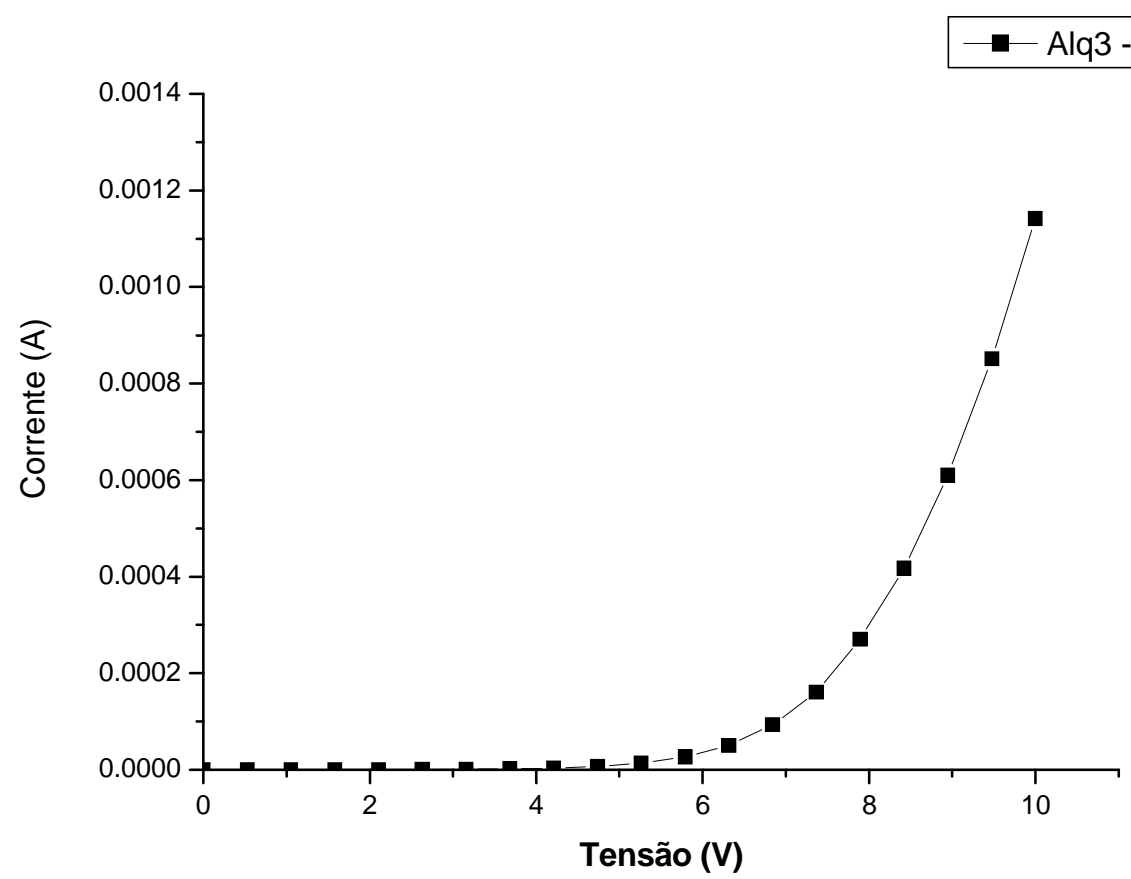

Figura 4.2.3.1 - Curva IxV de dispositivo com 14 nm de Alq3

O gráfico IxV dos dispositivos do lote 7 é ilustrado pela figura 4.2.3.1. Nota-se que os dispositivos possuem característica de diodo e uma tensão de operação de aproximadamente $7 \mathrm{~V}$.

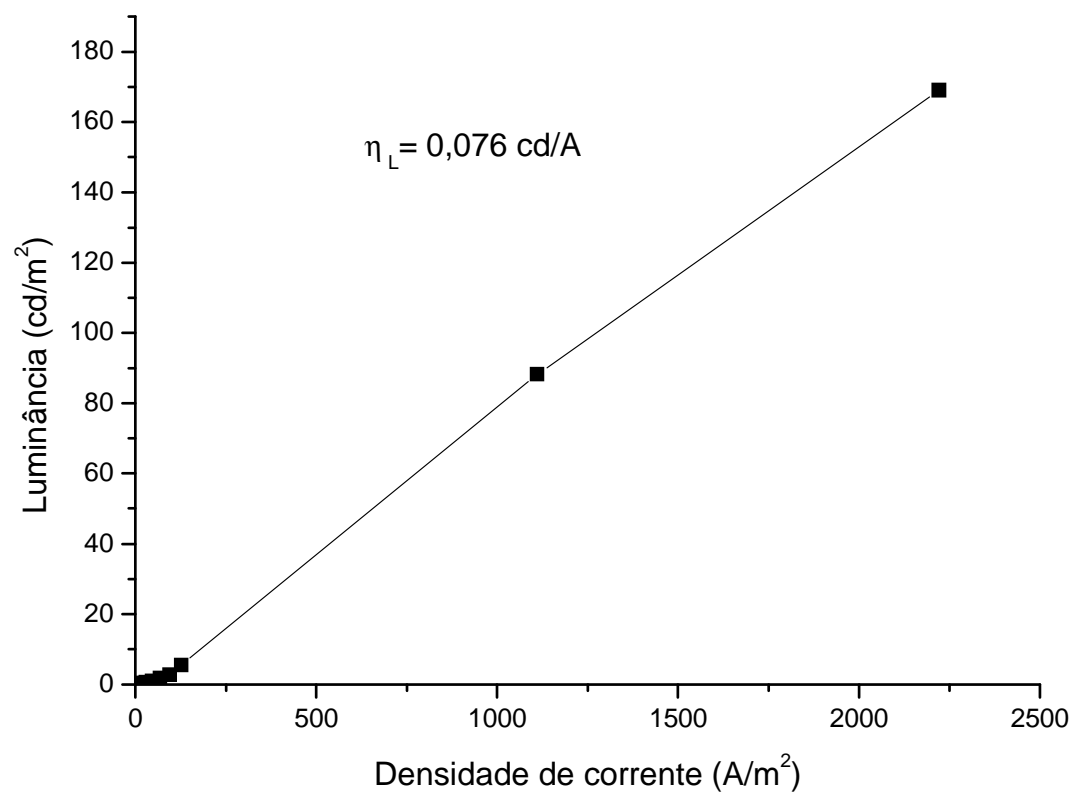

Figura 4.2.3.2 - Relação entre Luminância e Densidade de corrente de dispositivo com 14 nm de Alq3 
A figura 4.2.3.2 ilustra o gráfico LxJ dos dispositivos do lote 7 e apresenta o valor de $0,076 \mathrm{~cd} / \mathrm{A}$ de eficiência luminosa, calculado a partir de um ponto da região linear do gráfico. É importante lembrar que este valor é superior aquele calculado no lote 6 .

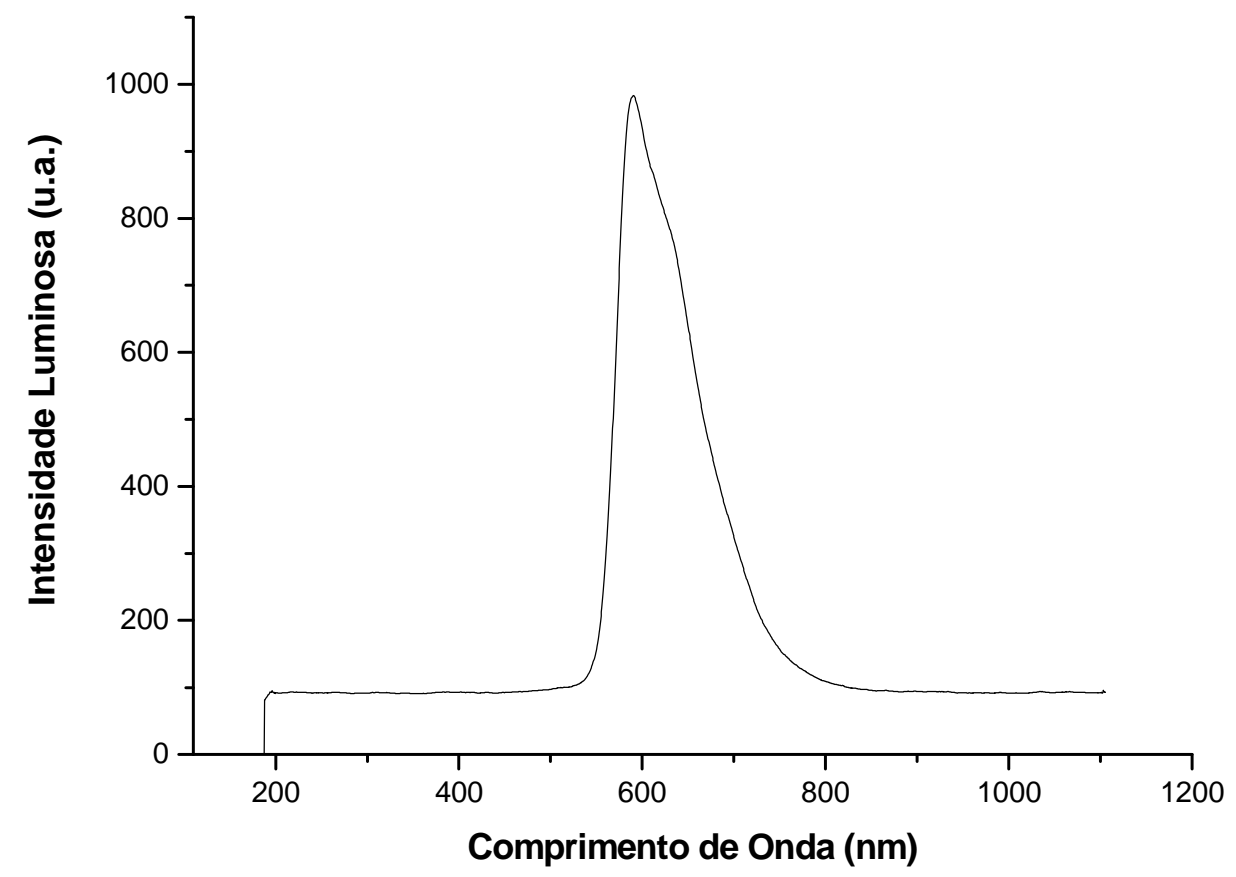

Figura 4.2.3.3 - Relação entre Intensidade luminosa e Comprimento de onda de dispositivo com 14nm de Alq3

Pode-se observar através do gráfico de intensidade luminosa x comprimento de onda representado pela figura 4.2.3.3 que, mais uma vez, o pico de emissão se manteve em torno de $600 \mathrm{~nm}$. Abaixo pode-se verificar os registros fotográficos frontal e lateral dos dispositivos fabricados ilustrados nas figuras 4.2.3.4 e 4.2.3.5. 


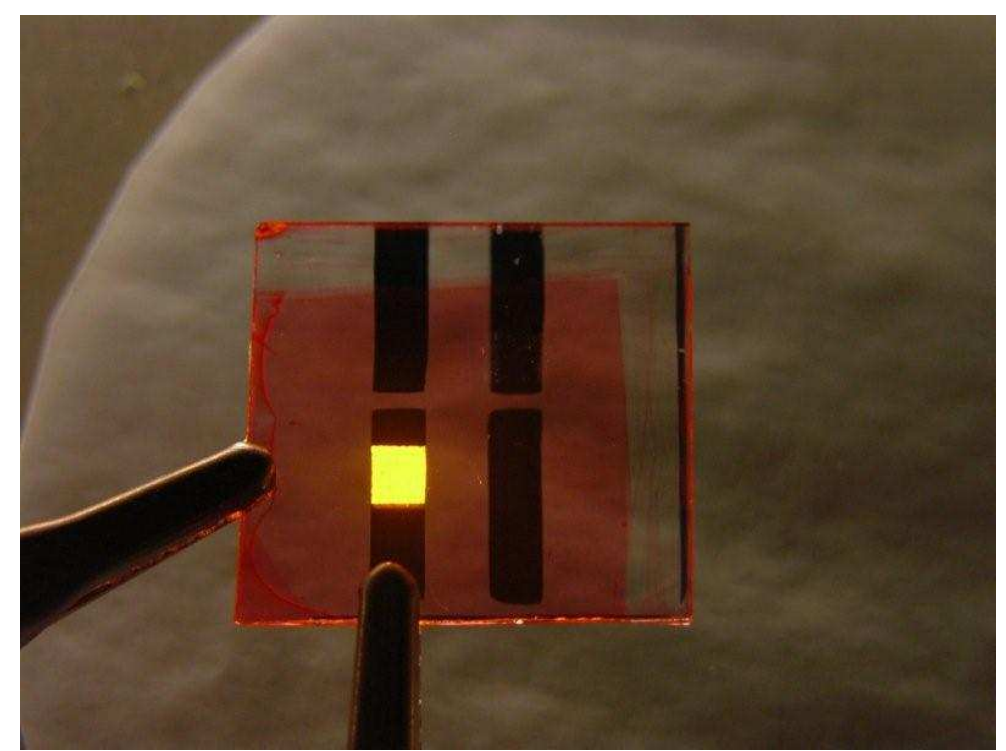

Figura 4.2.3.4 - Registro fotográfico frontal de dispositivo com 14nm de Alq3

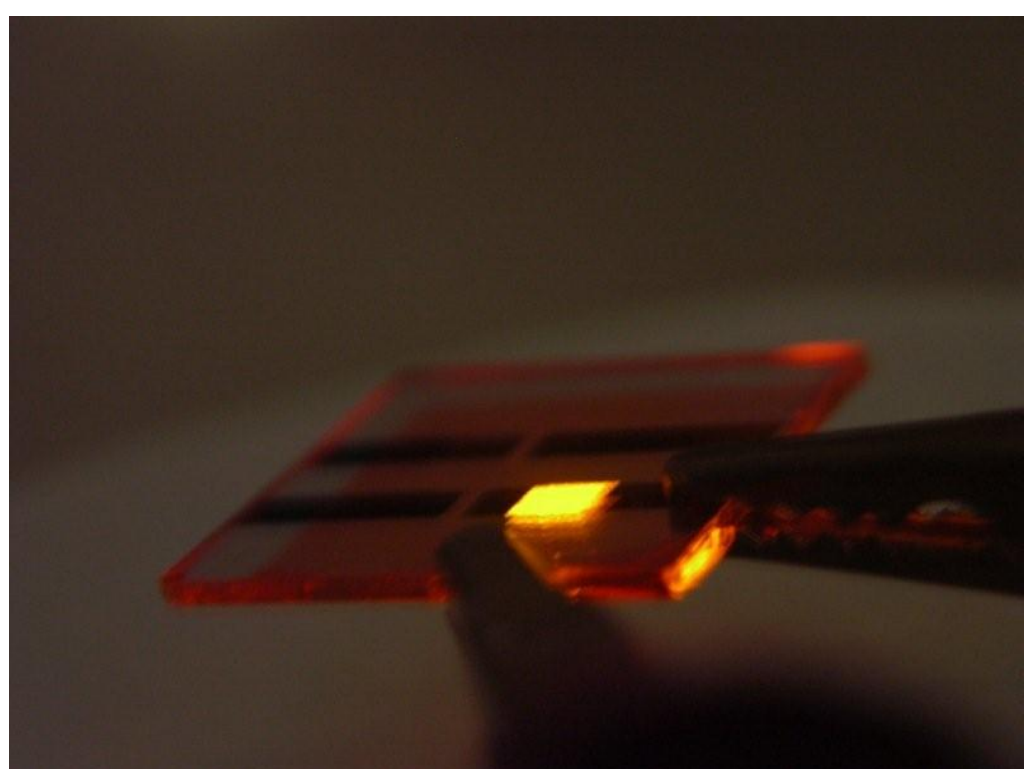

Figura 4.2.3.5 Registro fotográfico com vista lateral de dispositivo com 14nm de Alq3

\subsubsection{Lote 8}

Ainda no sentido de se obter um desempenho superior dos dispositivos com ETL, no quarto lote foram fabricados dispositivos com ETL de espessuras ainda mais reduzidas. $\mathrm{O}$ medidor de espessura da evaporadora registrou $3 \mathrm{~nm}$.

Os dispositivos fabricados neste lote sofreram uma deformação da área dos pixels ocasionada pelo posicionamento da máscara mecânica durante a deposição dos filmes evaporados. É necessário ressaltar, entretanto, que a nova área do dispositivo 
produzido foi levada em consideração para efeito de cálculo de eficiência luminosa e densidade de corrente.

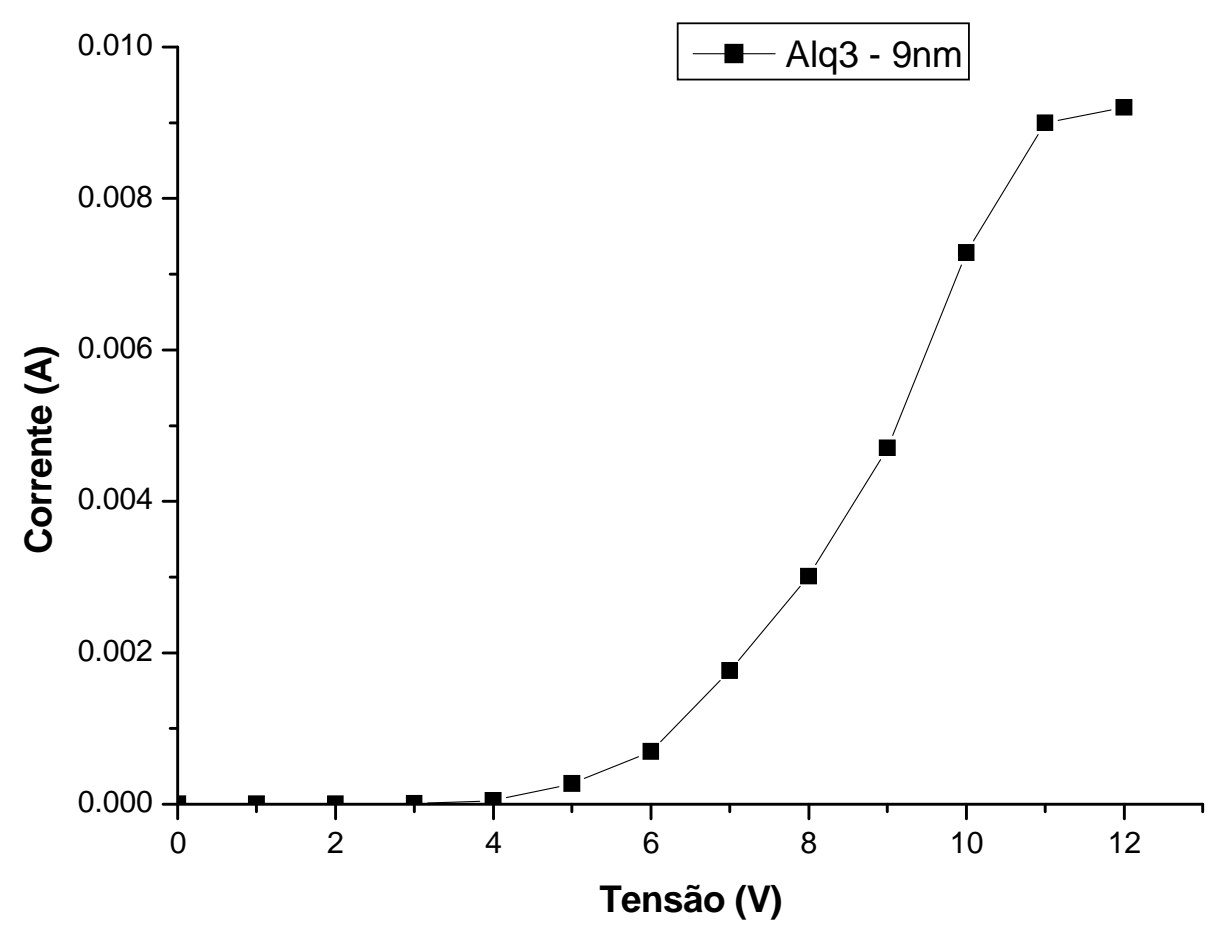

Figura 4.2.4.1 Curva IxV de dispositivo com 9nm de Alq3

$\mathrm{O}$ gráfico $\mathrm{IxV}$ dos dispositivos do lote 8 é ilustrado na figura 4.2.4.1. Nota-se o comportamento de diodo exibido por estes dispositivos, com uma tensão de operação de aproximadamente $6,5 \mathrm{~V}$. 


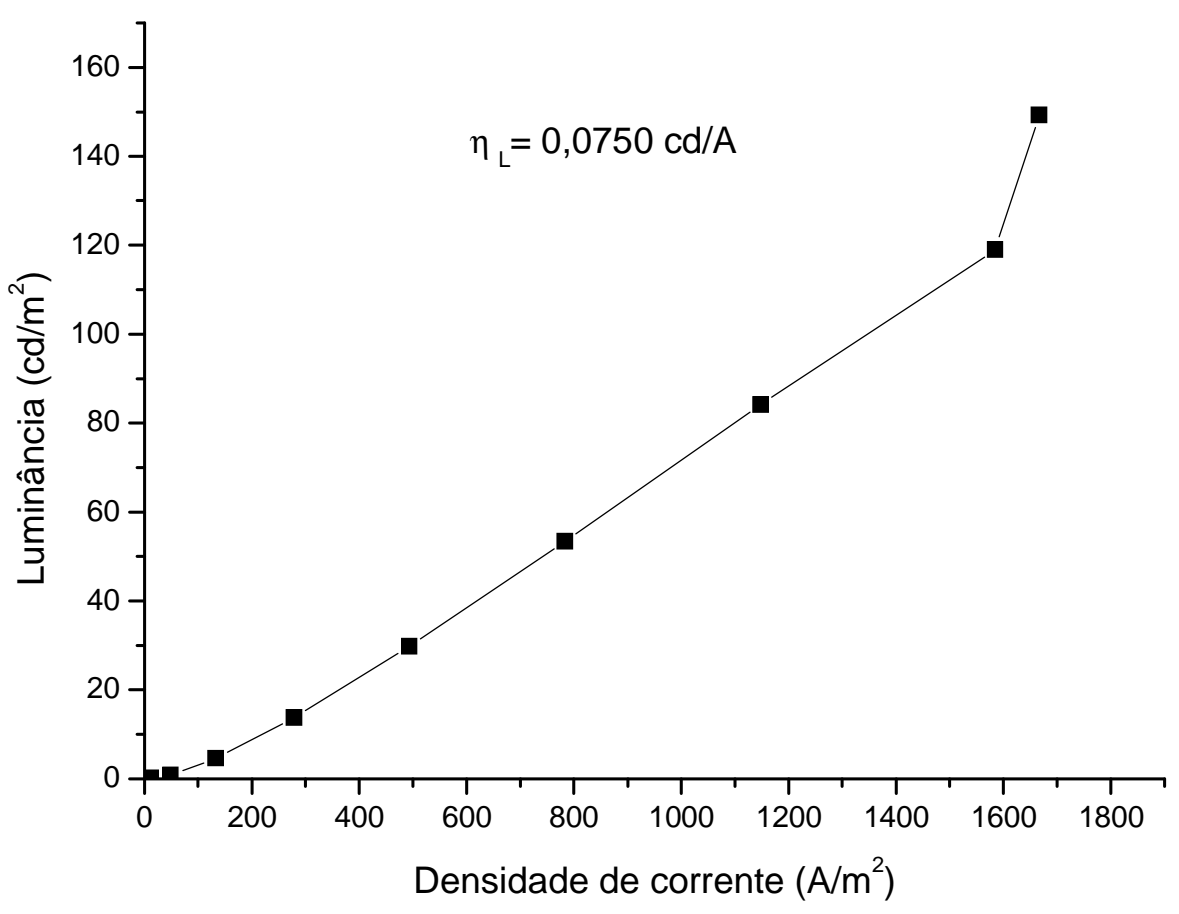

Figura 4.2.4.2 - Relação entre luminância e densidade de corrente de dispositivos com 9nm de Alq3

A figura 4.2.4.2 acima ilustra o gráfico LxJ dos dispositivos do lote 8 e o valor de 0,0750 cd/A de eficiência luminosa, calculado para um ponto da região linear do gráfico. Através deste resultado, notou-se que os dispositivos apresentaram eficiência luminosa similar àqueles que continham filmes de $9 \mathrm{~nm}$. 


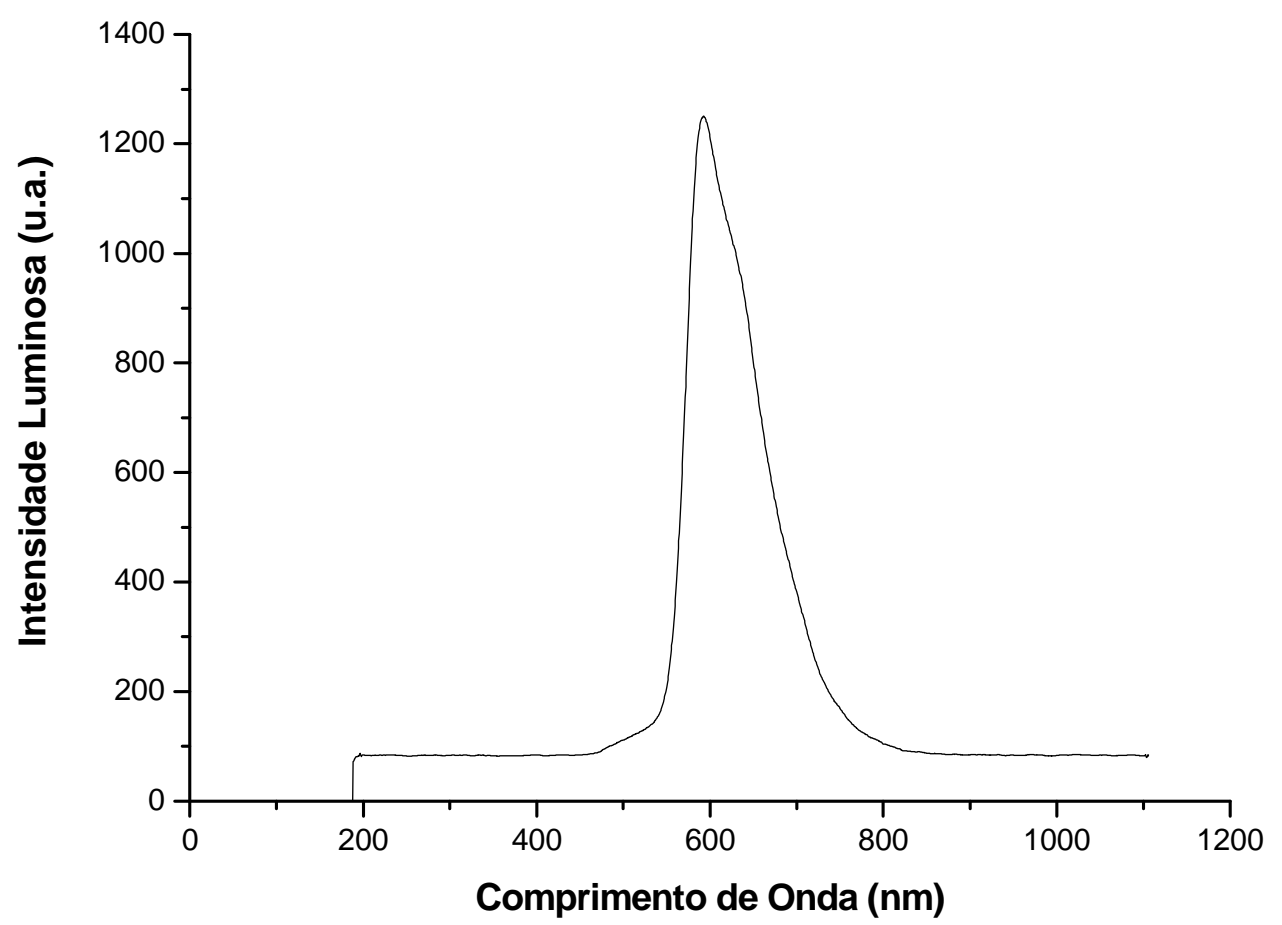

Figura 4.2.4.3 - Relação Intensidade luminosa x comprimento de onda de dispositivo com 9nm de Alq3

O pico de emissão permaneceu em torno de $600 \mathrm{~nm}$, como pode ser observado na figura 4.2.4.3 que ilustra a curva de intensidade luminosa $\mathrm{x}$ comprimento de onda dos dispositivos do lote 8. Mais uma vez o filme de Alq3 parece estar apenas contribuindo com o transporte de cargas, sem afetar a emissão do filme de $\mathrm{OC}_{1} \mathrm{C}_{10}-\mathrm{PPV}$.

A figura 4.2.4.4 abaixo mostra o registro fotográfico das amostras fabricadas neste lote. É necessário lembrar que por conta do deslocamento da máscara a área que apresentou emissão de luz ficou reduzida a $6 \mathrm{~mm}^{2}$. 


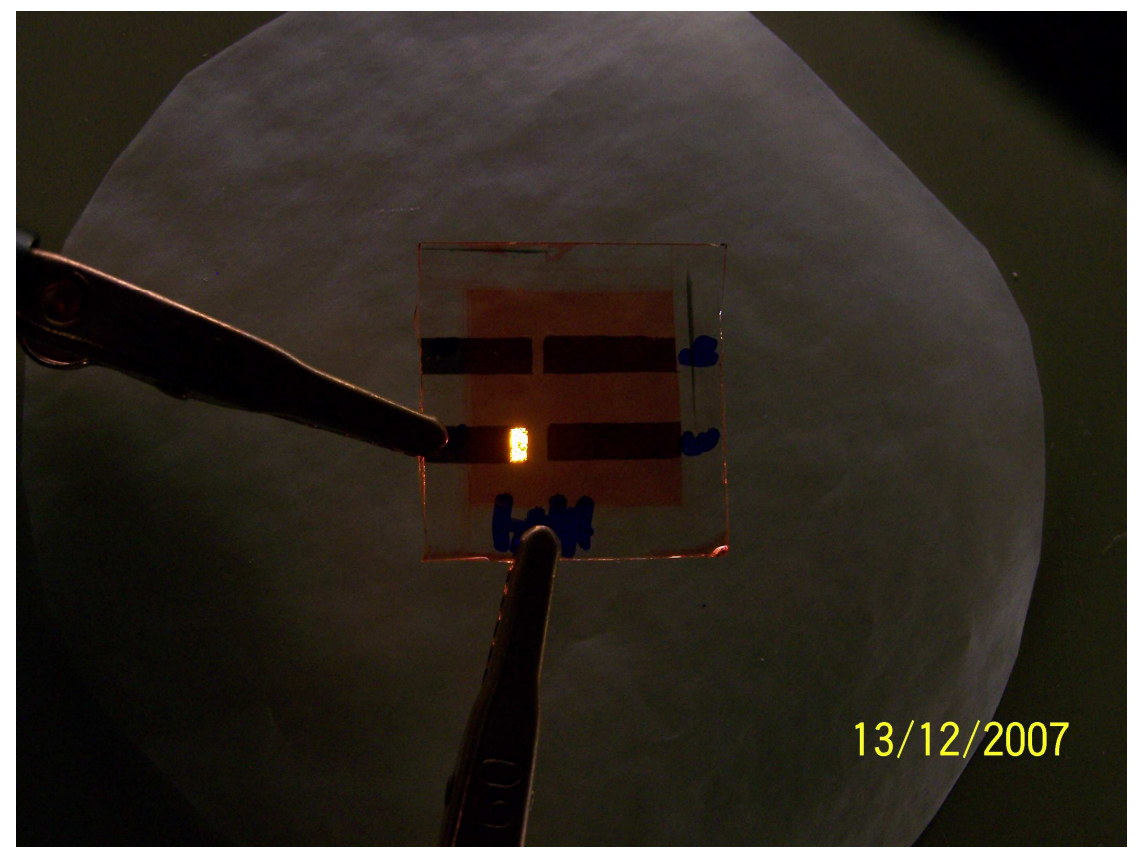

Figura 4.2.4.4 - Registro fotográfico de dispositivo com 9nm de ETL.

\subsubsection{Lote 9}

Apesar dos dispositivos que continham ETLs de 14 e 9nm terem apresentado comportamentos parecidos com desempenhos também semelhantes, foram desenvolvidos PLEDs com filmes de Alq3 ainda mais finos. Entretanto, o estudo da presença de ETL nos dispositivos fabricados foi encerrado neste último lote por conta da falta de precisão do medidor de espessura da evaporadora. Sabe-se que há uma certa disparidade entre as medidas apresentadas pelo medidor da evaporadora e as técnicas de medição externas. Entretanto, a medida apresentada durante a evaporação é o parâmetro de maior importância para que se obtenha a deposição desejada. Neste caso, foram fabricados dispositivos com filmes de Alq3 que apresentaram apenas $1 \mathrm{~nm}$ de espessura do medidor da evaporadora. Valores inferiores a este seriam limitados pela precisão do cristal, inviabilizando a reprodutibilidade dos filmes depositados.

As figuras a seguir representam o comportamento dos dispositivos do último dos lotes dedicados ao estudo da espessura da ETL. 


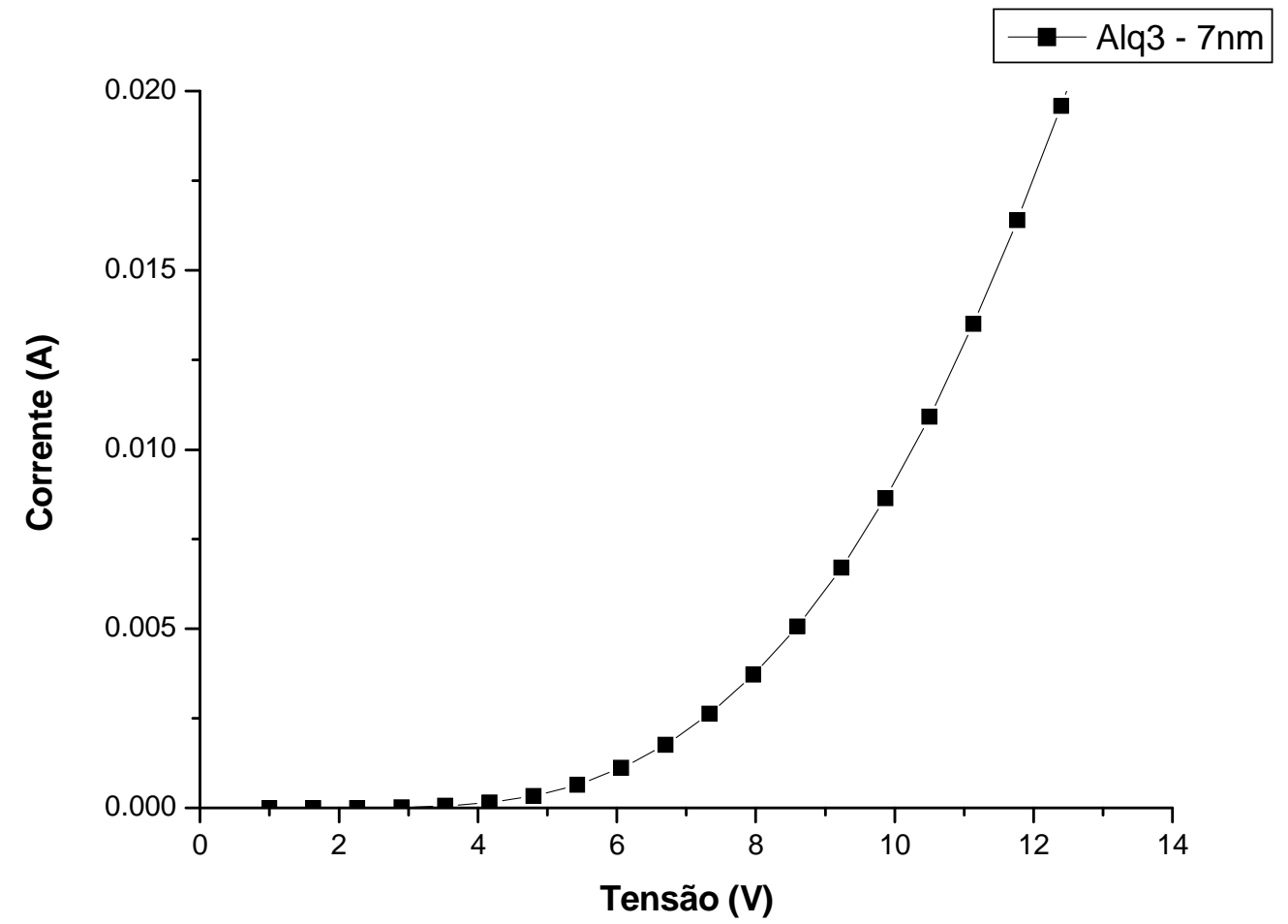

Figura 4.2.5.1 - Curva IxV de dispositivo com 7nm de ETL

A figura 4.2.5.1 acima ilustra o comportamento de diodo exibido por dispositivos do lote 9 , que apresentaram uma tensão de operação de aproximadamente 6V. 


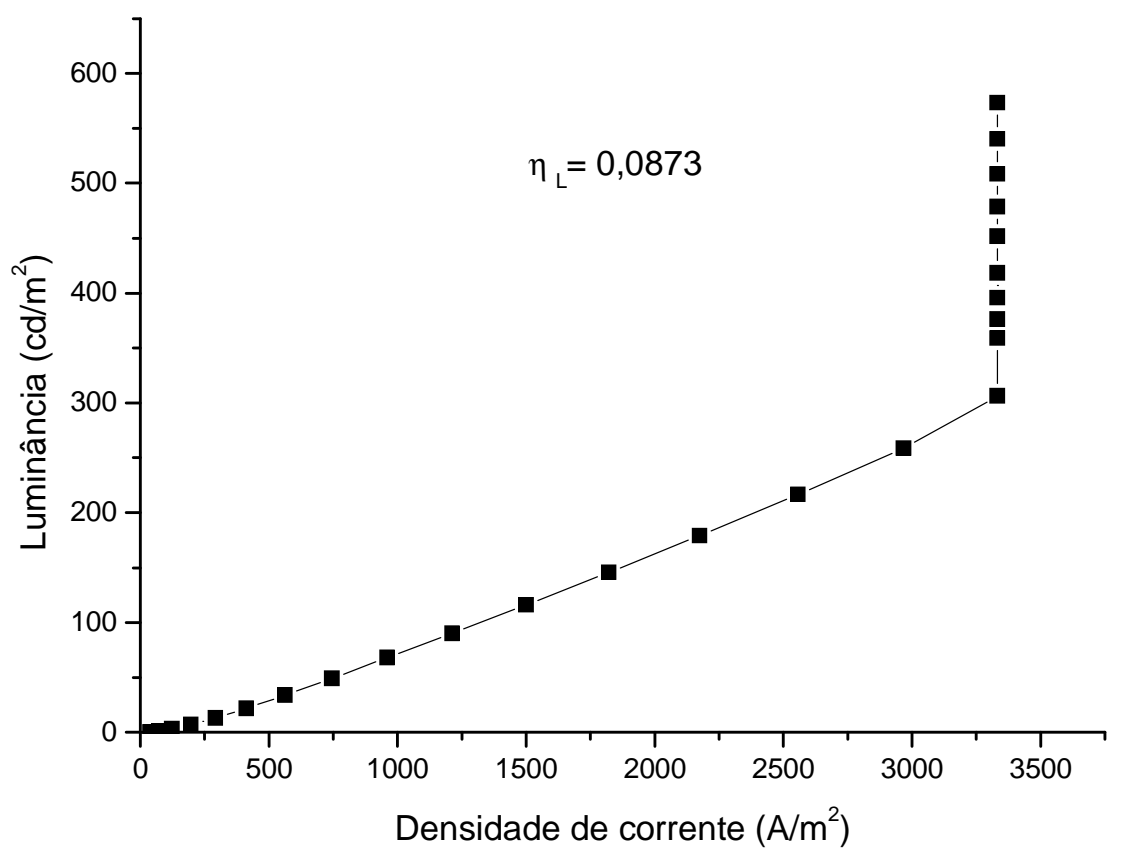

Figura 4.2.5.2 - Relação entre luminância e densidade de corrente de dispositivo com 7nm de ETL

O gráfico LxJ de dispositivos do lote 9 é ilustrado pela figura 4.2.5.2. O valor calculado de eficiência luminosa destes dispositivos é de $0,0873 \mathrm{~cd} / \mathrm{A}$ e a luminância máxima apresentada ultrapassava $500 \mathrm{~cd} / \mathrm{m}^{2}$, quase 10 vezes mais que a luminância máxima apresentada por dispositivos sem ETL. Como pode-se notar, foi utilizado um ponto da região linear do gráfico para que o cálculo de eficiência luminosa fosse realizado. Os resultados referentes a luminância eficiência luminosa deste lote de dispositivos se mostraram superiores a todos os outros fabricados anteriormente. 


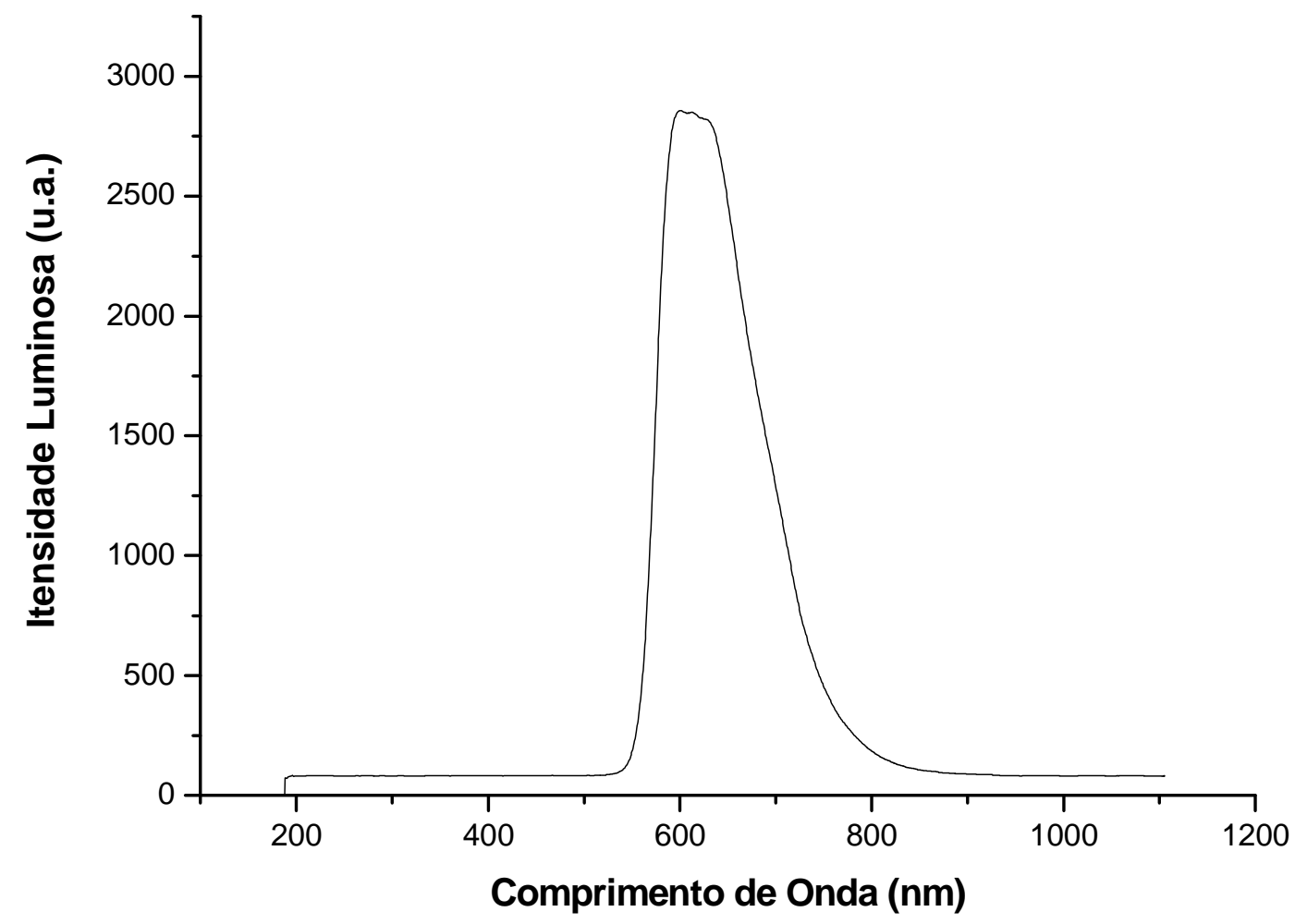

Figura 4.2.5.3 - Relação de Intensidade luminosa x comprimento de onda de dispositivo com $7 \mathrm{~nm}$ de ETL

A figura 4.2.5.3 ilustra o gráfico de intensidade luminosa x comprimento de onda dos dispositivos do lote 9, apresentando um pico de emissão de aproximadamente $600 \mathrm{~nm}$.

O registro fotográfico apresentado na figura 4.2.5.4 abaixo ilustra um dispositivo do Lote 9 sendo polarizado de maneira a atingir a emissão máxima de $500 \mathrm{~cd} / \mathrm{m}^{2}$. 


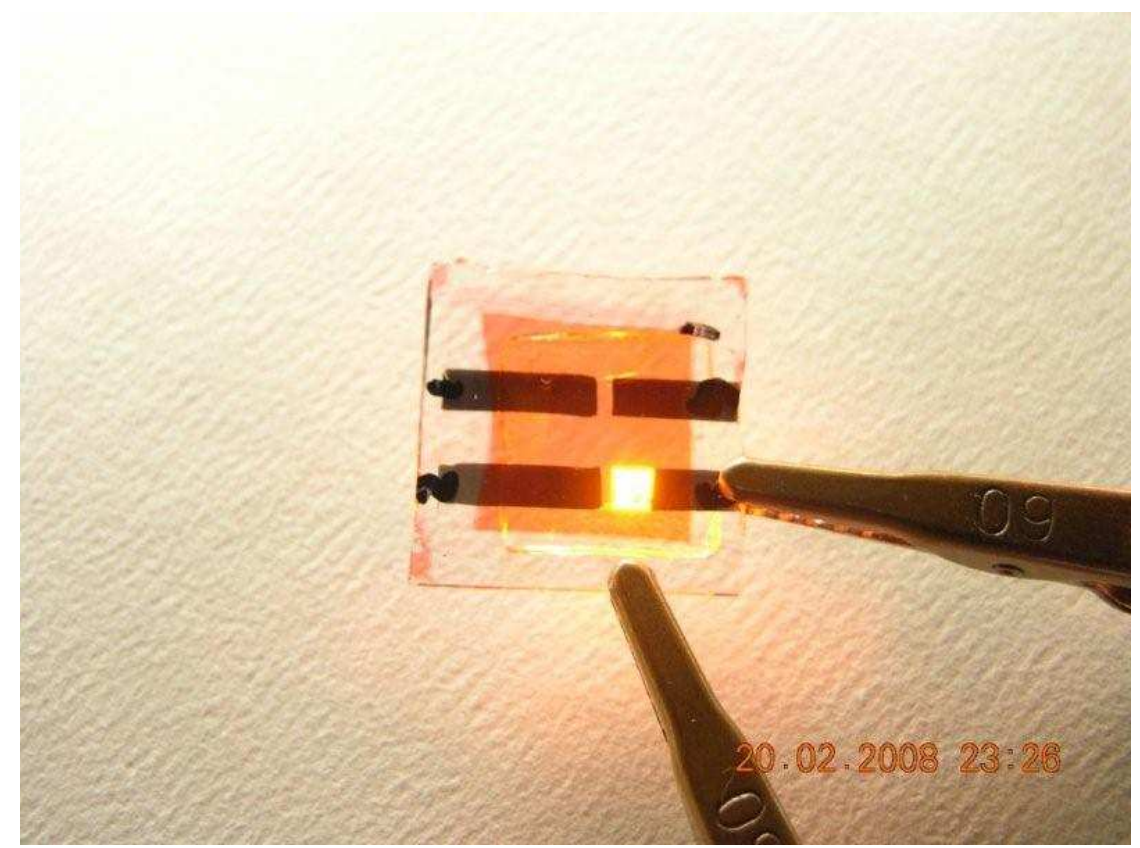

Figura 4.2.5.4 - Registro fotográfico de dispositivo com 7 nm de ETL

\subsubsection{Análise de resultados: filmes Alq3}

Para que seja possível uma análise mais facilitada sobre a relação da espessura do filme de Alq3 com o comportamento elétrico do dispositivo, as figuras e tabela abaixo relacionam resultados obtidos em todos os lotes fabricados com esta finalidade. 


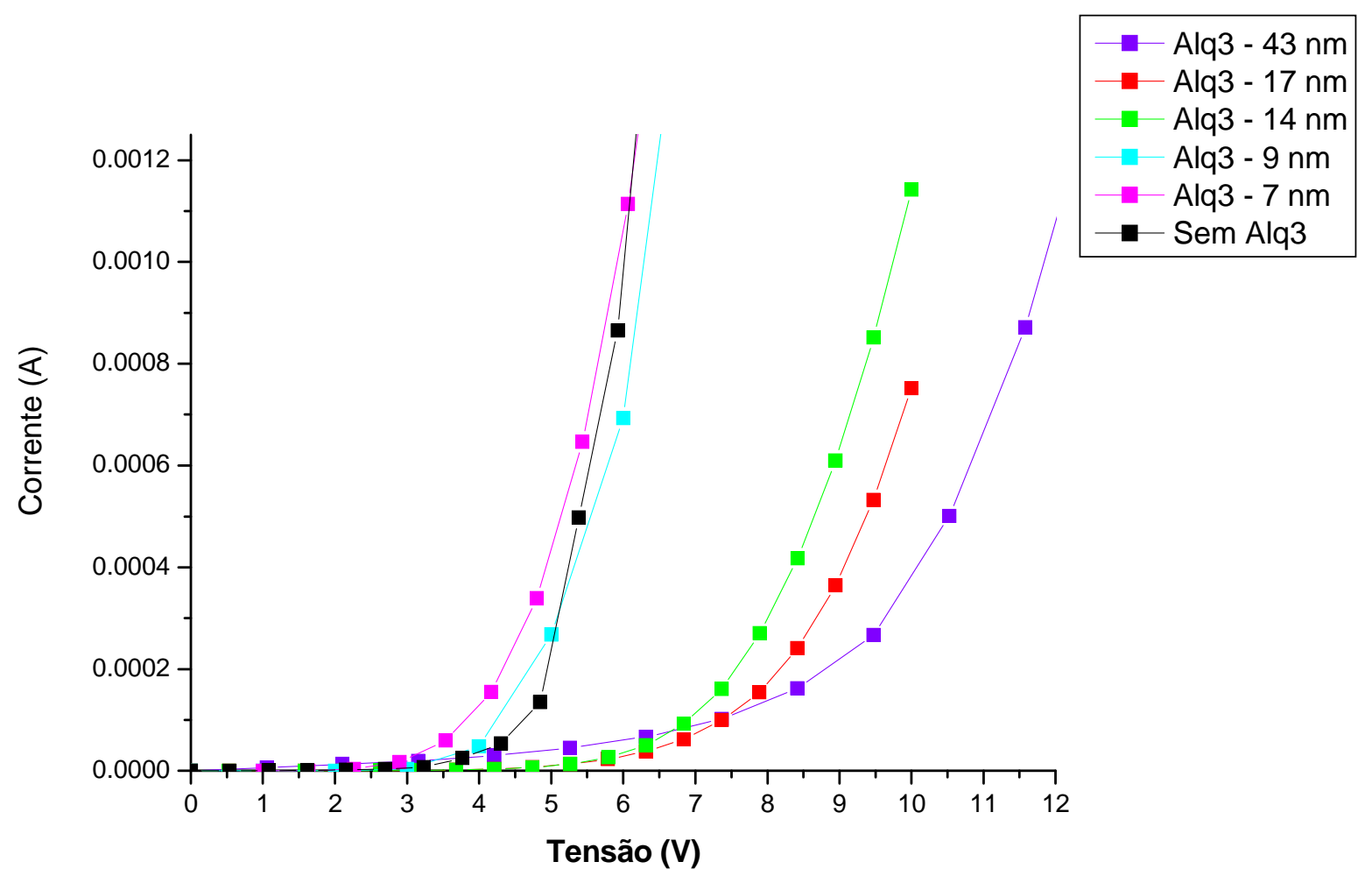

Figura 4.2.6.1 Relação de curvas IxV de dispositivos com e sem ETL

A figura 4.2.6.1 que relaciona as curvas $\mathrm{IxV}$ dos dispositivos sugere que espessuras elevadas de Alq3 implicam em um aumento considerável da tensão de operação destes dispositivos. A medida em que há uma redução da espessura da ETL, ocorre uma redução da tensão de operação, sendo que dispositivos com filmes de Alq3 de $7 \mathrm{~nm}$ e de $14 \mathrm{~nm}$ possuem a tensão de operação similar àquela medida em dispositivos sem ETL. Estas alterações são justificáveis, uma vez que a introdução de uma nova camada implicaria na necessidade de um campo elétrico maior para que a polarização seguida de emissão ocorra. É necessário lembrar que o filme de Alq3, apesar de ser um transportador de elétrons, não é condutor. Sendo assim, é aceitável que, para filmes espessos de Alq3, haja uma elevação na tensão de operação. 


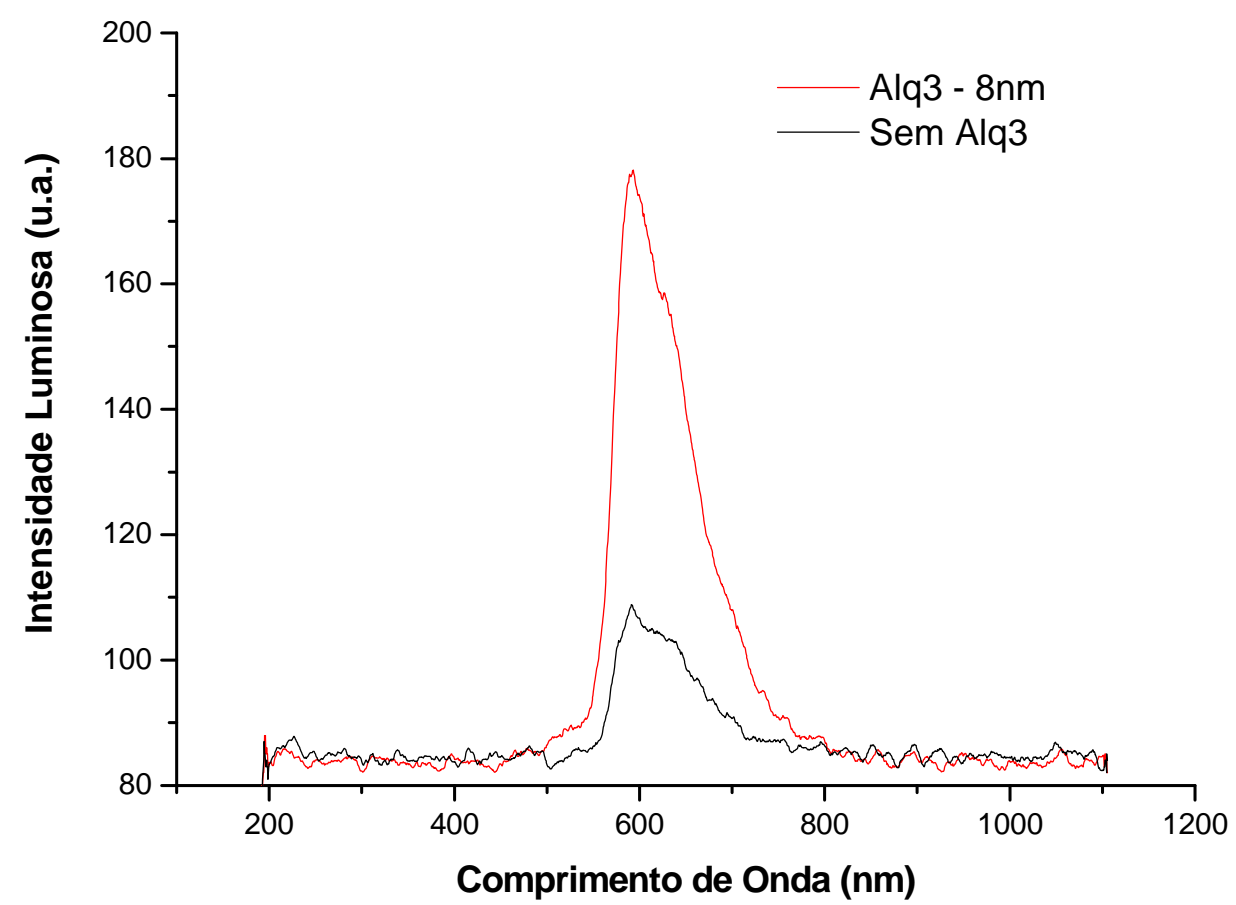

Figura 4.2.6.2 Intensidade $x$ comprimento de onda de dispositivos com e sem ETL de 17nm

A figura 4.2.6.2 acima ilustra o gráfico de intensidade luminosa x comprimento de onda dos dispositivos do lote 6 . Fica aqui claro que a camada transportadora de elétrons não produz nenhuma alteração no pico de emissão neste lote de dispositivos. 


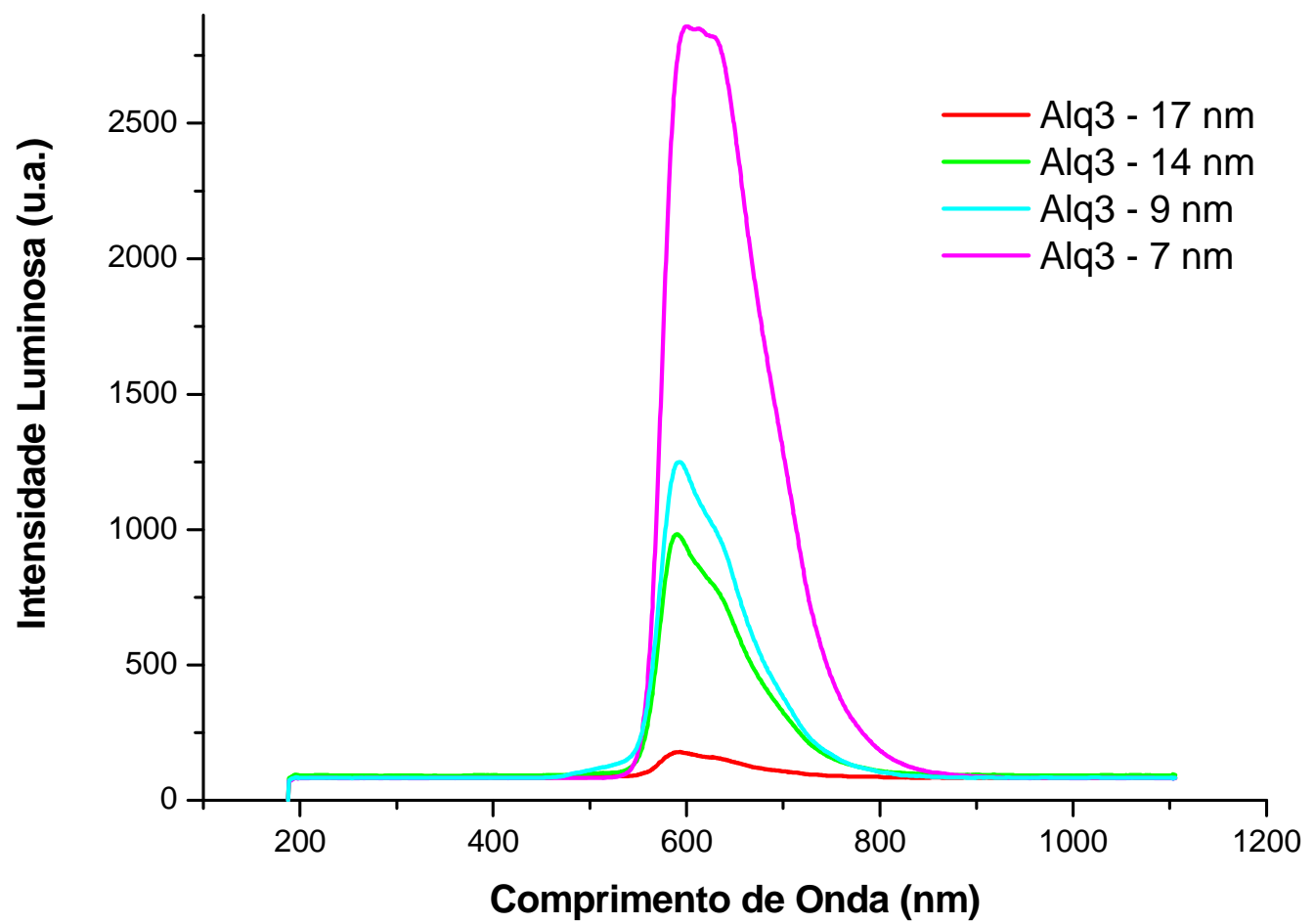

Figura 4.2.6.3 - Intensidade luminosa $x$ comprimento de onda de dispositivos com diferentes espessuras de ETL

O gráfico de intensidade luminosa $\mathrm{x}$ comprimento de onda representado pela figura 4.2.6.3 traz uma comparação óptica de todos os lotes de dispositivos produzidos para estudar o efeito das camadas transportadoras de elétrons em sua eficiência. A representação gráfica dos dispositivos sem ETL nesta mesma figura se tornou inviável por conta da baixa intensidade luminosa destes dispositivos quando comparados aos demais, o que implica na impossibilidade de visualização do pico de emissão.

Ainda se tratando da figura 4.2.6.3, é possível notar que a presença da ETL exerce uma influencia direta no desempenho do dispositivo. A presença do filme mais espesso de Alq3 já implica em um aumento da intensidade luminosa apresentada. Em adição, nota-se que quanto menor a espessura da ETL, maior a emissão apresentada e, ao analisar a tabela 4.2.6.1, maior a eficiência do dispositivo. 
Tabela 4.2.1 - Relação entre estruturas, espessura de Alq3, eficiência luminosa e luminância máxima dos dispositivos

\begin{tabular}{|c|c|c|c|}
\hline Estrutura & $\begin{array}{l}\text { Espessura } \\
\text { Alq3 (nm) }\end{array}$ & $\eta \mathbf{L}(\mathbf{c d} / \mathbf{A})$ & $\begin{array}{c}\text { Luminância } \\
\text { Máxima }\left(\mathbf{c d} / \mathbf{m}^{2}\right)\end{array}$ \\
\hline $\begin{array}{c}\text { ITO/PEDOT:PSS/OC }{ }_{1} \mathrm{C}_{10^{-}} \\
\text {PPV/Al }\end{array}$ & - & 0,023 & 57,5 \\
\hline $\begin{array}{c}\text { ITO/PEDOT:PSS/OC }{ }_{1} \mathrm{C}_{10^{-}} \\
\text {PPV/Alq3/Al }\end{array}$ & 8 & $\mathbf{0 , 0 3 9}$ & 166 \\
\hline $\begin{array}{c}\text { ITO/PEDOT:PSS/OC } \mathrm{CC}_{10} \mathrm{C}^{-} \\
\text {PPV/Alq3/Al }\end{array}$ & 6 & 0,076 & 177 \\
\hline $\begin{array}{c}\text { ITO/PEDOT:PSS/OC } \mathrm{OC}_{10} \mathrm{C}_{10^{-}} \\
\text {PPV/Alq3/Al }\end{array}$ & 3 & 0,075 & 298,9 \\
\hline $\begin{array}{c}\text { ITO/PEDOT:PSS/OC }{ }_{1} \mathrm{C}_{10^{-}} \\
\text {PPV/Alq3/Al }\end{array}$ & 1 & 0,087 & 573,4 \\
\hline
\end{tabular}

A tabela 4.2.6-1 mostra a inversa proporção entre espessura do filme de Alq3 e a eficiência do dispositivo ou a luminância máxima.

Através da análise do comportamento elétrico e óptico destes dispositivos apresentados este trabalho de mestrado reafirma relatos apresentados por Shin-Ju Lin, Han-Yi Ueng and Fuh-Shyang Juang em Effects of Thickness of Organic and Multilayer Anode on Luminance Efficiency $n$ Top-Emission Organic Light Emitting Diodes de que o material Alq3 pode contribuir de maneira significativa para o aumento da emissão como transportador de elétrons, sem alterar o espectro de emissão luminosa.

\subsection{Utilização de compósitos $\mathrm{OC}_{1} \mathrm{C}_{10}$-PPV:Alq3}

\subsubsection{Lote 10}

O primeiro lote de dispositivos desenvolvidos a partir de compósitos OC1C10PPV:Alq3 foi fabricado utilizando uma solução de $7 \mathrm{mg} / \mathrm{ml}$, sendo que $4 \%$ do total em massa de Alq3 e 96\% de OC1C10-PPV.

Os gráficos representados pelas figuras abaixo representam o comportamento elétrico e óptico dos dispositivos deste lote. 


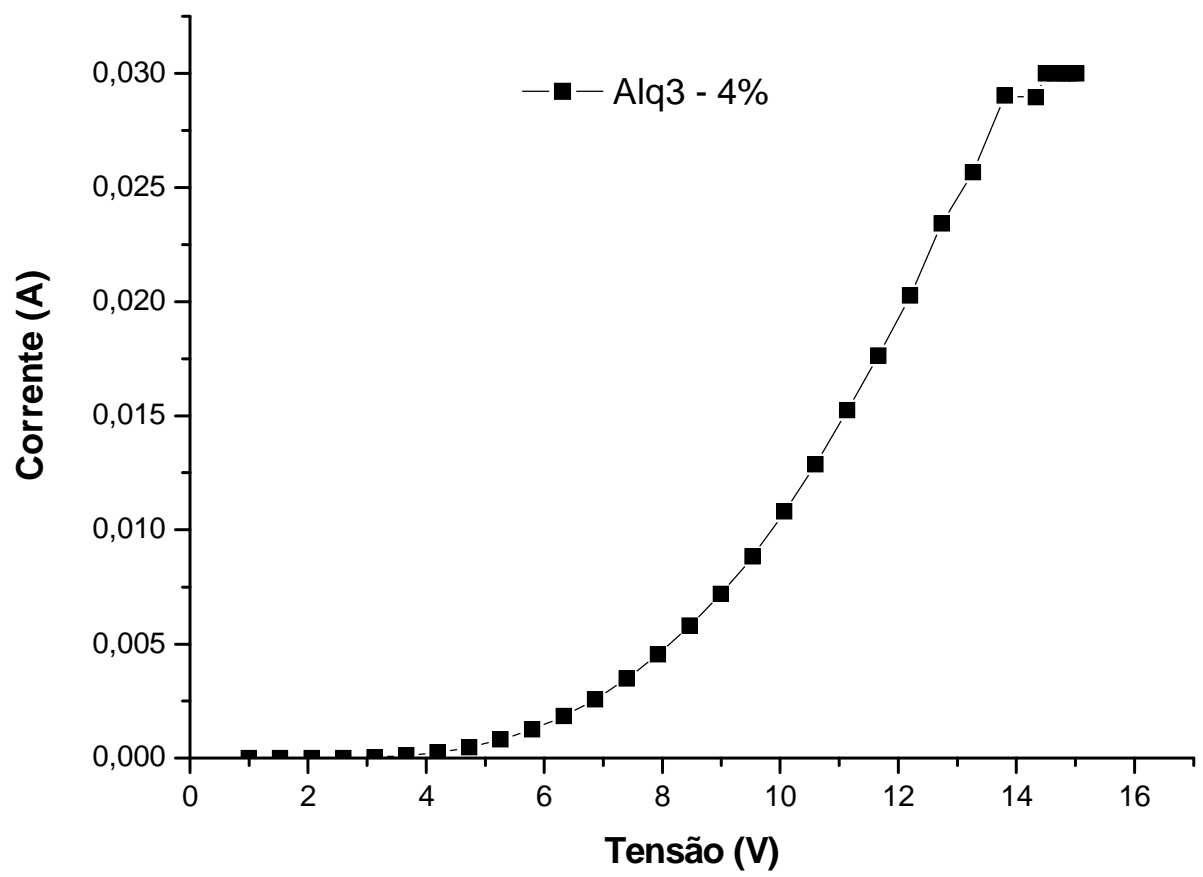

Figura 4.3.1.1 - Curva IxV de dispositivos com 4\% de Alq3 na camada ativa

A figura 4.3.1.1 ilustra o gráfico $\mathrm{IxV}$ dos dispositivos do lote 10. Estes dispositivos apresentam característica de diodo, com uma tensão de operação de aproximadamente $7 \mathrm{~V}$. 


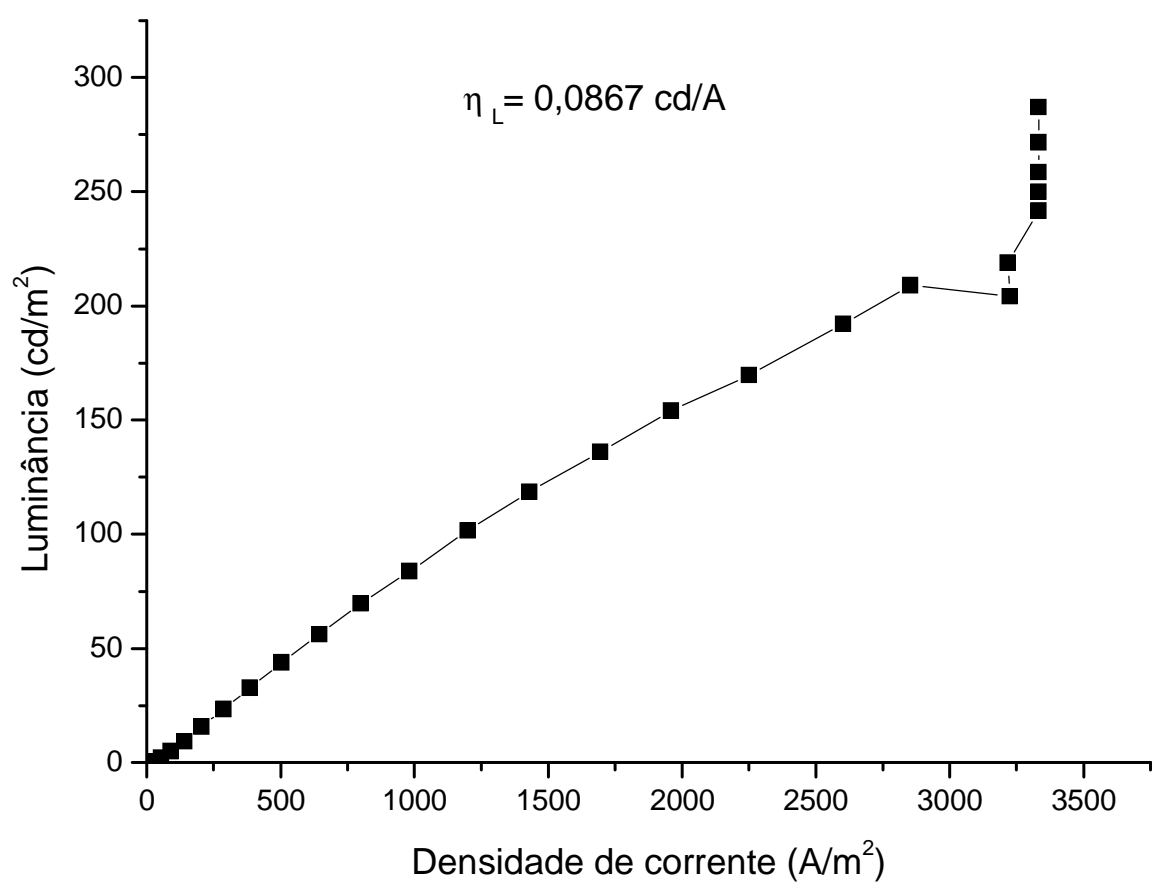

Figura 4.3.1.2 - Luminância x densidade de corrente de dispositivos com 4\% de Alq3 na camada ativa

O gráfico LxJ dos dispositivos do lote 10, representado pela figura 4.3.1.2 apresenta um valor de eficiência luminosa de 0,0876 cd/A. Este valor não apresenta diferença relevante na eficiência luminosa entre dispositivos que continham 4\% de Alq3 na camada ativa e dispositivos que não continham. 


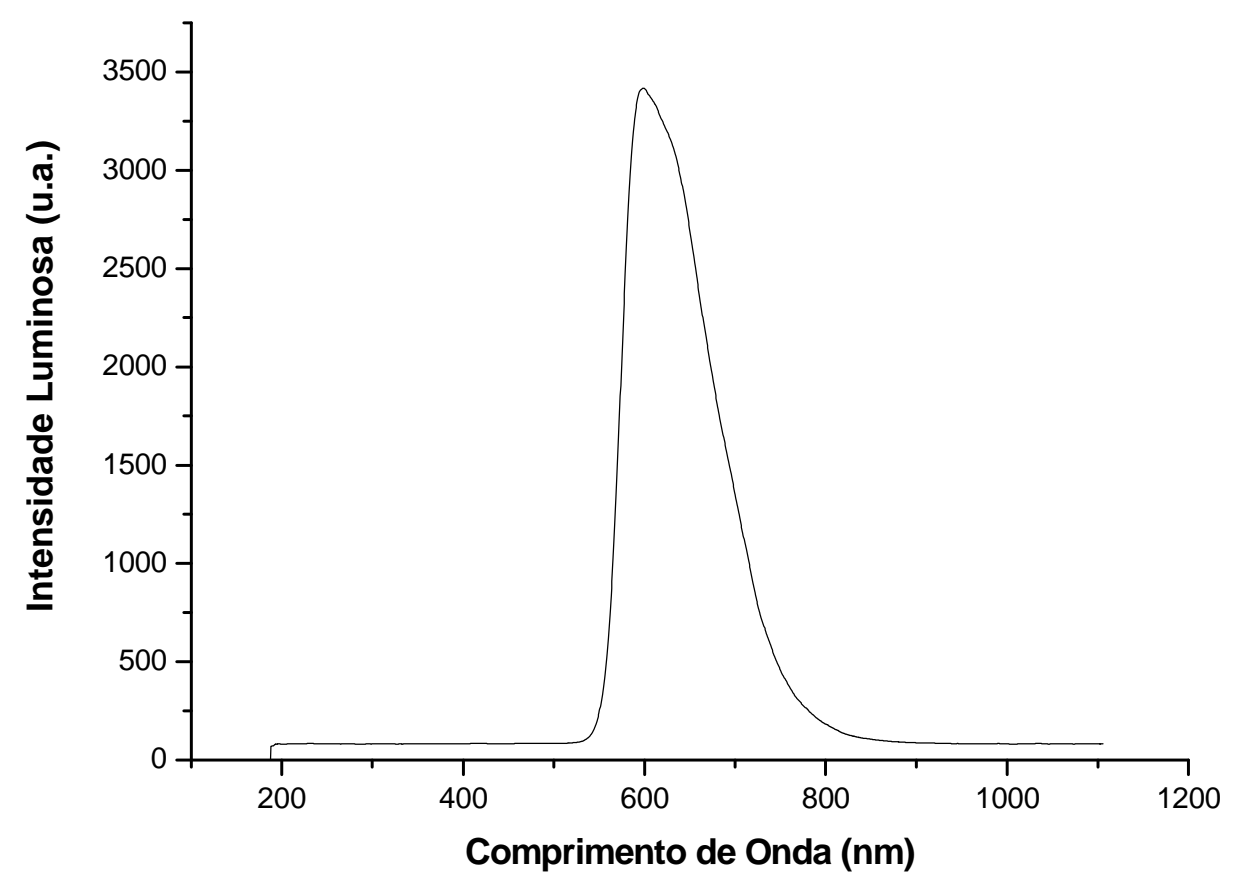

Figura 4.3.1.3 - Intensidade luminosa $x$ comprimento de onda de dispositivos com $4 \%$ de Alq3 na camada ativa

Apesar da adição de um novo material eletroluminescente na camada ativa, podese notar através do gráfico de intensidade luminosa x comprimento de onda, ilustrado pela figura 4.3.1.3, que não houve alteração significativa do pico de emissão dos dispositivos caracterizados, ou seja, o valor de $600 \mathrm{~nm}$ manteve-se constante apesar da introdução de Alq3 na solução polimérica. Entretanto, serão utilizadas as coordenadas de cromaticidade para que a influência do Alq3 na camada ativa fosse, de fato, analisada. Para dispositivos deste lote, foram obtidos os valores de $\mathrm{x}=0,5888$ e $\mathrm{y}=$ 0,4112 e a representação destes valores no diagrama de cromaticidade é dada pela figura 4.3.1.4. 


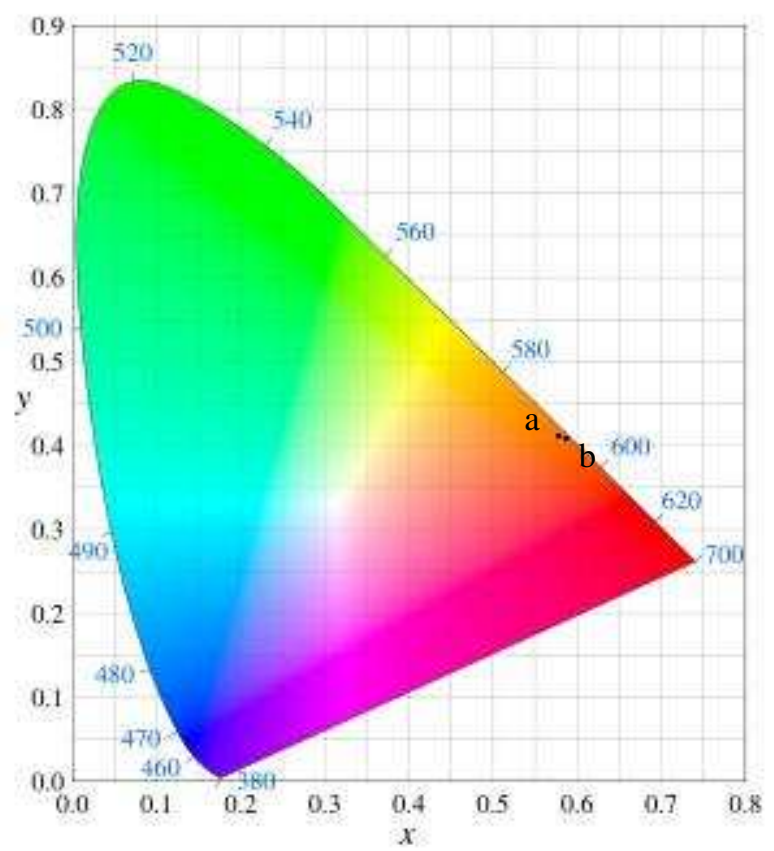

Figura 4.3.1.4 - Diagrama de cromaticidade de dispositivo com 4\% de Alq3 na camada ativa.

A introdução de $4 \%$ de Alq3 na solução polimérica parece não ter alterado a emissão dos dispositivos com relação aos dispositivos com a arquitetura inicial produzidos neste trabalho.

A figura 4.3.1.5 abaixo, ilustra o registro fotográfico de um dispositivo do lote 10.

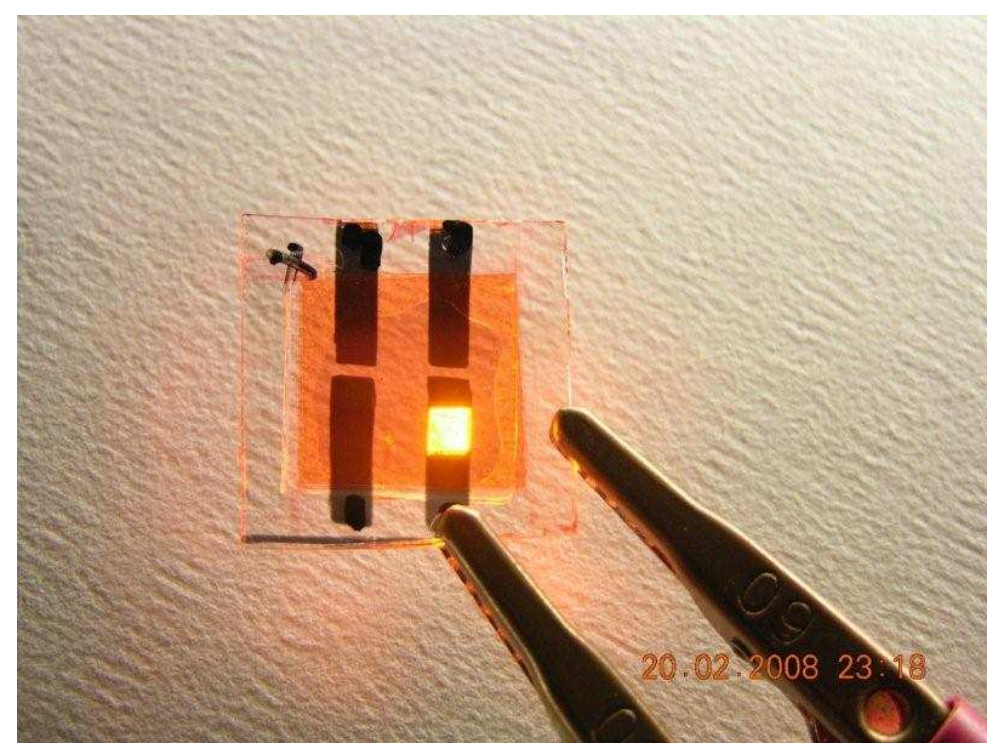

Figura 4.3.1.5 - Registro fotográfico de dispositivo com 4\% de Alq3 na camada ativa. 


\subsubsection{Lote 11}

Este conjunto de dispositivos foi desenvolvido com uma solução que continha $8 \%$ de Alq3 em massa e $92 \%$ de OC1C10-PPV. As figuras que se seguem representam o comportamento dos dispositivos.

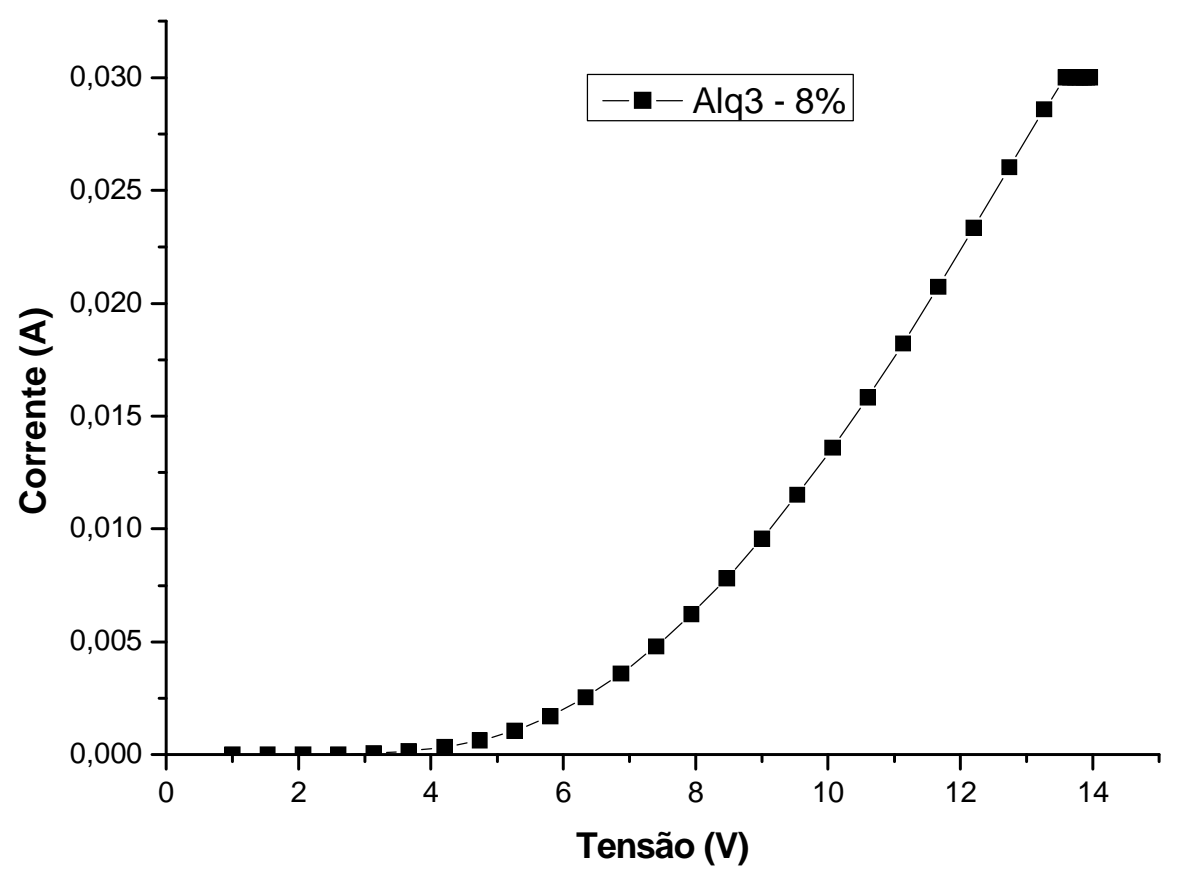

Figura 4.3.2.1 - Curva IxV de dispositivo com $8 \%$ de Alq3 na camada ativa.

A figura 4.3.2.1 ilustra o comportamento de diodo dos dispositivos do lote 11, com uma tensão de operação de aproximadamente $6,5 \mathrm{~V}$. 


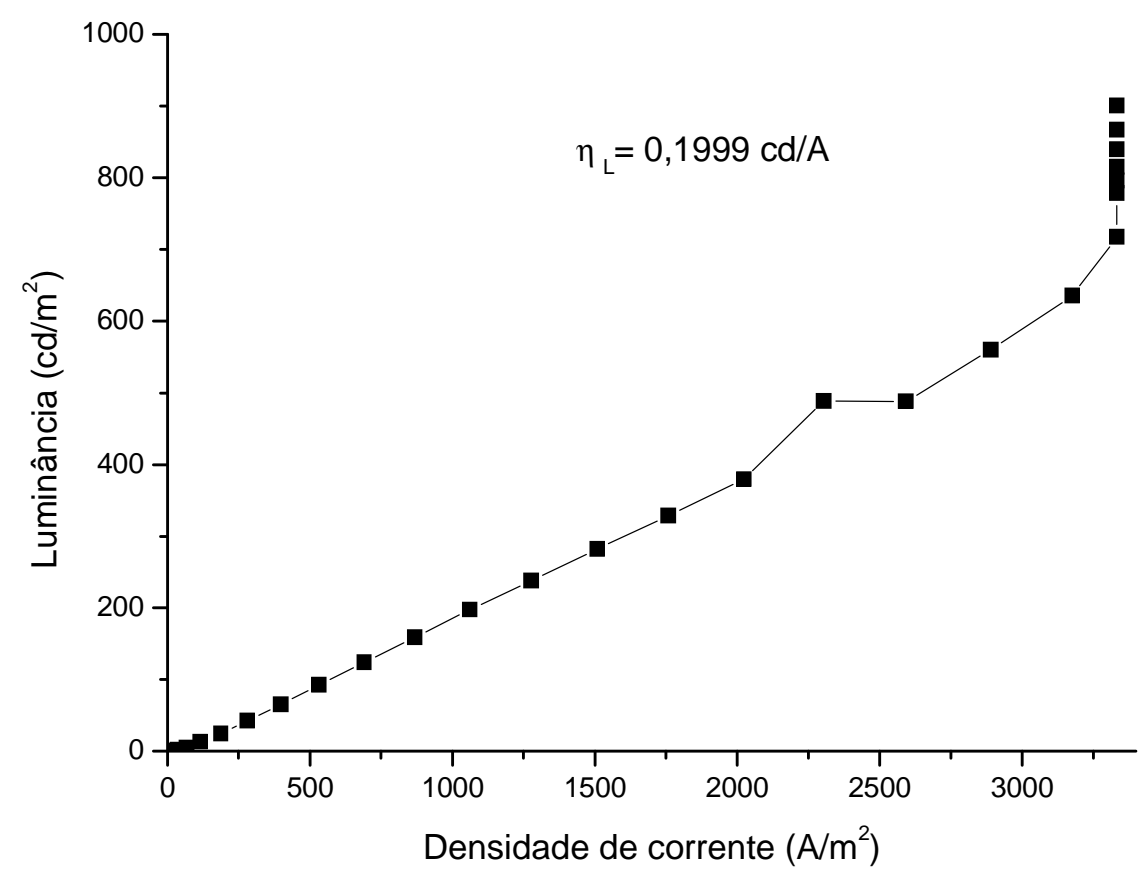

Figura 4.3.2.2 - Luminância x Densidade de corrente de dispositivo com 8\% de Alq3 na camada ativa.

A figura 4.3.2.2 ilustra a relação LxJ dos dispositivos do lote 11. Através de cálculo realizado utilizando um ponto da região linear do gráfico, observa-se um aumento significante da eficiência luminosa dos dispositivos do lote $11(0,1999 \mathrm{~cd} / \mathrm{A})$ com relação aos demais fabricados anteriormente. 


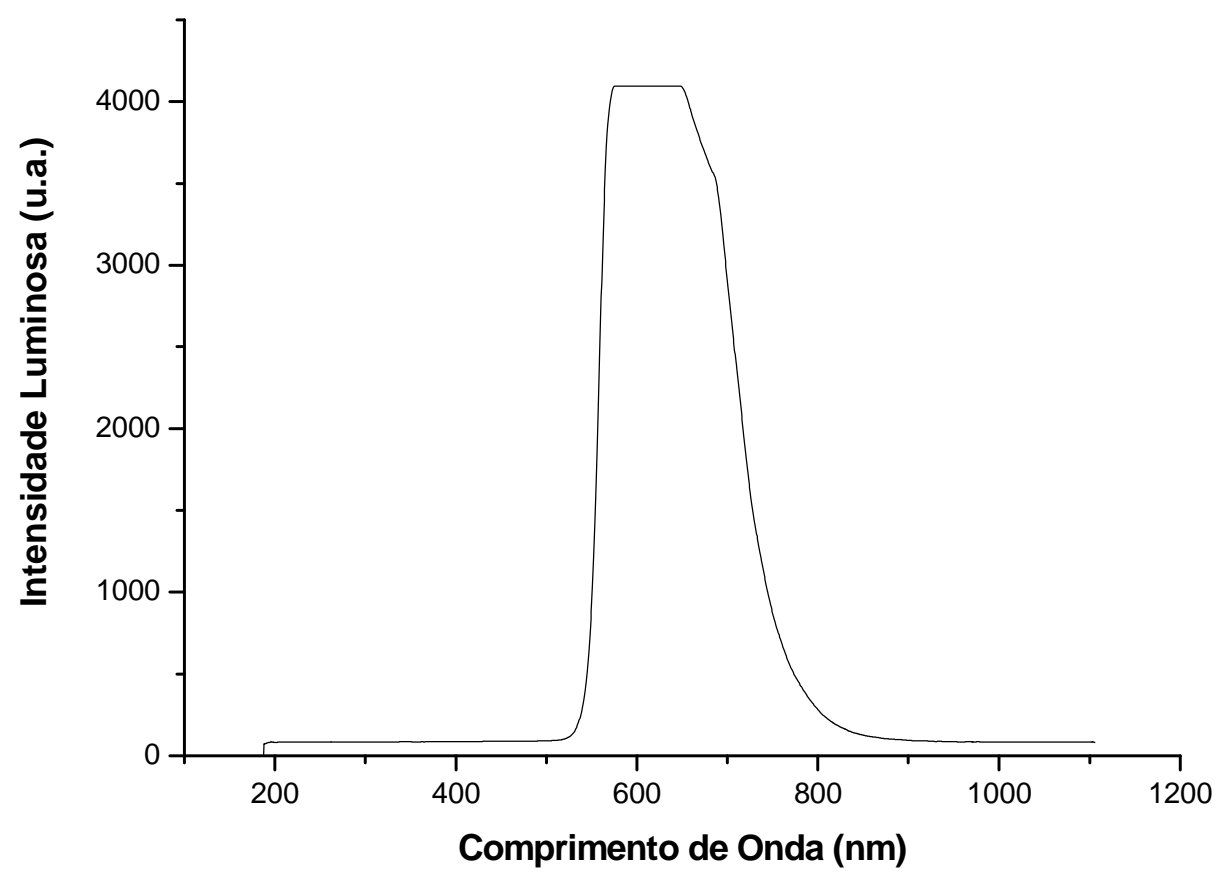

Figura 4.3.2.3 - Intensidade luminosa $x$ Comprimento de onda de dispositivo com $8 \%$ de Alq3 na camada ativa.

$\mathrm{O}$ gráfico de intensidade luminosa $\mathrm{x}$ comprimento de onda ilustrado pela figura 4.3.2.3 indica a impossibilidade de visualização do pico de emissão decorrente da alta luminância do dispositivo. Deste modo, foram registradas as coordenadas de cromaticidade para que fosse possível analisar a alteração do espectro de emissão dos dispositivos do lote 11. Para o valor utilizado no cálculo de eficiência luminosa, tem-se os valores de $\mathrm{x}=0,5565$ e $\mathrm{y}=0,4435$. A figura 4.3.2.4 abaixo ilustra o diagrama de cromaticidade do lote 11 (a) e de um dispositivo com a estrutura ITO/PEDOT:PSS/OC ${ }_{1} \mathrm{C}_{10}$-PPV/Al (b) para comparação. 


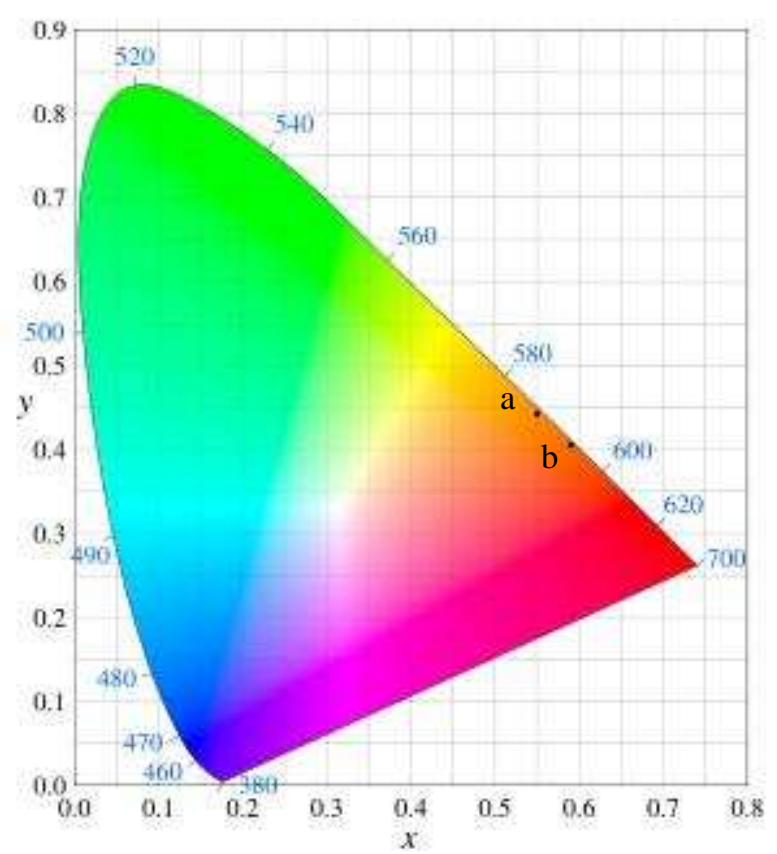

Figura 4.3.2.4 - Diagrama de cromaticidade de dispositivo com $8 \%$ de Alq3 na camada ativa.

É possível notar, através da figura 4.3.2.4, certa alteração no diagrama de cromaticidade a partir da introdução de $8 \%$ de Alq3 no filmes emissivo. Houve um deslocamento para uma região com comprimentos de onda menores. Como já foi mencionado, o Alq3 emite em um comprimento de onda de aproximadamente $530 \mathrm{~nm}$. Sendo assim, fica clara a contribuição emissiva do Alq3 nestes dispositivos.

A figura 4.3.2.5 abaixo ilustra o registro fotográfico de um dispositivo do lote 11. 


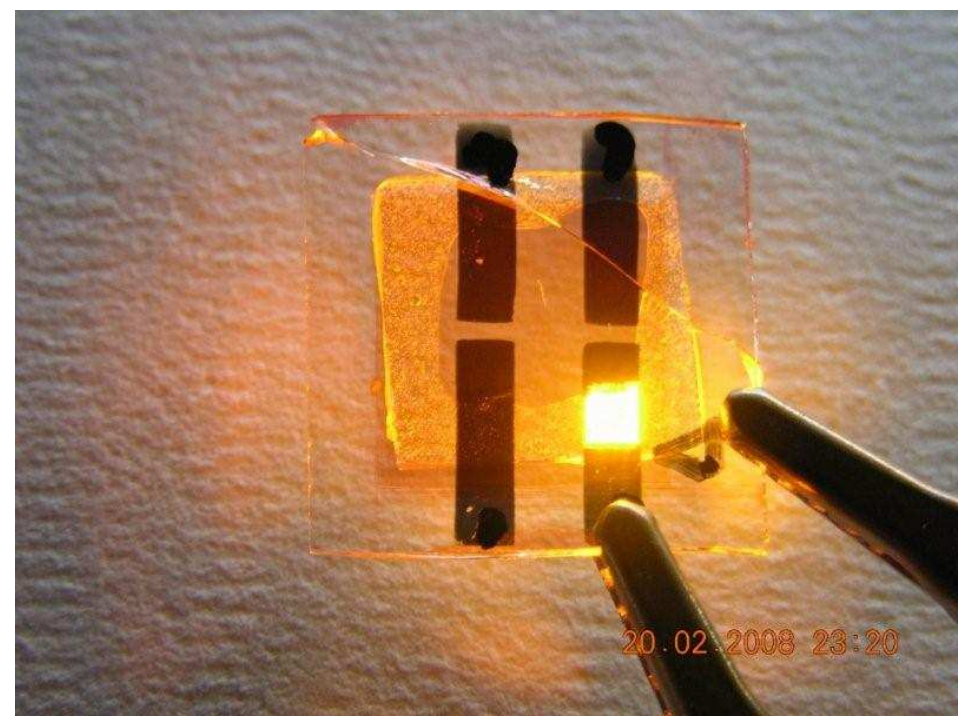

Figura 4.3.2.5 - Registro fotográfico de dispositivo com $8 \%$ de Alq3 na camada ativa.

\subsubsection{Lote 12}

No lote 12 foram fabricados dispositivos com 10\% de Alq3 na solução e $90 \%$ de $\mathrm{OC}_{1} \mathrm{C}_{10}$-PPV. Os gráficos a seguir descrevem o comportamento elétrico e óptico destes dispositivos.

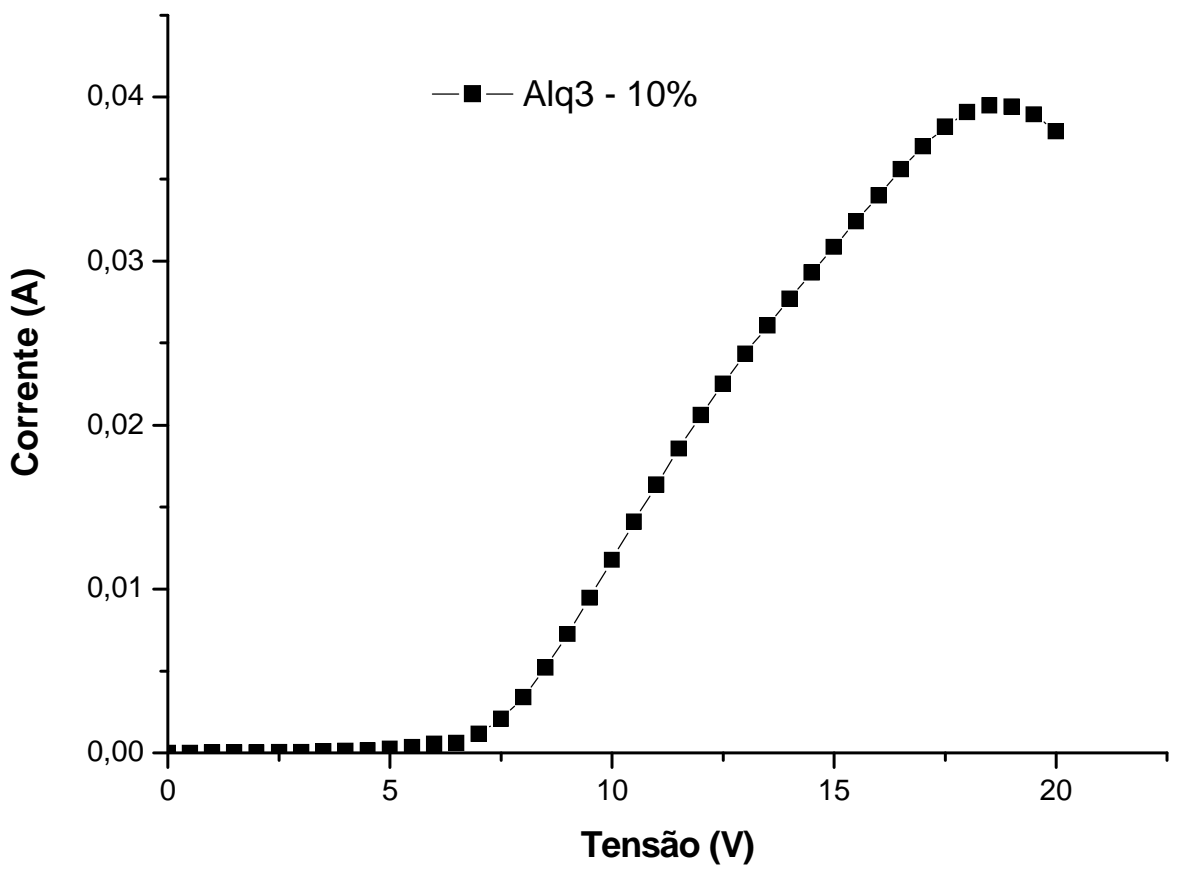

Figura 4.3.3.1 - Curva IxV de dispositivo com $10 \%$ de Alq3 na camada ativa. 
A curva IxV de dispositivos do lote 12 é representado pela figura 4.3.3.1. Nota-se no gráfico o comportamento de diodo apresentado pelo dispositivo, com tensão de operação de aproximadamente $8 \mathrm{~V}$.

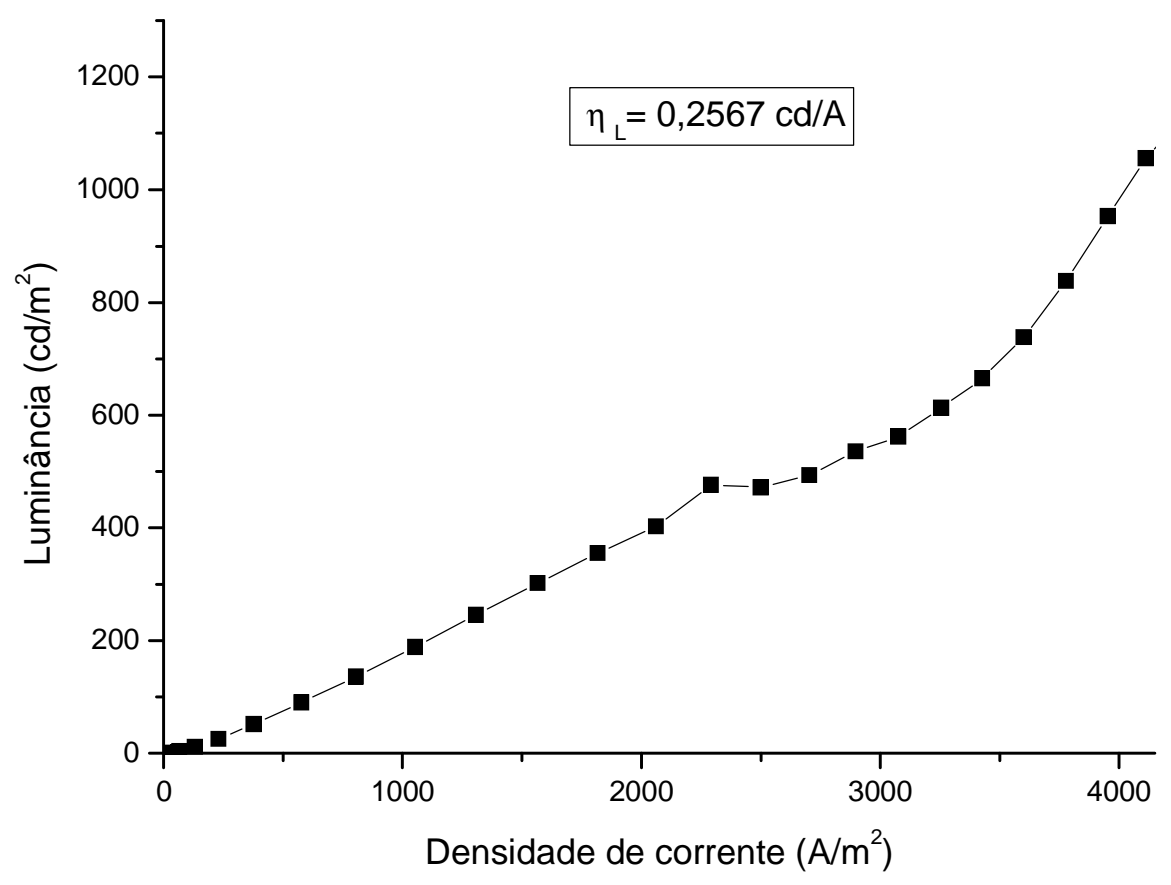

Figura 4.3.3.2 - Luminância x Densidade de corrente de dispositivo com 10\% de Alq3 na camada ativa.

A maior eficiência luminosa apresentada neste trabalho de mestrado é observada nos dispositivos do lote 12 . O cálculo foi realizado com um ponto da região linear do gráfico LxJ ilustrado pela figura 4.3.3.2. Assim como ocorreu com os dispositivos do lote 11, não foi possível obter curvas de intensidade luminosa x comprimento de onda. Desta maneira, para o mesmo ponto utilizado no cálculo de eficiência luminosa, foi registrado os valores das coordenadas de cromaticidade: $\mathrm{x}=0,5417$ e $\mathrm{y}=0,4581$. A figura 4.3.3.3 abaixo ilustra o diagrama de cromaticidade dos dispositivos do lote 12 (a) e de um dispositivo com a estrutura ITO/PEDOT:PSS/OC $\mathrm{C}_{10}$-PPV/Al (b) para comparação. 


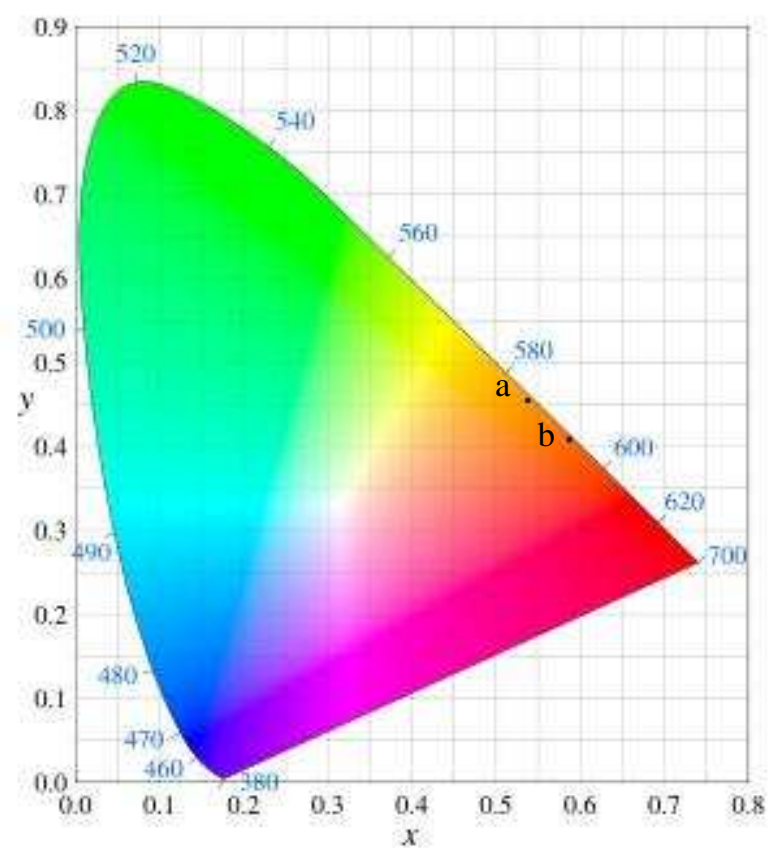

Figura 4.3.3.3 - Diagrama de cromaticidade de dispositivo com $10 \%$ de Alq3 na camada ativa.

Através do diagrama de cromaticidade, pode-se observar novamente a uma pequena contribuição de emissão proveniente de Alq3.

A figura 4.3.3.4 abaixo ilustra o registro fotográfico de dispositivo do lote 12 .

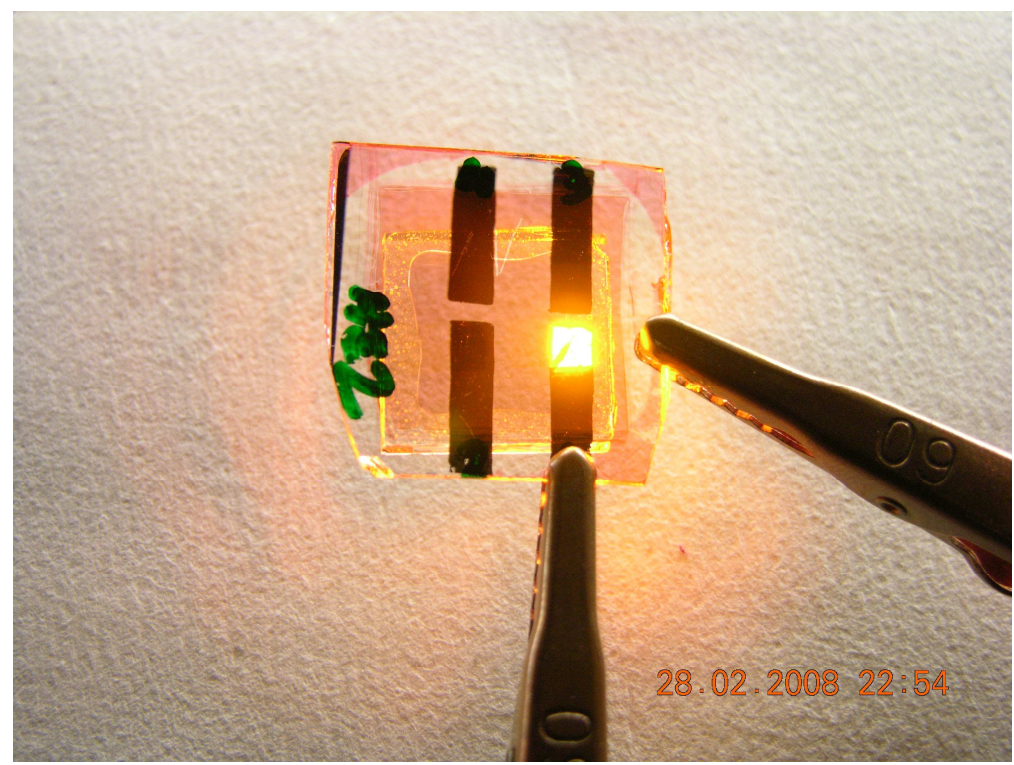

Figura 4.3.3.4 - Registro fotográfico de dispositivo com $10 \%$ de Alq3 na camada ativa. 


\subsubsection{Lote 13}

Os dispositivos do lote 13 foram fabricados com uma solução que continha $13 \%$ de Alq3. A caracterização elétrica e óptica dos dispositivos deste lote é apresentada a seguir.

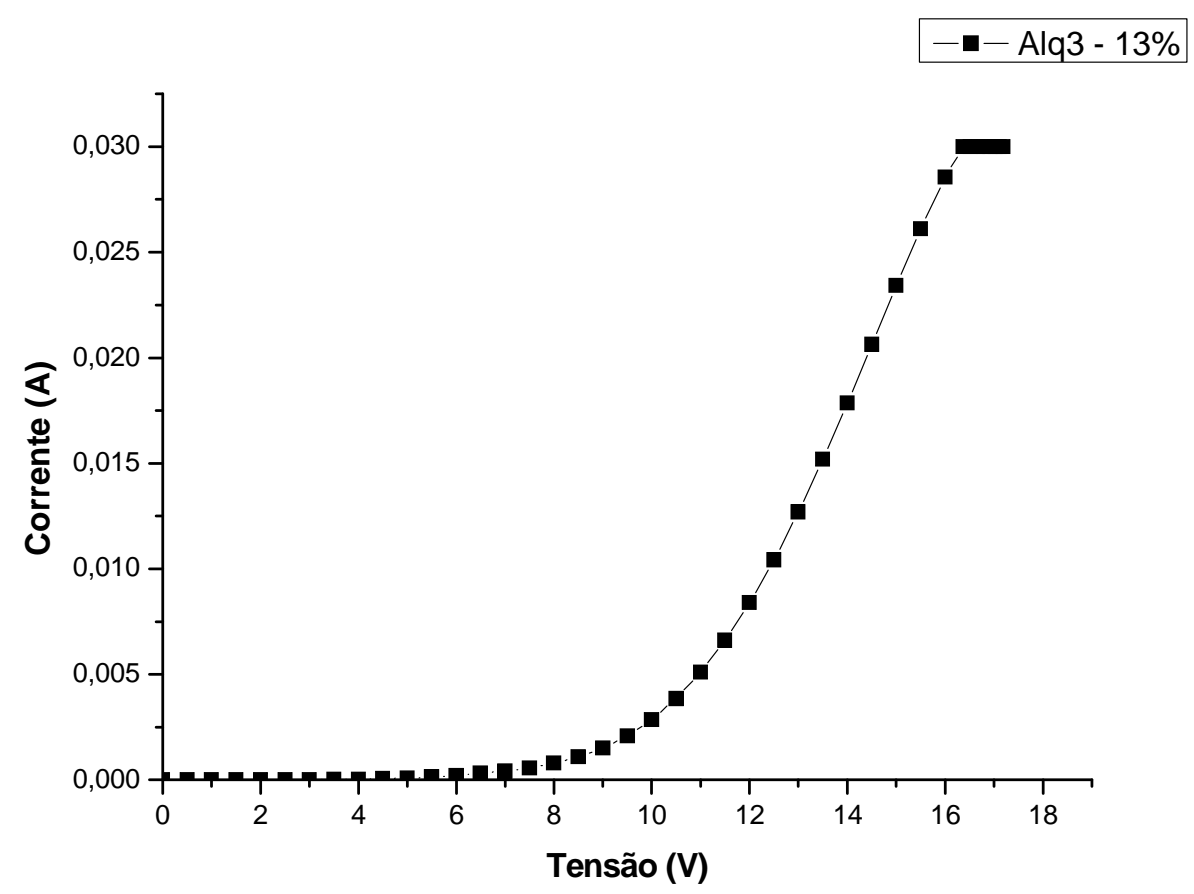

Figura 4.3.4.1 - Curva IxV de dispositivo com $13 \%$ de Alq3 na camada ativa.

A figura 4.3.4.1 acima ilustra o comportamento de diodo apresentado por dispositivos do lote 13, cuja tensão de operação está próxima de 10V. 


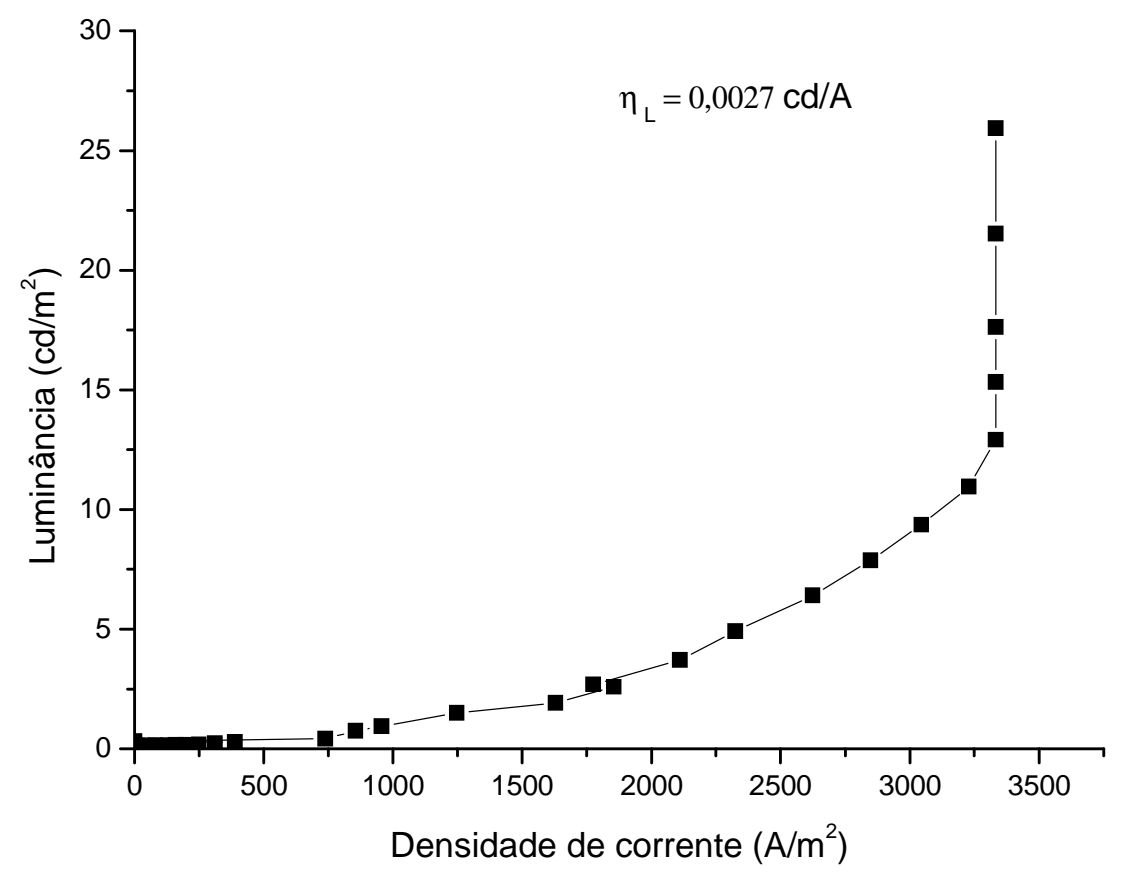

Figura 4.3.4.2 - Luminância $x$ Densidade de corrente de dispositivo com $13 \%$ de Alq3 na camada ativa.

A figura 4.3.4.2 ilustra a relação entre a densidade de corrente e a luminância dos dispositivos do lote 13. Nota-se também uma grande queda da eficiência luminosa dos dispositivos deste lote quando comparados aos resultados apresentados por dispositivos dos lotes 11 e 12. É interessante notar também que o valor da eficiência luminosa apresentado por dispositivos do lote 17 são muito próximos do valor apresentado por dispositivos do lote 9, ou seja, dispositivos com a estrutura ITO/PEDOT:PSS/OC ${ }_{1} \mathrm{C}_{10^{-}}$ $\mathrm{PV} / \mathrm{Alq} 3(1 \mathrm{~nm}) / \mathrm{Al}$.

A figura 4.3.4.4 abaixo mostra o diagrama de cromaticidade dos dispositivos deste lote para $\mathrm{x}=0,4619$ e $\mathrm{y}=0,5379$. Nota-se, também neste caso, certa diferença na localização do ponto referente ao dispositivo do lote 13 (a) e o ponto relacionado a um dispositivo com a estrutura ITO/PEDOT:PSS/OC $\mathrm{C}_{10}$-PPV/Al (b). 


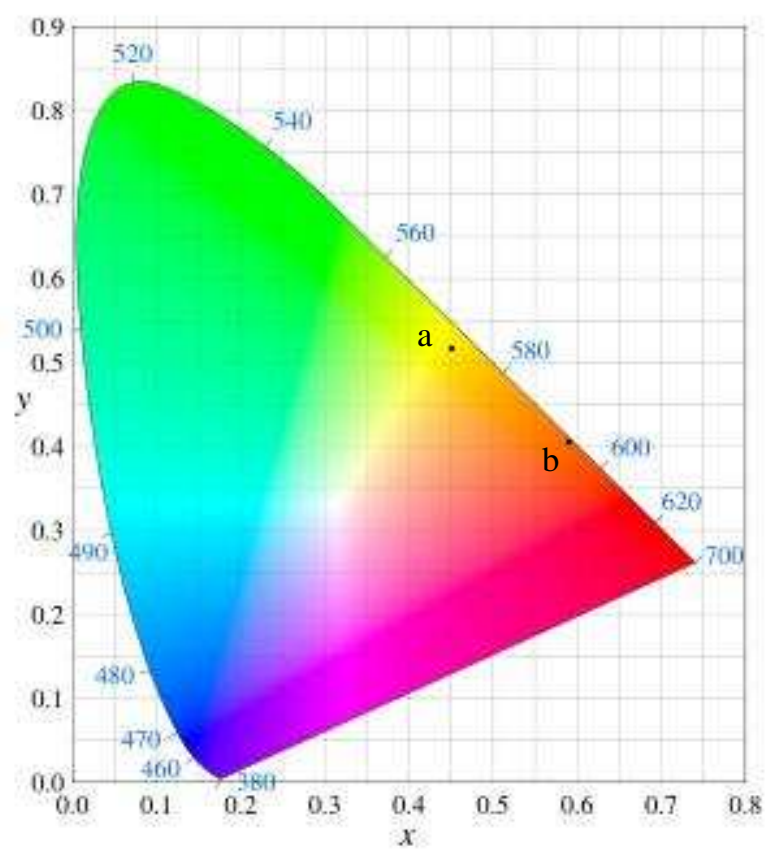

Figura 4.3.4.3 - Diagrama de cromaticidade de dispositivo com $13 \%$ de Alq3 na camada ativa.

O aumento da concentração de Alq3 na solução polimérica resultou em uma influência ainda maior deste material na emissão dos dispositivos. É fácil perceber o deslocamento da emissão no diagrama de cromaticidade acima. O ponto "a", que representa a emissão dos dispositivos produzidos neste lote se aproxima do pico de emissão do material transportador de elétrons e está mais afastado do ponto "b" que os dispositivos do lote 12 .

\subsubsection{Lote 14}

Na produção dos dispositivos do lote 14 foi utilizada uma solução com $16 \%$ de Alq3. As figuras a seguir ilustram o comportamento elétrico e óptico dos dispositivos fabricados. 


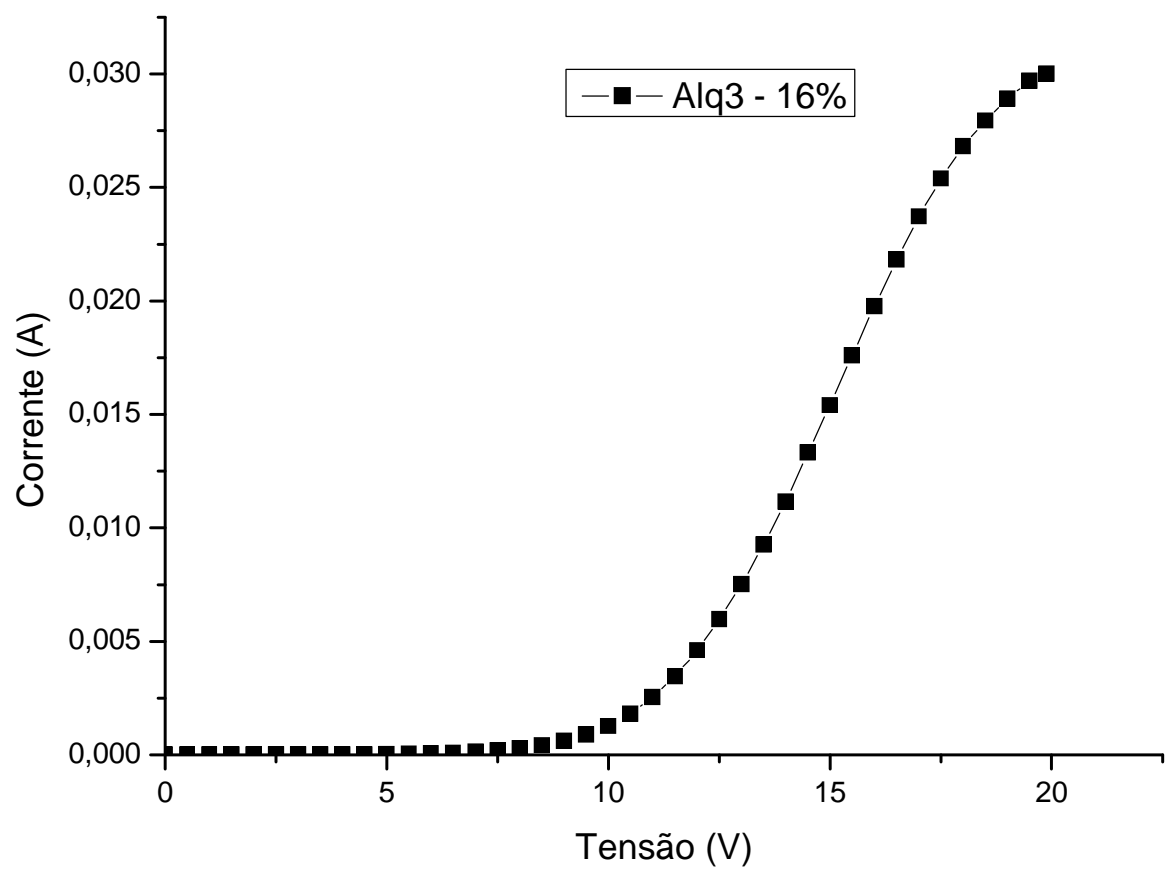

Figura 4.3.5.1 - Curva IxV de dispositivo com 16\% de Alq3 na camada ativa.

A figura 4.3.5.1 ilustra o comportamento de diodo exibido por dispositivos do lote 14 deste trabalho. Nota-se uma tensão de operação de aproximadamente $12 \mathrm{~V}$.

A figura 4.3.5.2 abaixo ilustra a relação entre a densidade de corrente e a luminância dos dispositivos deste lote. Foi utilizado um ponto da região linear do gráfico para calcular o valor de $0,034 \mathrm{~cd} / \mathrm{A}$, referente a eficiência luminosa do dispositivo. 


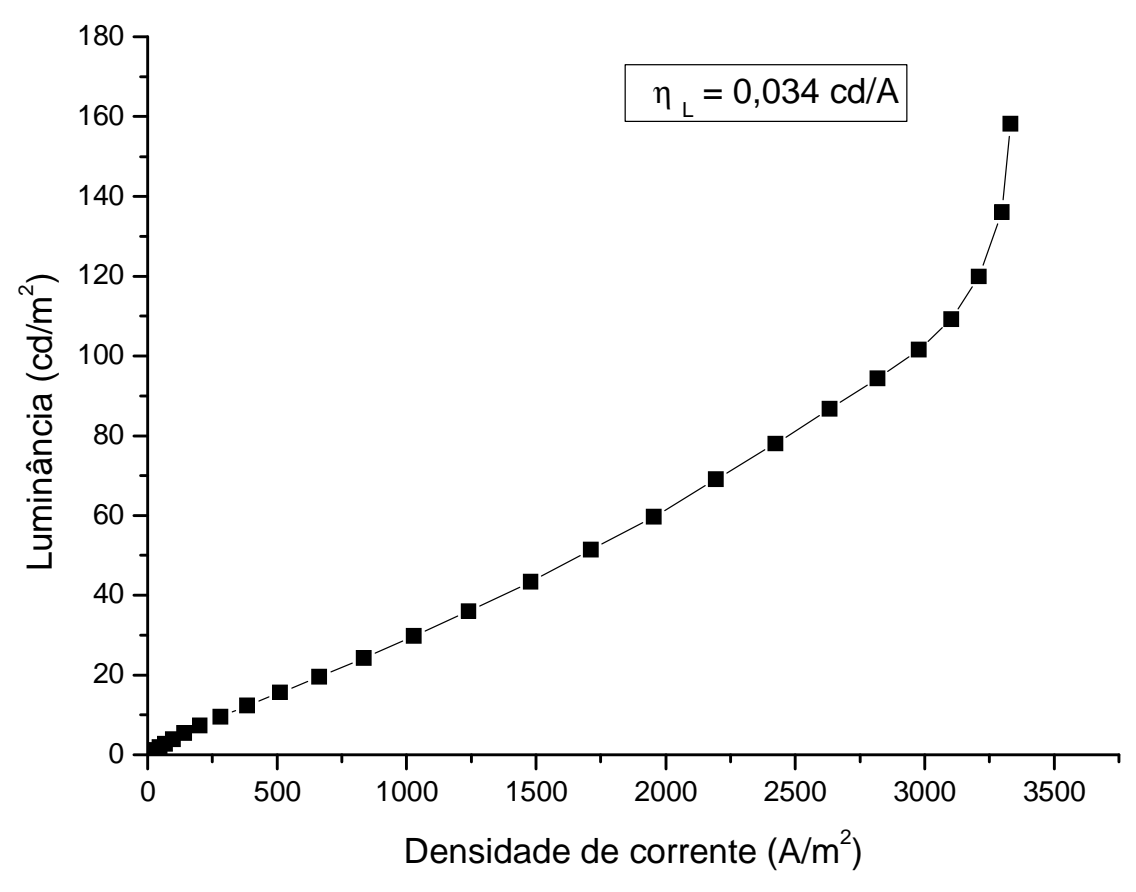

Figura 4.3.5.2 - Luminância x Densidade de corrente de dispositivo com 16\% de Alq3 na camada ativa.

O diagrama de cromaticidade do dispositivo de referência e de um dispositivo do lote 14 é representados na figura 4.3.5.3. As coordenadas de cromaticidade extraídas para dispositivos deste lote são $\mathrm{x}=0,4278$ e $\mathrm{y}=0,5719$. É possível notar o aumento da distância entre os dois pontos, indicando, mais uma vez, a relação da influência do Alq3 na emissão do dispositivo e a concentração deste material utilizada na solução polimérica. 


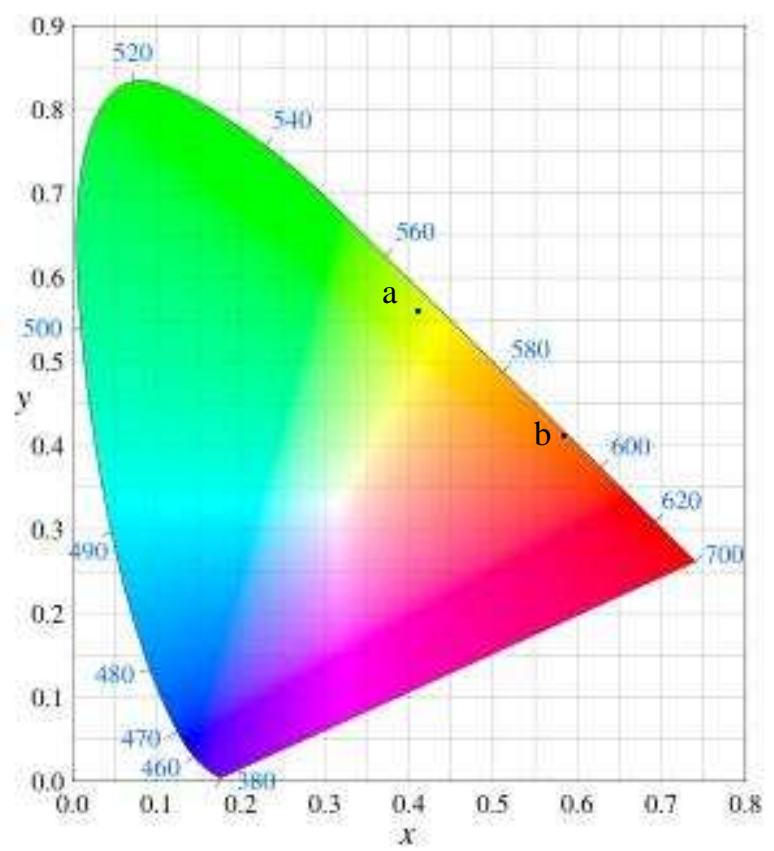

Figura 4.3.5.3 - Diagrama de cromaticidade de dispositivo com 16\% de Alq3 na camada ativa.

$\mathrm{Na}$ figura 4.3.5.4 abaixo pode-se observar o registro fotográfico de um dispositivo do lote 14.

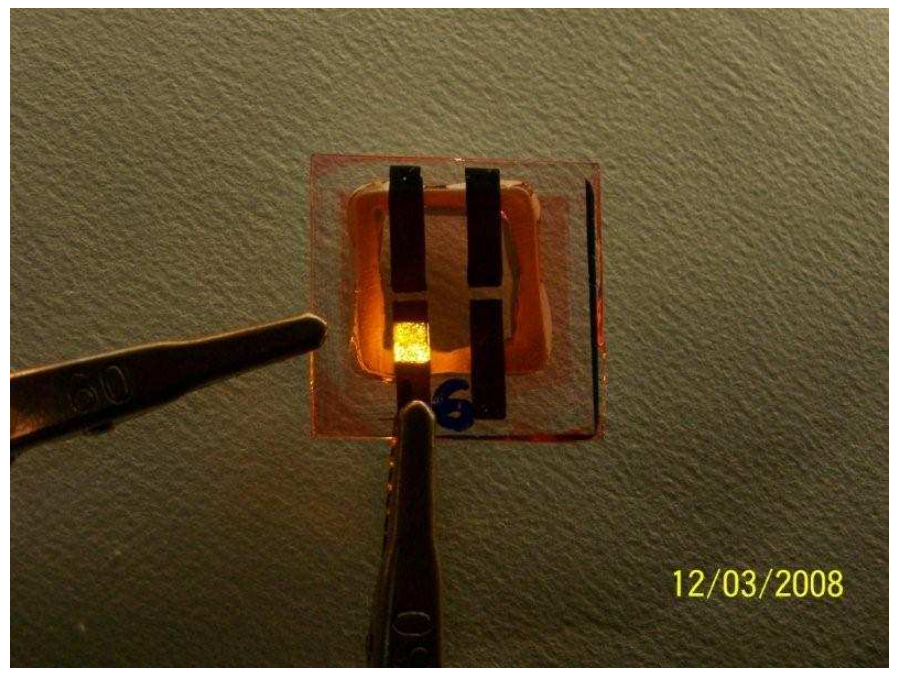

Figura 4.3.5.4 - Registro fotográfico de dispositivo com $16 \%$ de Alq3 na camada ativa.

\subsubsection{Lote 15}


No lote 15 foi utilizada uma solução polimérica com 19\% de Alq3 e 81\% de $\mathrm{OC}_{1} \mathrm{C}_{10}$-PPV, em massa. Os dados referentes à caracterização elétrica e óptica destes dispositivos são apresentados a seguir.

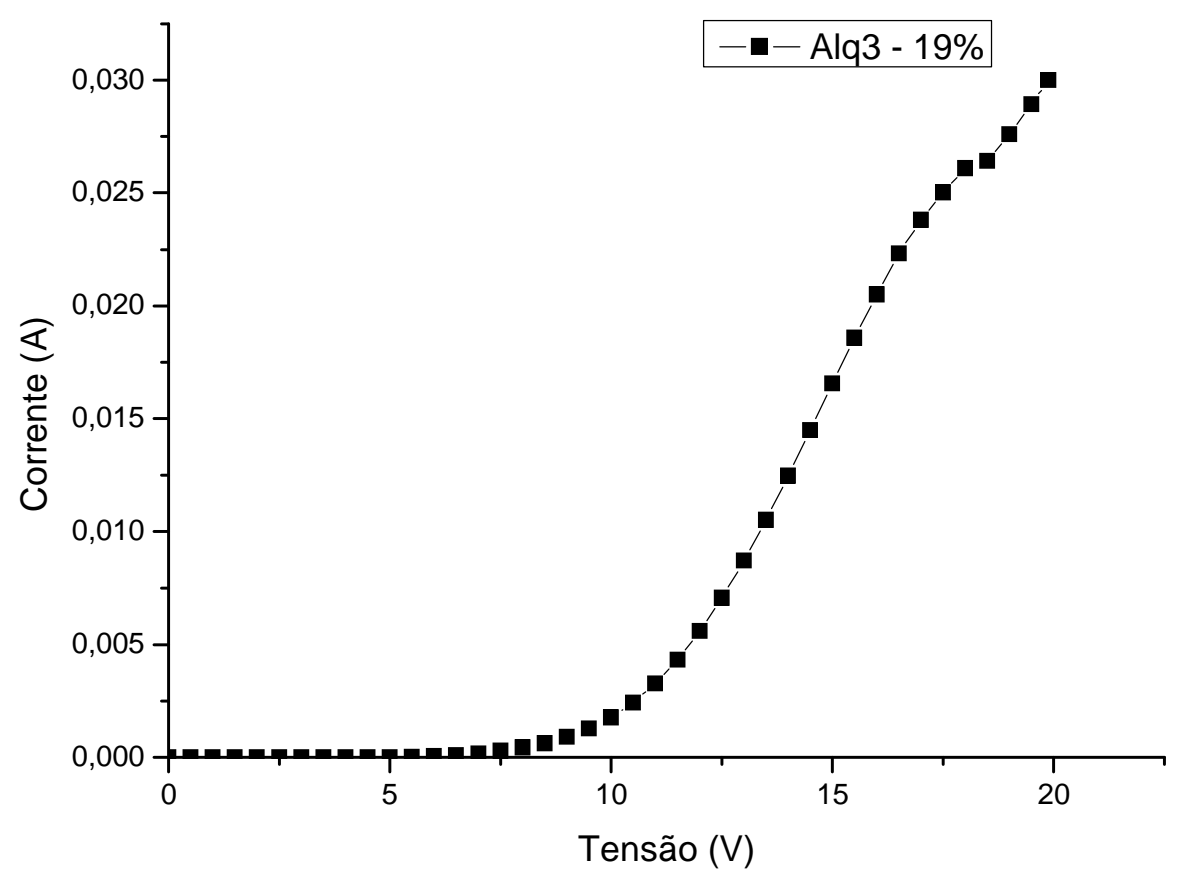

Figura 4.3.6.1 -Curva IxV de dispositivo com 19\% de Alq3 na camada ativa.

A figura 4.3.6.1 ilustra a curva $\mathrm{IxV}$ dos dispositivos do lote 15. Pode-se notar o comportamento de diodo exibido e uma tensão de operação de aproximadamente $12 \mathrm{~V}$.

A figura 4.3.6.2 a seguir ilustra a curva LxJ dos dispositivos deste lote. Nota-se um pequeno acréscimo na eficiência luminosa apresentada em relação ao lote anterior, calculada a partir de um ponto da região linear do gráfico. 


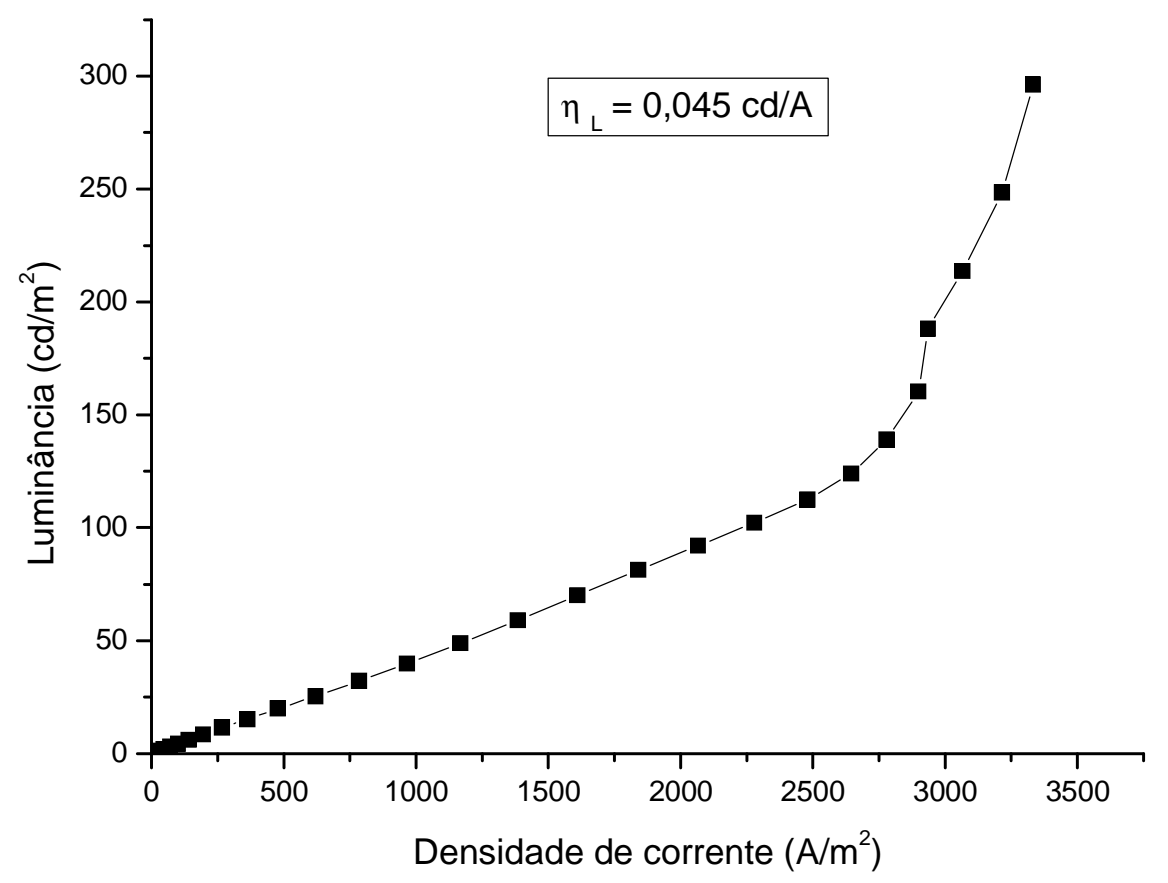

Figura 4.3.6.2 - Luminância $x$ Densidade de corrente de dispositivo com 19\% de Alq3 na camada ativa.

Para comparar o comportamento óptico dos dispositivos do lote 15 com os dispositivos inicialmente preparados neste trabalho foi utilizado o diagrama de cromaticidade, representado na figura 4.3.6.3. Os valores obtidos referentes às coordenadas de cromaticidade destes dispositivos são de $\mathrm{x}=0,4515$ e $\mathrm{y}=0,5485$. É também representado neste mesmo diagrama os valores de um dispositivo com a estrutura ITO/PEDOT:PSS/OC $\mathrm{C}_{10}$-PPV/Al para comparação. Neste caso também é possível verificar a distancia entre os pontos a e b, indicando a forte influência do Alq3 na emissão do dispositivo. 


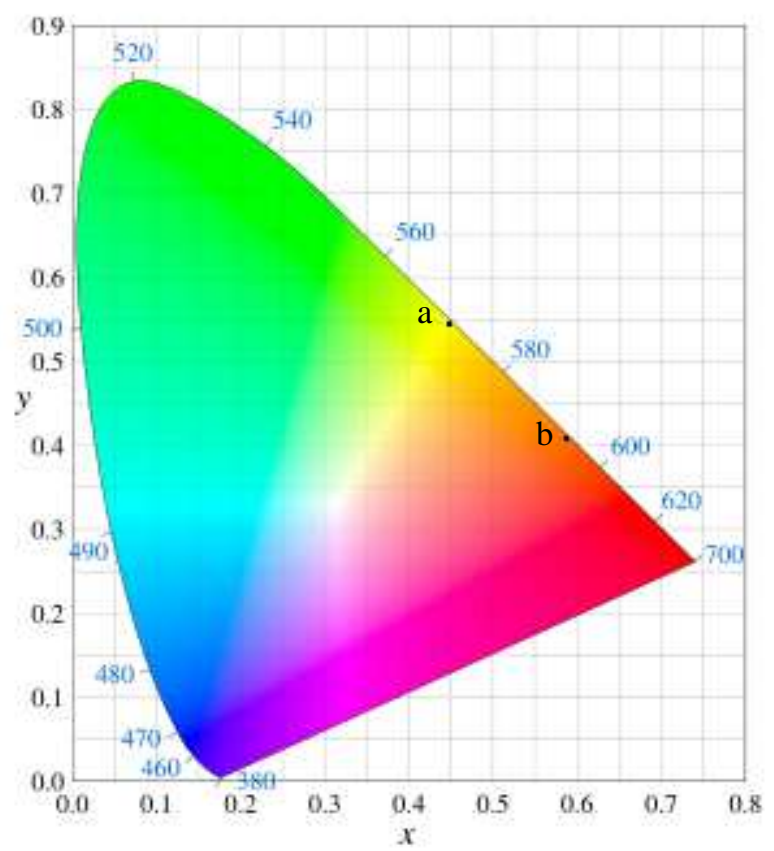

Figura 4.3.6.3 - Diagrama de cromaticidade de dispositivo com 19\% de Alq3 na camada ativa.

A figura 4.3.6.4 ilustra o registro fotográfico de um dispositivo do lote 15.

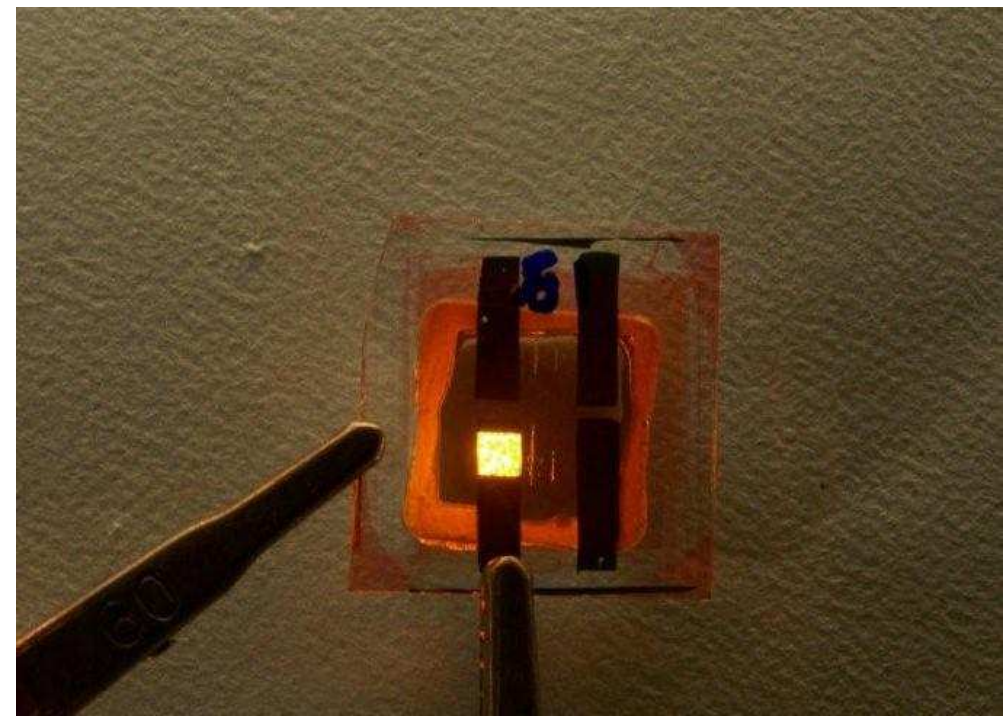

Figura 4.3.6.4 - Registro fotográfico de dispositivo com 19\% de Alq3 na camada ativa. 


\subsubsection{Lote 16}

Na produção do lote 16 deste trabalho foi utilizada uma solução com 23\% de Alq3 e $77 \%$ de $\mathrm{OC}_{1} \mathrm{C}_{10}$-PPV. A seguir são apresentados os dados de caracterizações elétricas e ópticas dos dispositivos deste lote.

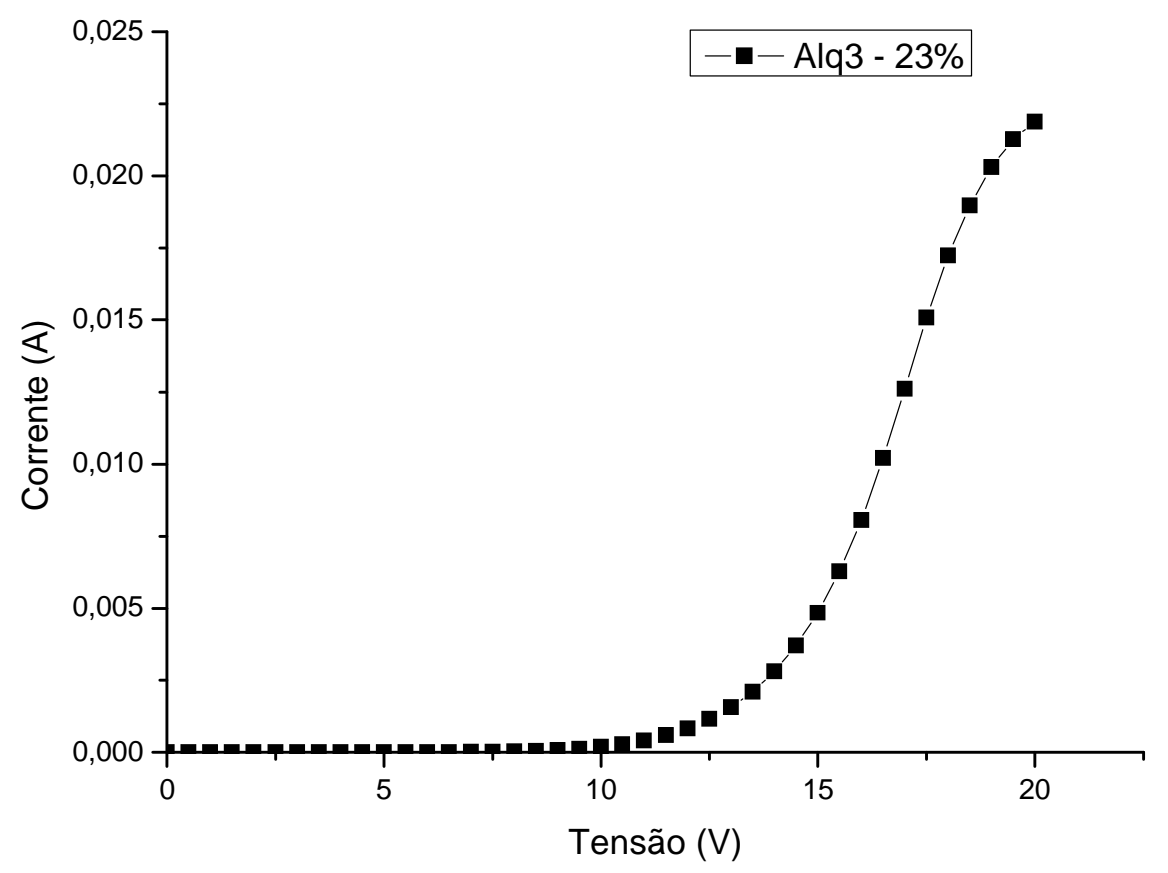

Figura 4.3.7.1 - Curva IxV de dispositivo com $23 \%$ de Alq3 na camada ativa.

A figura 4.3.7.1 acima ilustra o comportamento de diodo através de uma curva $\mathrm{IxV}$, apresentando uma tensão de operação de aproximadamente $14 \mathrm{~V}$. O aumento da tensão de operação pode se dar por conta da característica isolante do Alq3. Desta maneira, quanto maior a presença deste material na camada ativa ou quanto mais espesso o filme de ETL, maior a tensão de polarização apresentada pelo dispositivo. 


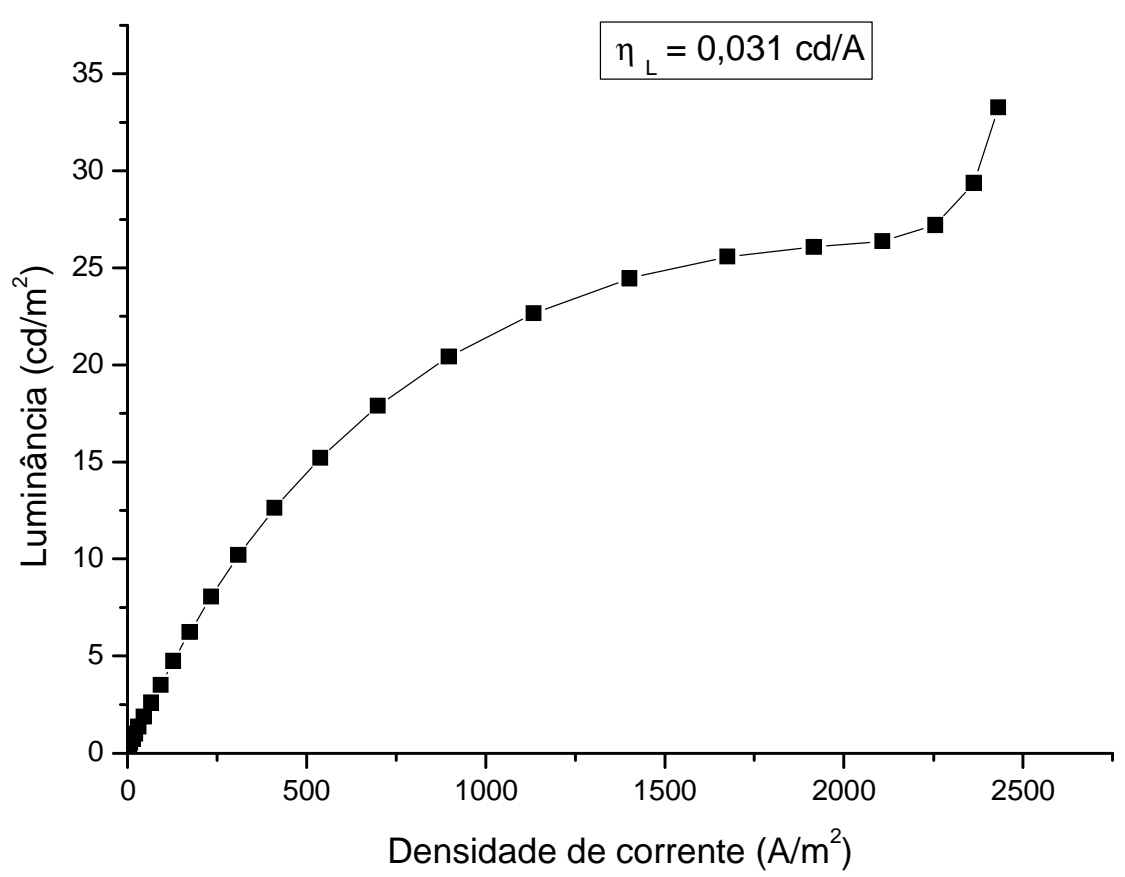

Figura 4.3.7.2 - Luminância x Densidade de correntede dispositivo com $23 \%$ de Alq3 na camada ativa.

A figura 4.3.7.2 apresenta a curva LxJ dos dispositivos do lote 16. Pode-se notar um decréscimo do valor da eficiência luminosa se comparada às dos dispositivos do lote 15.

O diagrama de cromaticidade dos dispositivos do lote 16 é ilustrado pela figura 4.3.7.3. Os valores referentes às coordenadas de cromaticidade destes dispositivos são de $\mathrm{x}=0,4538$ e $\mathrm{y}=0,5461$. Neste mesmo diagrama são representadas as coordenadas de um dispositivo com a estrutura ITO/PEDOT:PSS/OC ${ }_{1} \mathrm{C}_{10}-\mathrm{PPV} / \mathrm{Al}$ para comparação. Mais uma vez é possível notar a influência do Alq3 na emissão dos dispositivos. Notase também uma emissão muito parecida com a dos dispositivos do lote 15 . 


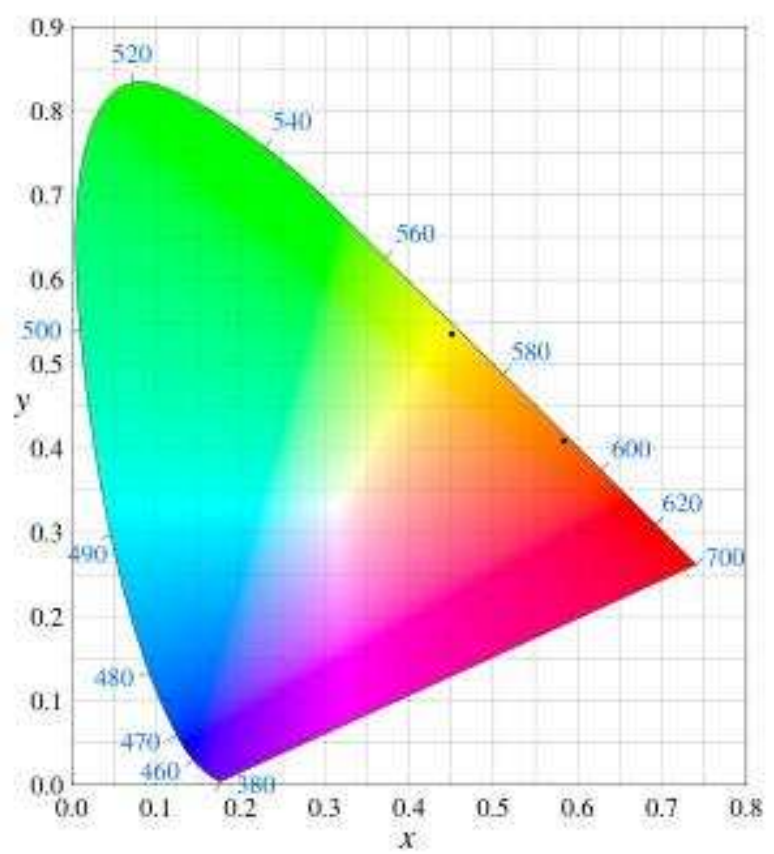

Figura 4.3.7.3 - Diagrama de cromaticidade de dispositivo com $23 \%$ de Alq3 na camada ativa.

Abaixo, na figura 4.3.7.4, pode-se observar o registro fotográfico de um dispositivo do lote 16 .

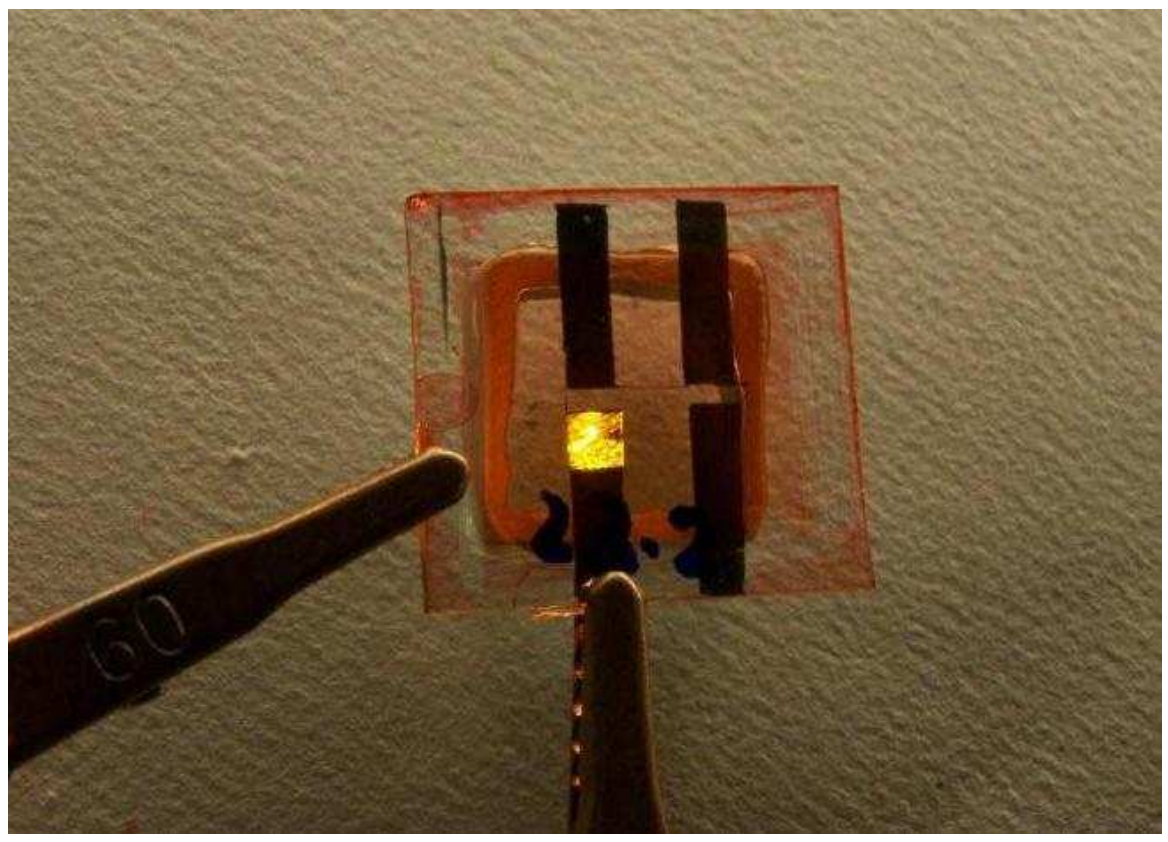

Figura 4.3.7.4 - Registro fotográfico de dispositivo com $23 \%$ de Alq3 na camada ativa. 


\subsubsection{Lote 17}

Pode-se, em uma primeira análise, dizer que os dispositivos do lote 12 apresentaram o melhor resultado. Entretanto, um último lote foi desenvolvido para avaliar a influência da ETL na eficiência destes dispositivos. Sendo assim, amostras sem ETL foram fabricadas, mantendo os filmes emissivos com 10\% de Alq3. As caracterizações elétrica e óptica deste último lote de dispositivos é apresentada a seguir.

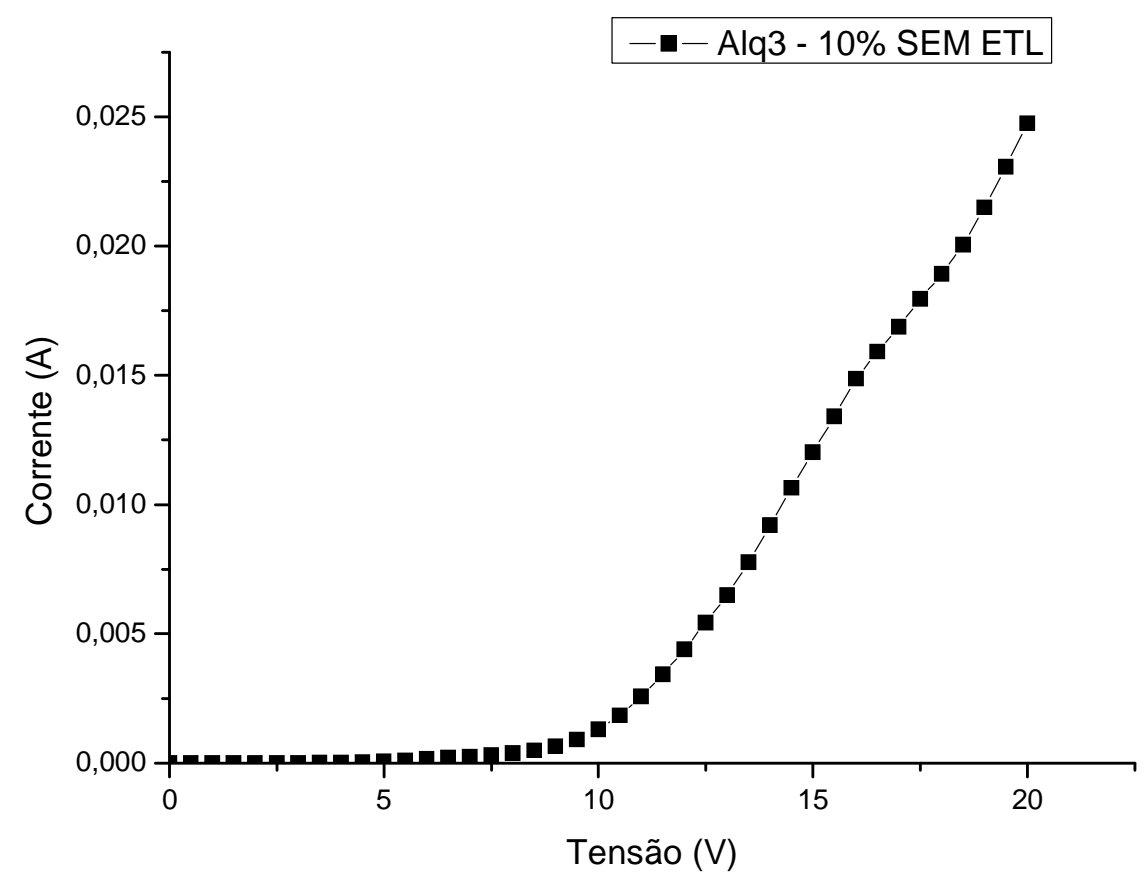

Figura 4.3.8.1 - Curva IxV de dispositivo com 10\% de Alq3 na camada ativa e sem ETL.

A curva IxV representada pela figura 4.3.8.1 ilustra o comportamento de diodo exibido pelo dispositivo, que possui uma tensão de operação de aproximadamente $12 \mathrm{~V}$, ou seja, o mesmo valor dos dispositivos do lote 12 .

A relação LxJ é ilustrada na figura 4.3.8.2. O cálculo da eficiência luminosa, realizado a partir de um ponto de uma região linear da curva, apresentou o valor de $0,0212 \mathrm{~cd} / \mathrm{A}$. 


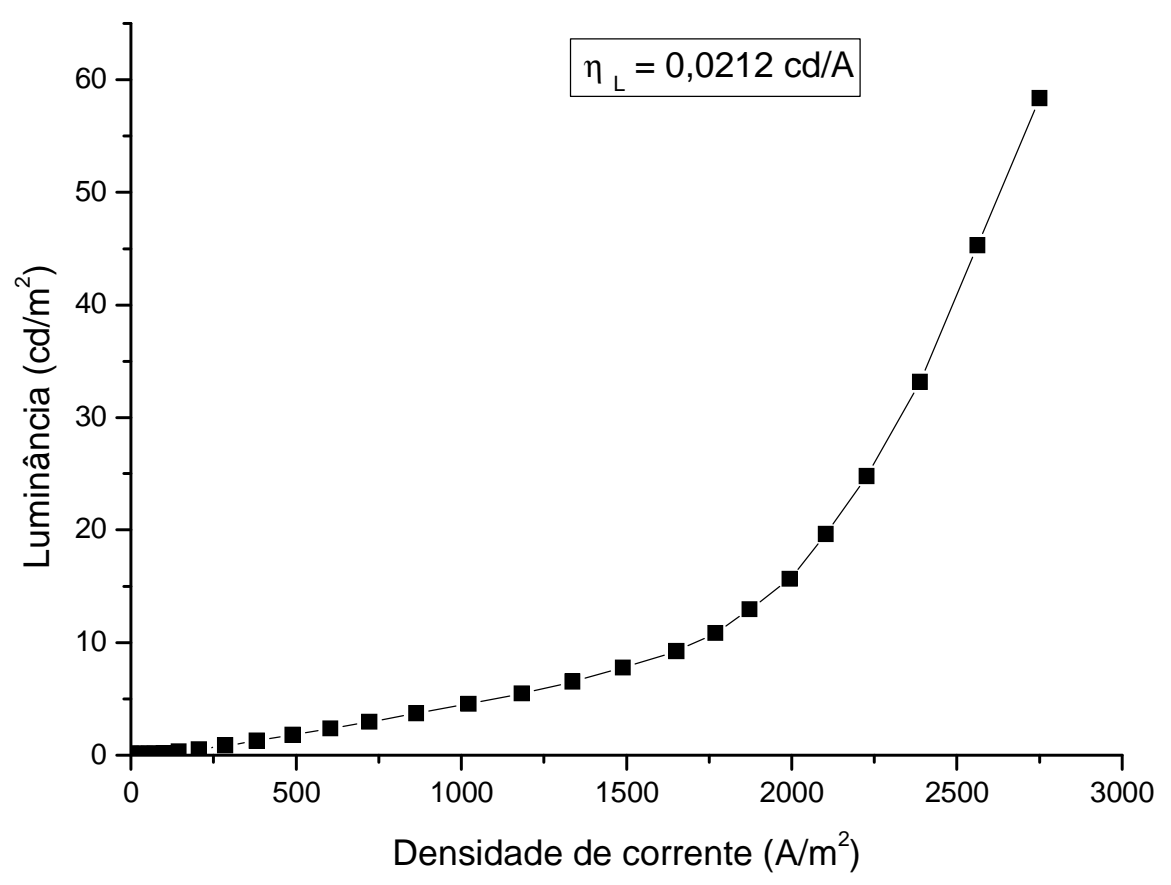

Figura 4.3.8.2 - Cruva IxV de dispositivo com 10\% de Alq3 na camada ativa e sem ETL

Uma última análise óptica foi realizada neste trabalho com a finalidade de comparar um dispositivo sem ETL, mas com adição de Alq3 na camada ativa, com os dispositivos inicialmente produzidos. Sendo assim, a figura 4.3.8.3 abaixo ilustra o diagrama de cromaticidade com coordenadas de 3 dispositivos: um com a estrutura ITO/PEDOT:PSS/OC $\mathrm{C}_{10}$-PPV/Al, outro com a estrutura ITO/PEDOT:PSS/OC $\mathrm{C}_{10^{-}}$ PPV/Alq3(7nm)/Al e outro com a estrutura ITO/PEDOT:PSS/OC ${ }_{1} \mathrm{C}_{10^{-}}$ PPV:Alq3(10\%)/Alq3(7nm)/Al. As coordenadas de cromaticidade dos dispositivos deste lote são $\mathrm{x}=0,4578$ e $\mathrm{y}=0,5425$. 


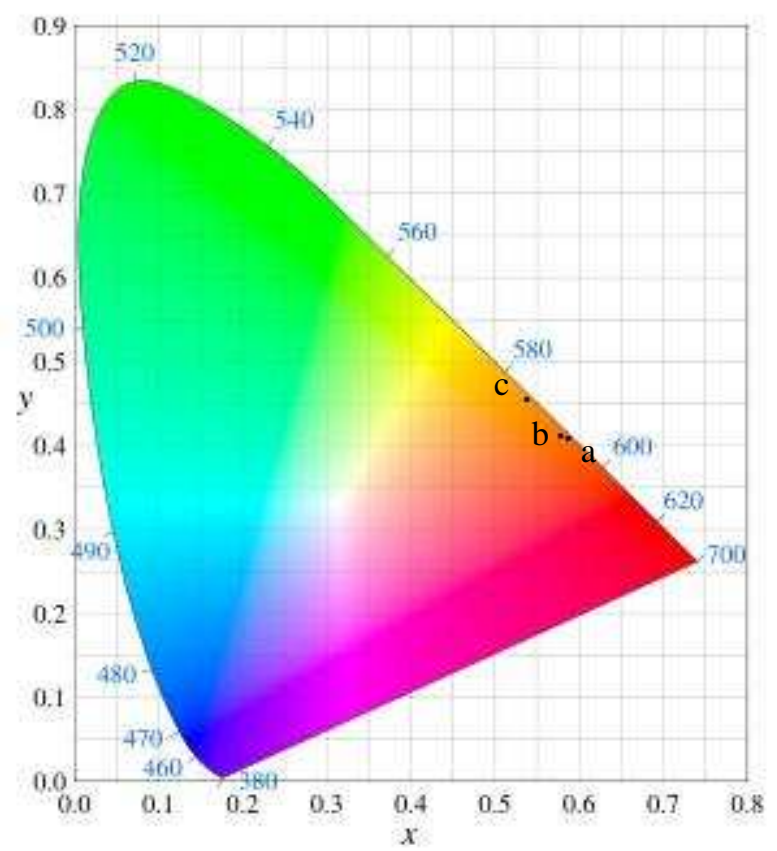

Figura 4.3.8.3 - Diagrama de cromaticidade de (a) dispositivos sem qualquer presença de Alq3, (b) com $10 \%$ de Alq3 na camada ativa e sem ETL e (c) com $10 \%$ de Alq3 e com 7 nm de ETL.

Como pode-se notar, o ponto "b" que representa os dispositivos sem ETL e com $10 \%$ de Alq3 na camada ativa se encontra mais próximo do ponto "a" (estrutura 2) do que o ponto "c" (dispositivos com 10\% de Alq3 na camada ativa e com ETL). Desta maneira, pode-se dizer que a alteração da emissão do dispositivo é provocada pela união dos dois fatores: ETL e presença de compósitos.

A figura 4.3.8.4 abaixo relaciona as curvas $\mathrm{IxV}$ dos dispositivos fabricados a partir de compósitos e um dispositivo sem introdução de Alq3 na camada ativa. 


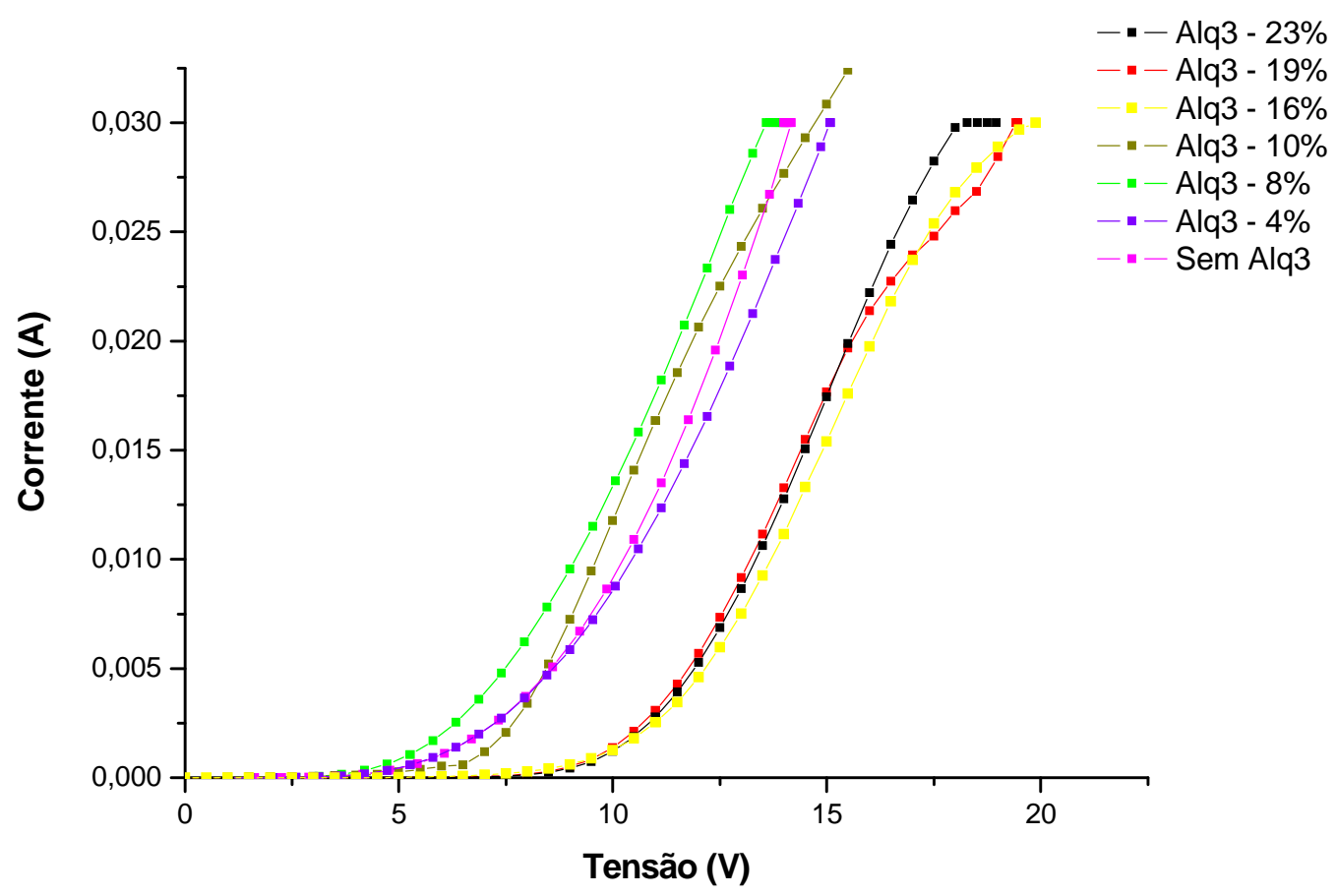

Figura 4.3.8.4 - Curvas IxV de dispositivos feitos com compósitos $\mathrm{OC}_{1} \mathrm{C}_{10}$-PPV:Alq3 e de dispositivo com $\mathrm{OC}_{1} \mathrm{C}_{10}$-PPV apenas

Através do gráfico ilustrado na figura 4.3.8.4 é possível notar que para pequenas concentrações de Alq3 na solução polimérica, há pouca alteração no valor da tensão de operação dos dispositivos. Entretanto, para concentrações de Alq3 iguais ou superiores a $16 \%$ ocorre um deslocamento relevante da curva, indicando um aumento na tensão de operação dos dispositivos.

A tabela 4.3.8-1 abaixo relaciona os lotes referentes aos compósitos $\mathrm{OC}_{1} \mathrm{C}_{10^{-}}$ PPV:Alq3 e seus respectivos valores de eficiência luminosa. 
Tabela 4.3.1 Relação dos lotes produzidos a partir de compósitos e seus respectivos valores de eficiência luminosa

\begin{tabular}{|c|c|c|}
\hline LOTE & EFICIÊNCIA LUMINOSA & OBSERVAÇÕES \\
\hline LOTE 10 & 0,0867 & $4 \%$ Alq3/1nm ETL \\
\hline LOTE 11 & 0.1999 & $8 \%$ Alq3/1nm ETL \\
\hline LOTE 12 & 0,2567 & $10 \%$ Alq3/1nm ETL \\
\hline LOTE 13 & 0,0027 & $13 \%$ Alq3/1nm ETL \\
\hline LOTE 14 & 0,034 & $16 \%$ Alq3/1nm ETL \\
\hline LOTE 15 & 0,045 & $19 \%$ Alq3/1nm ETL \\
\hline LOTE 16 & 0,031 & $10 \%$ Alq3 SEM ETL \\
\hline LOTE 17 & 0,0212 & \\
\hline
\end{tabular}

Nota-se que concentrações superiores a $10 \%$ de Alq3 na solução polimérica, causaram um efeito negativo na eficiência luminosa dos dispositivos. Novos estudos devem ser realizados no sentido de compreender melhor os fenômenos introduzidos pela adição deste material transportador de cargas no interior da camada ativa.

Os resultados apresentados nesta última etapa do trabalho reafirmam experimentos realizados por A. Petrela et al. em que a introdução de materiais transportadores de carga na camada ativa pode aumentar a eficiência do dispositivo. 


\section{Conclusões}

Este trabalho estudou as propriedades elétricas e ópticas de dispositivos poliméricos emissores de luz com 4 estruturas diferentes: ITO/OC ${ }_{1} \mathrm{C}_{10}-\mathrm{PPV} / \mathrm{Al}$, ITO/PEDOT:PSS/OC $\mathrm{C}_{10}$-PPV/Al, ITO/PEDOT:PSS/OC $\mathrm{C}_{10}$-PPV/LiF/Al, ITO/PEDOT:PSS/OC ${ }_{1} \mathrm{C}_{10}$-PPV/Alq3/Al, ITO/PEDOT:PSS/OC ${ }_{1} \mathrm{C}_{10}$-PPV:Alq3/Alq3/Al e ITO/PEDOT:PSS/OC ${ }_{1} \mathrm{C}_{10}$-PPV:Alq3/A1. Todos os experimentos desenvolvidos neste trabalho visaram o aumento da eficiência dos dispositivos, a partir, em um primeiro momento, da introdução de camadas transportadoras de elétrons e, sem seguida, da adição deste mesmo material na camada ativa polimérica.

A primeira conclusão observada foi que dispositivos fabricados sem a adição de PEDOT:PSS apresentam características de curto circuito por conta da alta rugosidade do filme polimérico emissivo. Desta maneira, o uso de uma fina camada de PEDOT:PSS se faz necessário em todos os dispositivos. A presença do filme de PEDOT:PSS pode também ser responsável pela passagem de corrente entre os pixels de uma mesma linha, provocando a eletroluminescência em pontos, a princípio, não polarizados. Sendo assim, o novo leiaute utilizado se mostrou mais eficiente, uma vez que elimina o efeito da polarização não desejada.

A idéia inicial da adição da camada transportadora de elétrons de LiF foi abandonada por conta da dificuldade de se depositar filmes da ordem de $4 \mathrm{~nm}$ através da evaporação térmica. Os dispositivos fabricados na primeira etapa deste trabalho e que continham o filme de LiF não apresentaram grandes contribuições para o aumento da eficiência luminosa. Muito provavelmente a espessura, apesar de não ter sido medida, tenha ultrapassado o limite de $4 \mathrm{~nm}$ sugerido pela bibliografia; nesta situação, o LiF passa atuar como um bloqueador de corrente e não como um transportador de elétrons.

A utilização de Alq3 como camada transportadora de elétrons se fez necessária para que o aumento da eficiência fosse alcançado. A melhor espessura de ETL se deu com $7 \mathrm{~nm}$, resultando em um aumento da eficiência luminosa de 5 vezes com relação ao dispositivo original, sem ETL. Notou-se também que altas espessuras de ETL aumentam a tensão de operação do dispositivo. Entretanto, mesmo com o maior valor 
de espessura testado, pode ser observado um aumento da eficiência luminosa dos dispositivos.

Ainda no sentido de aumentar a eficiência luminosa do dispositivo, a introdução de materiais na solução polimérica já sugerida pela literatura é neste trabalho comprovada. A inclusão de 4\% de Alq3 na solução, a menor concentração testada, não contribuiu para o aumento da eficiência do dispositivo; entretanto, quando se trata dos dispositivos produzidos com estes compósitos, este lote foi o único que não apresentou mudança na emissão dos PLEDs. Concentrações de 8\% e 10\% de Alq3 aumentaram de maneira significativa a eficiência, mas apresentaram pequenas alterações nas coordenadas de cromaticidade dos dispositivos. Quando houve a adição de concentrações superiores a $10 \%$ de Alq3 na solução polimérica, notou-se grande alteração na emissão dos PLEDs e nenhuma contribuição no aumento da eficiência destes dispositivos. Para finalizar este trabalho de mestrado, um último lote com o compósito que apresentou os melhores resultados (10\% de Alq3) foi produzido e a ETL foi retirada. Notou-se que a eficiência do dispositivo se torna bastante reduzida, quando comparada ao mesmo dispositivo com ETL, e a emissão volta a se aproximar daquela obtida para dispositivos produzidos no início do trabalho. 


\section{Perspectivas para trabalhos futuros}

Este trabalho de mestrado dá abertura para novas discussões e estudos sobre eficiência de dispositivos poliméricos emissores de luz relacionada a camadas transportadoras de carga e uso de compósitos como camada ativa. Notou-se que a relação existente entre a concentração de Alq3 introduzida na solução polimérica, a eficiência e a emissão do dispositivo ainda necessitam de um estudo mais aprofundado. Testar diferentes concentrações e estudar mais detalhadamente a teoria envolvida nesta questão seria um bom caminho a ser seguido na continuidade deste trabalho. 


\section{Bibliografia}

1 M. Pope, H. Kallmann, P. Maganante, J.Chem. Phys., 38, p. 2042 (1963).

2 C. W. Tang, S. A. Van Slyke, Organic electroluminescent diodes Appl. Phys. Lett., 51, p. 1098 (1987).

${ }^{3}$ Chiang C. K. , Finger C. R., Heeger, A. J., Shirakawa H., Louis E. J., S. C. MacDiarmid A. G., Electrical conductivity in doped polyacetylene, Phys. Rev. Let.39, 1098 (1977)

${ }^{4}$ A.J. Heeger, et al, J Chem Soc; 594, 1979

5 J. H. Burroughes,D.D.C. Bradley, A.R. Brown, R.N. Marks, K. Mackay, R.H. Friend, P.L. Burns, A.B. Holmes, Light emitting diodes based on conjugated polymers, Nature, 347, p. 539 (1990).

6 http://www.cdtltd.co.uk - acesso em maio de 2008.

${ }^{7}$ H.S. Wooa,_, B.S. Kima, C.G. Kima, J.J. Oha, M.S. Kima, S.J. Parka, T.W. Kwona, S.J. Choa, D.K. Parka, S.H. Jinb - Real blue-emitting light-emitting diodes based on fluorine derivative polymers - Journal of Crystal Growth 288 (2006) 137-139

${ }^{8}$ http://forums.navigatoris.net/resource-shack/1180-etris-flexible-oled-prototype.html acesso em maio de 2008.

${ }^{9}$ http://www.research.philips.com - acesso em maio de 2008.

${ }^{10}$ H. Kobayashi, S. Kanbe, S. Seki, H. Kigchi, M. Kimura, I. Yudasaka, S. Miyashita, T. Shimoda, C. R. Towns, J. H. Burroughes, R. H. Friend - A novel RGB multicolor lightemitting polymer display - Synthetic Metals 111-112_2000.125-128.

${ }^{11}$ Cui T., Yi L., Chen B., Zhu M., Varahramyan K., Printed polymeric passive RC filters and degradation characteristics - Solid-State Electronics 49 853-859 2005

12 Tae-Woo Lee,a_ Ohyun Kwon, Mu-Gyeom Kim, Sang Hun Park, Jaegwan Chung, Sang Yeol Kim, Youngsu Chung, Joon-Yong Park, Eunsil Han, Dal Ho Huh, Jong-Jin Park, and Lyongsun $\mathrm{Pu}$ Hole-injecting conducting-polymer compositions for highly efficient and stable organic light-emitting diodes - Applied Physics Letters 87, 231106, 29 Nov 2005

${ }^{13}$ S.R. Tseng, S. C. Lin, H. F. Meng, H. H. Liao, C. H. Yeh, H. C. Lai, S. F. Horng, C. $\mathrm{S}$. Hsu - General method to solution-process multilayer polymer light-emitting diodes Applied Physics Letters 88, 163501 _2006_

${ }^{14}$ S. R. Tseng, H. F. Meng, C. H. Yeh, H.C. Lai, S. F. Horng, H. H. Liao, C. S. Hsuc, L. C. Lin - High-efficiency blue multilayer polymer light-emitting diode fabricated by a general liquid buffer method - Synthetic Metals 158 (2008) 130-134

${ }^{15}$ T. Zhang, Z. Xu, L. Qian, F. Teng, Y.S. Wang, X.R. Xu Optical and morphological investigation in interaction of dual dopants in poly(N-vinylcarzole) -Journal of Luminescence 122-123 (2007)

${ }^{16}$ J. Myung-Sup, L. Tae-Woo, L. Jingyu Hyeon, S. Byung Hee, In-Sun Jung Synthesis and characterizations of a polyimide containing a triphenylamine derivative as an interlayer in polymer light-emitting diode Polymer (47) 2670-2676 March 2006 
17 C. Tengstedt, A. Crispin, C.-H. Hsu, C. Zhang, I.D. Parker,W.R. Salaneck, M. Fahlman Study and comparison of conducting polymer hole injection layers in light emitting devices Organic Electronics 6 21-33, Mach 2005

${ }^{18}$ R.H. Friend, Electronic properties of conjugated polymers, Phys. Chem. Elec. Ions in Cond. Mat., 625 (1984).

19 T.A. Skothein, Handbook of conducting polymers Vol I, Ch. 21, 22 e 24, 1st Ed., Marcel Dekker Inc. (1986).

${ }^{20}$ R. F. BIANCHI, Estudo das propriedades eletrônicas e ópticas de filmes e dispositivos poliméricos. 2002. 141p. Tese (doutorado), Instituto de Física de São Carlos, Universidade de São Paulo, 2002.

${ }^{21}$ N.C. Greenham, R.H. Friend, Semiconductor device physics of conjugated polymers, Sol. Stat. Phys. 49, 1 ( 1995).

${ }^{22}$ G. Hadziioannou, P. F. van Hutten Semiconducting Polymers p. 424.

${ }^{23}$ H. Antoniades, M. A. Abkowitz, and B. R. Hsieh, Appl. Phys. Lett. 65, 2030 (1994).

${ }^{24}$ P. W. M. Blom and M. C. J. M. Vissenberg, Mater. Sci. Eng., R. 27, 53(2000).

${ }^{25}$ S. Quan, F. Teng, Z. Xu, L. Qian, Y. Wang Improved polymer light-emitting diodes by the tuning of charge balance Solid-State Electronics 50 1506-1509 (2006)

${ }^{26}$ H. F. Meng and Y. S. Chen, Phys. Rev. B 70, 115208 (2004).

${ }^{27}$ M. J. Tsai, H.F. Meng Electron traps in organic light-emitting diodes, Journal of Apllied Physics 97, 114502 (2005)

${ }^{28}$ K. H. Choi, D. H. Hwang, H. M. Lee, L.M. Do, T. Zyung, Electroluminescent behaviours of polymer/organic heterostructure devices Synthetic Metals 96123 126(1998)

${ }^{29}$ D. Braun, A.J. Heeger, Appl. Phys. Lett. 58 (1991) 1982.

${ }^{30}$ Y. H. Niu, Y. L. Tung, Y. Chi, C. F. Shu, J. H. Kim, B. Chen, J. D. Luo, A. J. Carty, A. K. Y. Jen, Chem. Mater., 17, 3532 (2006).

31 K.M. Yeh, Y. Chen - Improved performance of polymer light-emitting devices based on blend of MEH-PPV and vinyl copolymer with 1,3,4-oxadiazole chromophores Organic Electronics 9 (2008) 45-50

${ }^{32}$ H. Arwin, R. Jansson, Line Shape analysis of ellipsometric spectra on thin conducting polymer films, Electrochimica Acta 39, 2, 211 - 2115 (1994).

${ }^{33}$ R.F. Bianchi, D.T. Balogh, D. Gonçalves, R.M. Faria, E.A. Irene, Characterization of MH-PPV films - photoxidative process using refractive index measurements, Mol. Cryst. Liq. Cryst. 374, 457 (2002).

${ }^{34}$ Y. Cao, G.Yu.I.D. Parker, A.J. Heeger, J. Appl. Phys. 883618 (2000).

35 R.H. Friend, R.W. Gymer, A.B. Holmes, J.H. Burroughes, R.N. Marks, C. Taliani, D.D.C. Bradley, D.A. Dos Santos, J.L. Bre'das, M. Lo“gdlund, W.R. Salaneck - Nature 397 (1999) 121.

36 D Braun, A.J. Heeger Visible light emission from semiconducting polymer diodes Appl. Phys. Lett. 58(18), 6 may 1991. 
37 I.D. Parker Carrier Tunneling and device characteristics in polymer light-emitting diodes - J.Apply. 75(3), 1 February 1994

38 A.J. Hof, van Kranenburg, P.H. Woerlee Calculation of Interface State Tunneling Proceeding of the SAFE/IEEE workshop, nov 2000.

39 S. Karg, W. Riess, V. Dyakonov, M. Schwoerer - Electrical and optical characterization of poly(phenylene-vinylene) light emitting diodes - Synthetic metals, 54427 - 433 (1993).

${ }^{40}$ G. Hadziioannou, P. F. van Hutten Semiconducting Polymers Chemistry, Physics and Engineering - p. 367.

${ }^{41}$ G. Hadziioannou, P. F. van Hutten Semiconducting Polymers Chemistry, Physics and Engineering - p. 370.

${ }^{42}$ I. D. Parker Carrier Tunneling and device characteristics en polymer light-emitting diodes - J.Apply. 75(3), 1 Febrary (1994).

43 P.M. Borsenberger, L. Pautmeier, H. Bassler - Charge transport in disordered molecular solids- J. Chem. Phys. 94 (8), 15 April (1991)

${ }^{44}$ G. Hadziioannou, P.F. van Hutten - Semiconducting Polymers Chemistry, Physics and Engineering. Content 12.

${ }^{45}$ S. Besbes, A. Ltaief, K. Reybier, L. Ponsonnet, N. Jaffrezic, J. Davenas, H. Ben Ouada - Injection modifications by ITO functionalization with a self-assembled monolayer in OLEDs - Synthetic Metals 197-200 (2003)

${ }^{46}$ G. Hadziioannou, P. F. van Hutten - Semiconducting Polymers Chemistry, Physics and Engineering - p. 379.

47 D. Braun - Electronic Injection and Conduction Processes for Polymer Devices Polymer Devices 2622 - 2629 (2003).

48 S. R. Forrest, D. D. C. Bradley, M. E. Tompson - Measuring the Efficiency of Organic Light-Emitting Devices - Advanced Materials - 2003.

${ }^{49}$ H. Y. Chen, W. Y. Lam, D. Luo, Y. L. Ho, B. Z. Tang, D. B. Zhu, M. Wong, H. S. Kwok -Highly efficient organic light-emitting diodes with a silole-based compoundApplied Physics Letters - 2002

50 X. Gong, J. C. Ostrowski, D. Moses, G. C. Bazan, A. L. Heeger Electrophosphorescence fronm a polymer guest-host system with an iridium complex as guest: Föster energy transfer and charge trapping - Advanced Functional Materials, 2003.

${ }^{51}$ C. Liu, J. Li, B. Li, Z. Hong, F. Zhao, S. Liu, W. Li - Triphenylamine-functionalized rhenium complex as a highly efficient yellow-green emitter in electrophosphorescent devices - Applied Physics Letters 89, 243511 (2006).

${ }^{52}$ L. Hontis, V. Vrindts, L. Lutsen, D. Vanderzande, J. Gelan The Gilch polymerisation towards $O C_{1} C_{10}-P P V$ : indications for a radical mechanism Polymer 42 5793-5796 (2001).

${ }^{53}$ M. Pientka, V. Dyakonov, D. Meissner, A. Rogach, D. Talapin, H. Weller, L. Lutsen and D. Vanderzande - Photoinduced charge transfer in composites of conjugated polymers and semiconductor nanocrystals Nanotechnology - 163-170 (2004) 
${ }^{54}$ S. Yang, Y. Jiang, Z. Xu, F. Teng, Y. Hou, X. Xu - Electroluminescence of blends of hole-transporting polymer and hole-blocking polymer - Physica B 373 (2006) 229-232

${ }^{55}$ F. Xue Yuan, Z. Jia-Yu, X. Chum-Xiang, Q. Yi, C. Yi Ping Eletroluminescence of mult-layered organic light-emitting diode utilizing Trans-4-[p-[N - methyl - N (hydroxymethyl) amino] styryl] $N$ - methylphridinium Tetraphenylborate as the active layer. Chin. Phys. Lett Vol. 23, p.1607-1609, Jun (2006).

${ }^{56}$ M.H. Andreasson, J. Martensson, T. G. Andersson - Porphyrin doping of Alq3 for electroluminescence- Current Applied Physics 8 (2008) 163-166

57 R. Friend D. Bradley, A. Holmes Polymer LEDs - Physics World - p. 42, 46 (1992)

${ }^{58}$ J. Manca, W. Bijneans, R. Kibooms, J. D’Haen, M. Dólieslaeger, Ting-Di Wu, W. De Ceuninck, L. De Schepper, D. Vanderzande, J. Gelan, L. Stals. Effect of oxygen on the elctrical characteristics of PPV-LEDs, Limburg University Centrum, 134-137, (1998)

$\left[{ }^{59}\right]$ C. C. WU, C. I. WU, J. C. STURM, A. KAHN, Surface modification of indium tin oxide by plasma treatment: An effective method to improve the efficiency, brightness, and reliability of organic light emitting devices , Appl. Phys. Lett. 70 (11), 1348 (1997).

${ }^{60}$ M. Cecchi, H. Smith, D. Braun. "Method to optimize polymer film spin coating for polymer LED mostradores", 2000 ICMS Meeting

${ }^{[61]}$ M.A.Reijme, M.P. de Jong, D.P.L. Simons, M. Schok, L.J. van IJzendoorn, A.W. Denier van der Gon, H.H. Brongersma, M.J.A. de Voigt - The distribution of InClx compounds in model polymeric LEDs:Acombined low and high-energy ion beam analysis study - Nuclear Instruments and Methods in Physics Research B 194 (2002) 346-354

${ }^{\left[{ }^{62]}\right.}$ Seong Hyun Kim, Sang Chul Lim, Jung Hun Lee, Taehyoung Zyung - Conduction mechanism of organic semiconductor AlQ3: Impedance spectroscopy analysis - Current Applied Physics 5 35-37 (2005)

${ }^{[63]}$ Y. Kwona, J. J. Baekb, J. H. Songb, B. J. Jangb, L. S. Parkb, S. W. Parkc, H. N. Chod - Energy transfer and electro-optical properties of doped PLED devices Materials Science and Engineering C 24 139-141 (2004) 